\title{
Male-Female Workplace Friendships: Third Party Coworkers' Perceptions of and Behavior toward Organizational Peers in Cross-Sex Workplace Friendships
}

Hailey G. Gillen

West Virginia University

Follow this and additional works at: https://researchrepository.wvu.edu/etd

\footnotetext{
Recommended Citation

Gillen, Hailey G., "Male-Female Workplace Friendships: Third Party Coworkers' Perceptions of and Behavior toward Organizational Peers in Cross-Sex Workplace Friendships" (2014). Graduate Theses, Dissertations, and Problem Reports. 262.

https://researchrepository.wvu.edu/etd/262

This Dissertation is protected by copyright and/or related rights. It has been brought to you by the The Research Repository @ WVU with permission from the rights-holder(s). You are free to use this Dissertation in any way that is permitted by the copyright and related rights legislation that applies to your use. For other uses you must obtain permission from the rights-holder(s) directly, unless additional rights are indicated by a Creative Commons license in the record and/ or on the work itself. This Dissertation has been accepted for inclusion in WVU Graduate Theses, Dissertations, and Problem Reports collection by an authorized administrator of The Research Repository @ WVU. For more information, please contact researchrepository@mail.wvu.edu.
} 
Male-Female Workplace Friendships: Third Party Coworkers' Perceptions of and Behavior toward Organizational Peers in Cross-Sex Workplace Friendships

\author{
Hailey G. Gillen
}

Dissertation submitted

to the Eberly College of Arts and Sciences

at West Virginia University

in partial fulfillment of the requirements for the degree of

Doctor of Philosophy in

Communication Studies

\author{
Rebecca M. Chory, Ph.D., Chair \\ Melanie Booth-Butterfield, Ph.D. \\ Elizabeth L. Cohen, Ph.D. \\ Christine E. Rittenour, Ph.D. \\ Renee L. Cowan, Ph.D. \\ Department of Communication Studies
}

\author{
Morgantown, West Virginia \\ 2014
}

Keywords: Workplace friendship, cross-sex friendship, workplace romance, credibility, unfair advantages, relationship motives, trust, obstructionism, information manipulation, aggression, equity theory

Copyright 2014 Hailey G. Gillen 


\title{
ABSTRACT \\ Male-Female Workplace Friendships: Third Party Coworkers' Perceptions of and Behavior toward Organizational Peers in Cross-Sex Workplace Friendships
}

\author{
Hailey G. Gillen
}

Workplace relationships range from professional working relationships, to workplace friendships, to romantic relationships at work. Cross-sex (male-female) workplace relationships, including friendships, are especially important for women, as research suggests they may help women to break through the "glass ceiling." Cross-sex workplace friendships are often perceived as romantic (e.g., Elesser \& Peplau, 2006; Marks, 1994) and workplace romances are generally perceived negatively (Cowan \& Horan, 2014, in press; Gillen \& Chory, 2014a; Horan \& Chory, 2009, 2011, 2013; Malachowski, et al., 2012). Guided by equity theory (Adams, 1965) and feminist organizational communication theorizing (Buzzanell, 1994), it is therefore hypothesized that organizational members in cross-sex workplace friendships will also be perceived negatively by their coworkers and targeted for antisocial behaviors. Further, as female members of workplace romances are consistently perceived more negatively than male members, it is hypothesized that female members of cross-sex workplace friendships will be perceived more negatively and will be targeted for antisocial behaviors more than male members. The following dissertation outlines three studies that examine organizational members' perceptions (credibility, motives, unfair advantages, and trust) of and behavior (obstructionism, information manipulation, and aggression) toward cross-sex workplace friendship partners. The first study is formative research employing a questionnaire with open-ended items to survey working adults who have personally observed cross-sex workplace friendships. Study 2 employs scenarios depicting a hypothetical coworker in a variety of workplace relationships (friendship, romance, professional). The third study employs a questionnaire with quantitative measures to survey working adults who have personally observed a cross-sex workplace friendship. Results indicate that although, overall, organizational members' perceptions of cross-sex workplace friendships do not seem to be overwhelmingly negative, organizational members do identify negative implications of these relationships. Further, results provided limited but encouraging support for equity theory. Finally, results indicate that organizational members often perceive that cross-sex workplace friendships are romantic, which is associated with organizational members' perceptions of increased workplace problems and antisocial behavior toward the coworkers in the cross-sex workplace friendships. 


\section{TABLE OF CONTENTS}

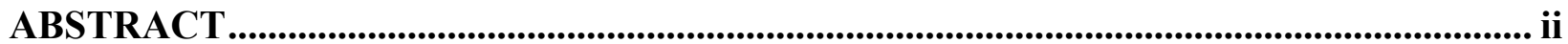

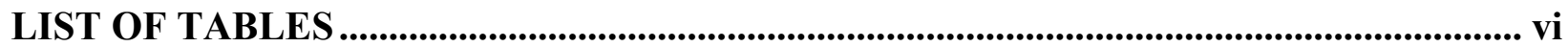

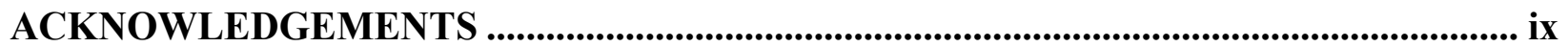

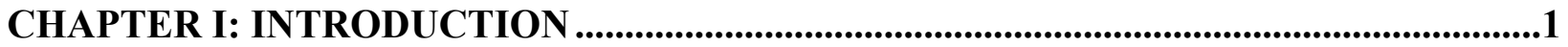

Literature Review ...........................................................................................................................5

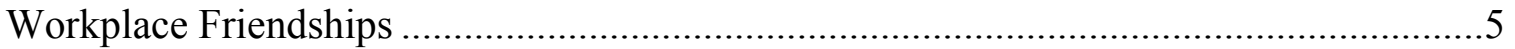

Male-Female Workplace Friendships .........................................................................

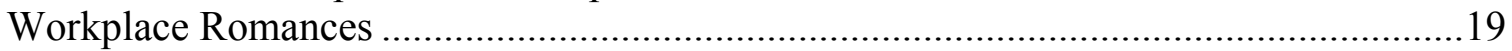

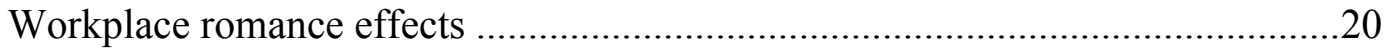

Status dynamic of relational partners.............................................................22

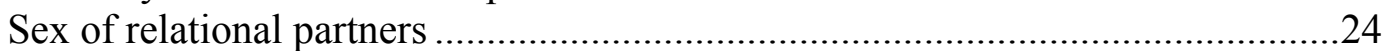

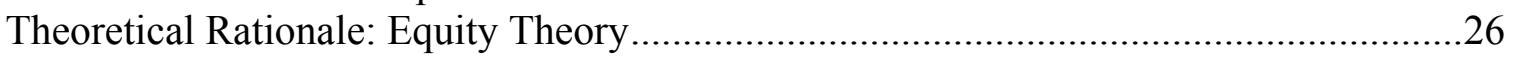

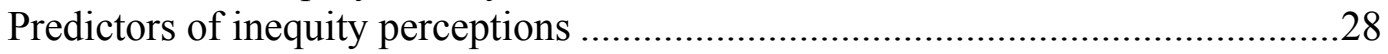

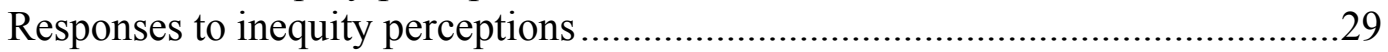

Statement of Problem ...........................................................................................................................31

Hypotheses and Research Questions..................................................................................................33

Relationship type: Romance, friendship, and professional relationship.............................34

Sex composition of relationship: Cross-sex and same-sex .................................................37

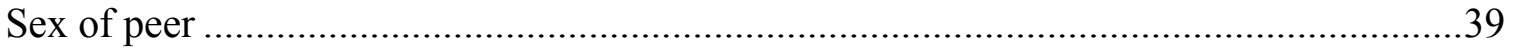

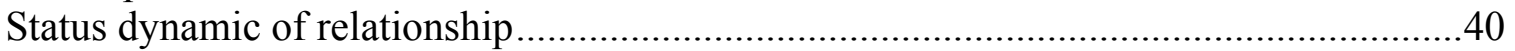

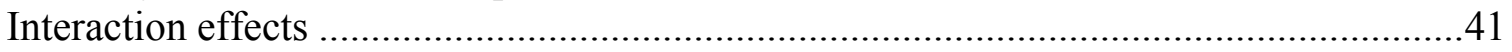

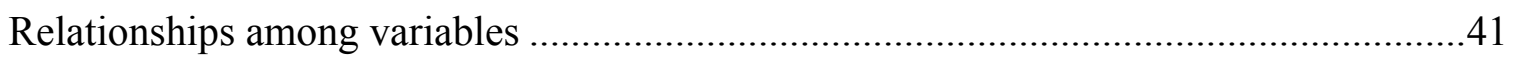

CHAPTER II: STUDY ONE .........................................................................................4

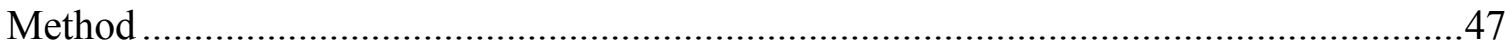

Participants and procedures .........................................................................4

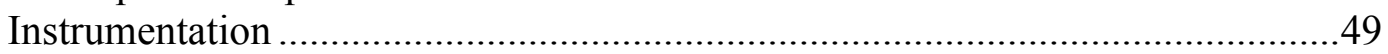

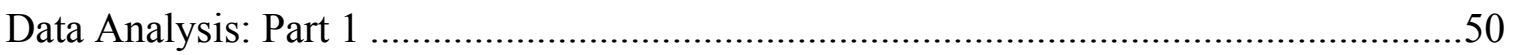

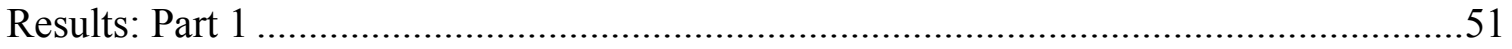

Research question 1: Descriptions ....................................................................51

Research question 2: Issues ...........................................................................53

Research question 3: Equity-related perceptions .............................................54

Research question 4: Behaviors ......................................................................56

Research question 5: Equity-restoration behaviors ...........................................58

Additional respondent thoughts ...................................................................59

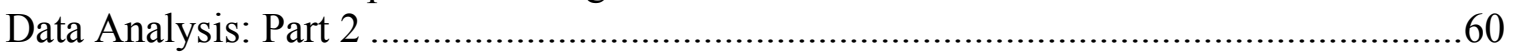

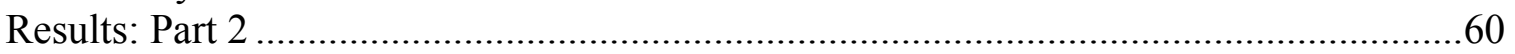

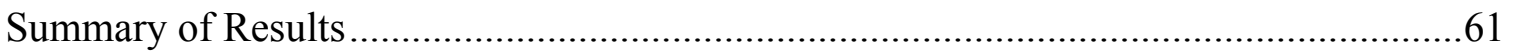

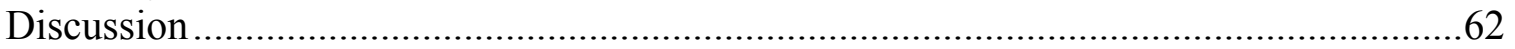

CHAPTER III: STUDY TWO_............................................................................................68

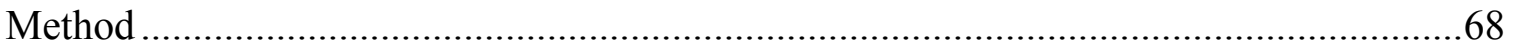

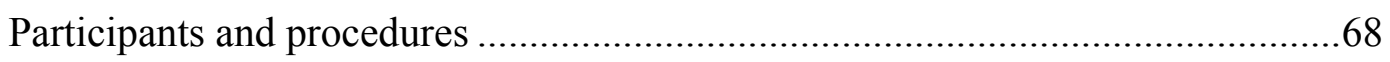

Experimental design and manipulation............................................................

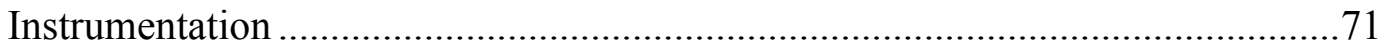

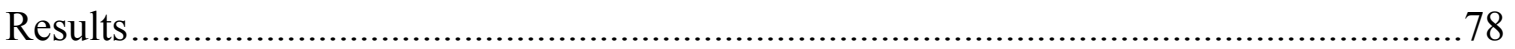




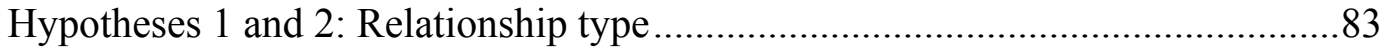

Hypotheses 3 and 4: Sex composition of the relationship .....................................86

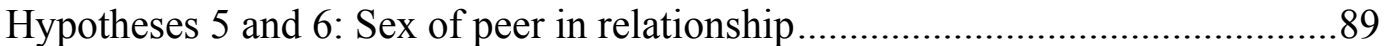

Research question 6: Interactions ....................................................................92

Hypotheses 9 and 10: Trust, motives, and unfair advantages correlations .............94

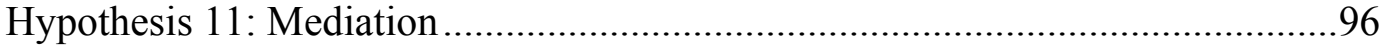

Research questions 7 and 8: Credibility correlations and mediation....................100

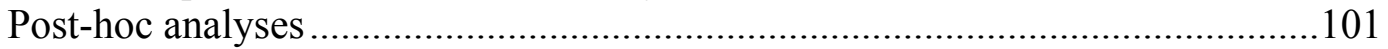

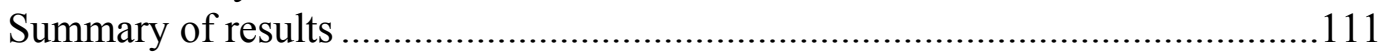

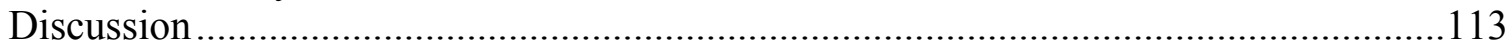

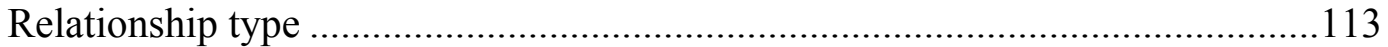

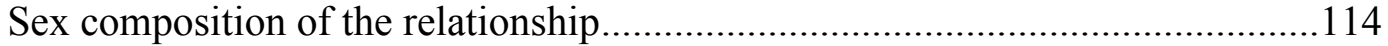

Sex of the peer reported on .......................................................................116

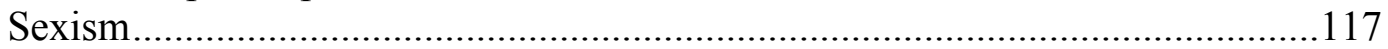

CHAPTER IV: STUDY THREE......................................................................................119

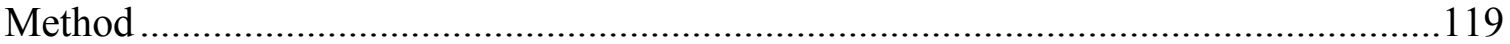

Participants and procedures ......................................................................119

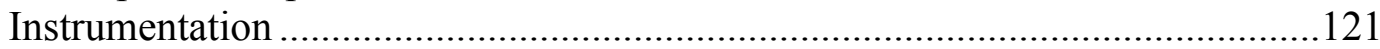

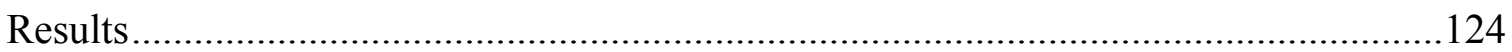

Hypotheses 5 and 6: Sex of peer in relationship...........................................128

Hypotheses 7 and 8: Status dynamic of the relationship ....................................131

Research question 6: Interactions ................................................................134

Hypotheses 9 and 10: Trust, motives, and unfair advantages correlations ...........136

Hypothesis 11: Mediation ..............................................................................138

Research questions 7 and 8: Credibility correlations and mediation...................139

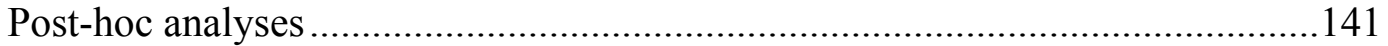

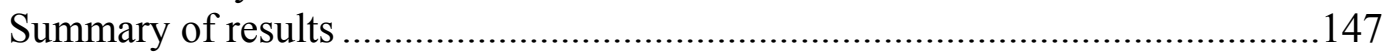

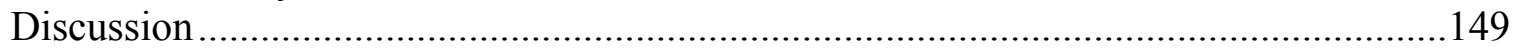

Status dynamic of relationship......................................................................149

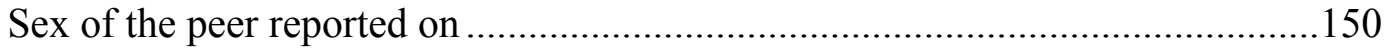

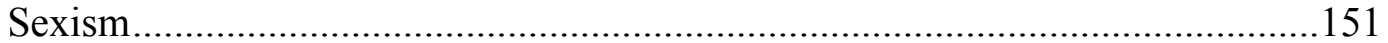

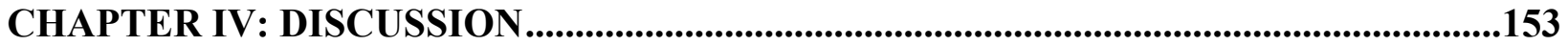

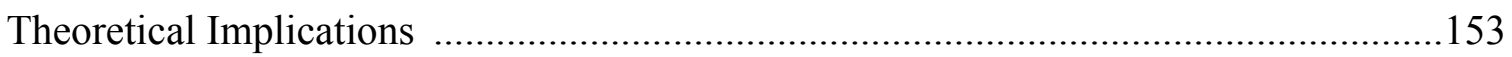

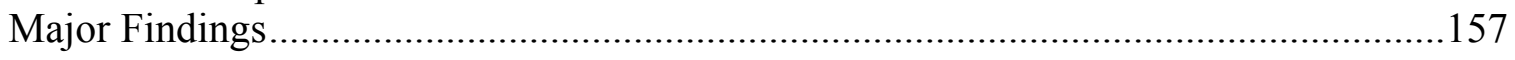

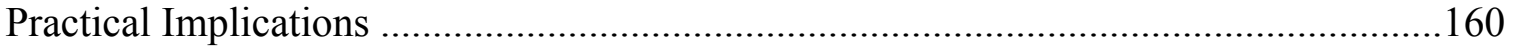

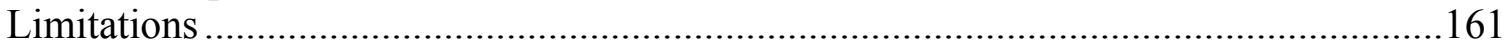

Future Research Directions..............................................................................162

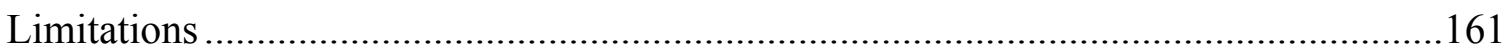

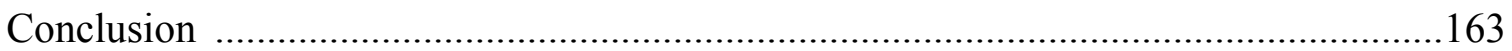

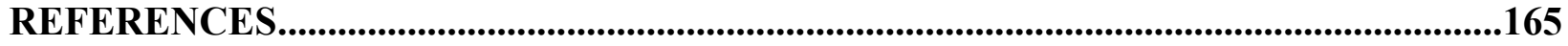

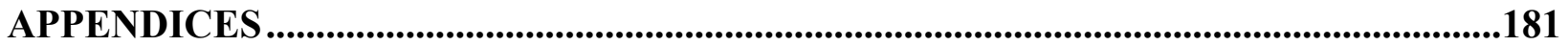

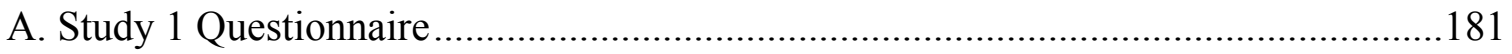

B. Study 1 Code Categories and Definitions ................................................................184

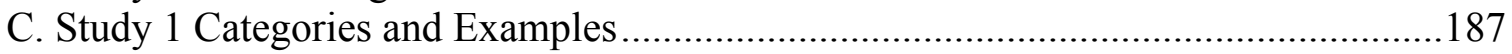

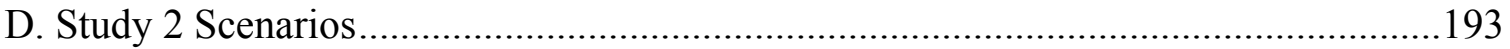

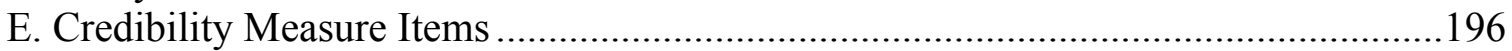




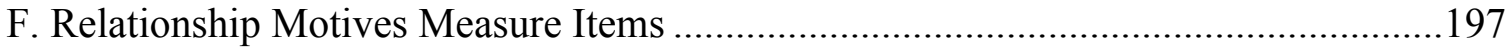

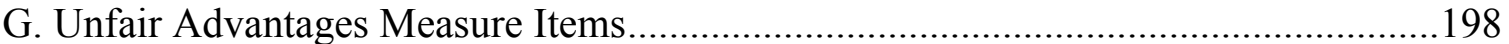

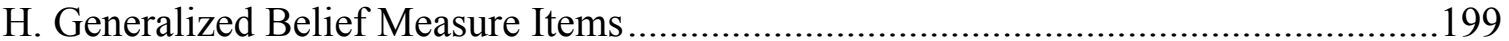

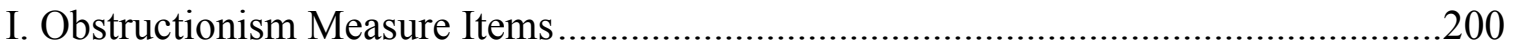

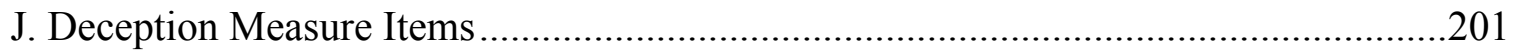

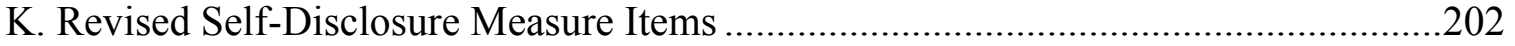

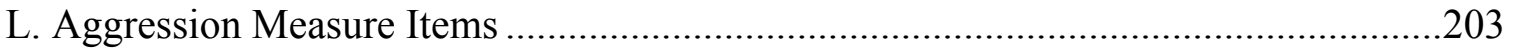

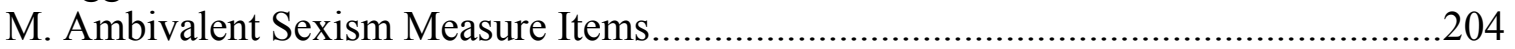

N. Suspected Romance Measure Items......................................................................206

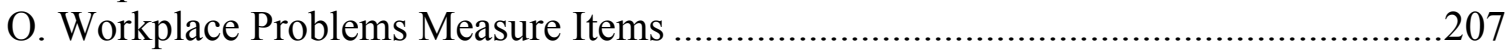

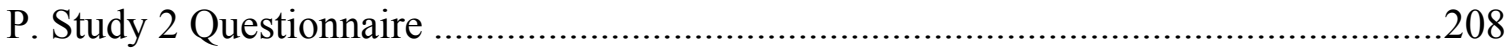

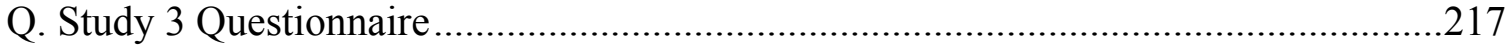




\section{LIST OF TABLES}

Table 1. Research Questions and Hypotheses Addressed by Study .45

Table 2. Study 1: Frequency of Response Categories for Items \#1, \#2, \#3, and \#6 .56

Table 3. Study 1: Frequency of Response Categories for Items \#4 and \#5 .59

Table 4. Study 1: Prevalence of Themes Among Participants 61

Table 5. Study 2: Intercorrelations among Variables. 79

Table 6. Study 2: Mean Differences Among Relationship Types .80

Table 7. Study 2: Mean Differences Between Sex of Peer Reported on 81

Table 8. Study 2: Mean Differences Between Same-Sex and Cross-Sex Relationships .82

Table 9. Study 2: Results for Hypotheses 1 and 2 .85

Table 10. Study 2: Results for Hypotheses 3 and 4 .88

Table 11. Study 2: Results for Hypotheses 5 and 6 .91

Table 12. Study 2: for Research Question 6 ..... .93

Table 13. Study 2: Results of Hypotheses 9 and 10 .95

Table 14. Study 2: Results of Hypotheses 9 and 10 Supplementary Regression Analyses 96

Table 15. Study 2: Results of Research Question 7.

Table 16. Study 2: Effect of Relationship Type on Suspected Romance and Workplace Problems

Table 17. Study 2: Sex Composition of the Relationship as a Predictor of Suspected Romance and Workplace Problems .104

Table 18. Study 2: Coworker Sex as a Predictor of Suspected Romance and Workplace

Problems .105 
Table 19. Study 2: The Interaction of Coworker Sex, Relationship Type, and Sexism as a

Predictor of Suspected Romance and Workplace Problems

Table 20. Study 2: Relationship Motives as Predictors of Suspected Romance and Workplace

Problems

.107

Table 21. Study 2: Relationship Motives, Trust, and Unfair Advantages as Predictors of

Suspected Romance and Workplace Problems.

Table 22. Study 2: Credibility as a Predictor of Suspected Romance and Workplace

Problems

Table 23. Study 3: Intercorrelations among Variables.

Table 24. Study 3: Mean Differences Between Cross-Sex Workplace Friendships with a

Superior and with a Peer or Subordinate

Table 25. Study 3: Mean Differences Between Sex of Peer Reported On

Table 26. Study 3: Results of Hypotheses 5 and 6

Table 27. Study 3: Results of Hypotheses 7 and 8 .133

Table 28. Study 3: Results of Research Question 6 .135

Table 29. Study 3: Results of Hypotheses 9 and 10 .137

Table 30. Study 3: Results of Hypothesis 9 and 10 Supplementary Regression Analyses.........138

Table 31. Study 3: Results of Research Question 7 .140

Table 32. Study 3: Coworker Sex and Sexism as Predictors of Suspected Romance and

Workplace Problems .141

Table 33. Study 3: Status Dynamic and Sexism as Predictors of Suspected Romance and Workplace Problems .142 
Table 34. Study 3: The Interaction of Coworker Sex, Status Dynamic, and Sexism as a Predictor of Suspected Romance and Workplace Problems

Table 35. Study 3: Friendship Motives as Predictors of Suspected Romance and Workplace

Problems .144

Table 36. Study 3: Friendship Motives, Trust, and Unfair Advantages as Predictors of Suspected Romance and Workplace Problems 145

Table 37. Study 3: Credibility as a Predictor of Suspected Romance and Workplace

Problems .147 


\section{ACKNOWLEDGEMENTS}

First, I would like to thank my advisor, Rebecca M. Chory, as this dissertation (and my $\mathrm{PhD}$ ) would never have been possible without her patience, encouragement, guidance, and invaluable knowledge (such as the insight to not include "bros before hoes" in this dissertation). Dr. Chory, thank you for being patient and supportive through my moments of panic and my never-ending questions. I look forward to working together in the future on this project and many others!

Second, I extend my gratitude to my committee, for their invaluable assistance and feedback throughout this process. Dr. Booth-Butterfield, Dr. Cohen, Dr. Rittenour, Dr. Cowan, and Dr. Bowman, thank you for your advice, knowledge and support. Without you, this dissertation would not have been possible.

Third, to the staff, faculty, and students at West Virginia University, thank you for providing an environment of guidance, learning, and support throughout my time in this program. Once a Mountaineer, always a Mountaineer. To my professors, thank you for your support and invaluable knowledge. To my fellow doctoral students, thank you for the laughter, camaraderie, and thought-provoking discussions we've shared over the last 3 years. To my students, thank you for letting me share my knowledge and passion for communication with you.

Finally, I could never have come this far without the love and support of my amazing family. Mom and Dad, your love and never-ending encouragement means more to me than I could ever hope to express. Austin, thank you for always supporting me in addition to being my academic inspiration and personal tech-support. Ben, your support, love and patience through this stressful journey means the world to me. I could not have written this dissertation "from with 
couch" without you. Thank you all for the incredible role you've played in this journey and in my life. I can't thank you enough. 


\section{CHAPTER I: INTRODUCTION}

Cross-sex workplace friendships, or friendships at work between a man and a woman, have received little empirical attention, despite being a potentially rich area of research. The dissertation presented here aims to examine these unique workplace relationships. Specifically, three studies investigate the perceptions coworkers have of the individuals involved and the behaviors coworkers engage in toward the friendship participants.

Workplace relationships have been studied extensively in organizational communication research. These relationships have been distinguished according to their productive-destructive nature and the equal-unequal status dynamic of the relational partners.

The productive-destructive nature of workplace relationships involves the manner in which relationships in the workplace can be positive, pro-social, and beneficial to individuals and the organization or destructive and detrimental to individuals and successful organizational functioning. Two specific types of positive relationships are workplace friendships and workplace romances. A workplace friendship occurs when employees consider themselves friends in addition to simply being coworkers (Sias, 2008). Workplace friendships yield a number of positive effects, including increased instrumental and emotional support, support in understanding the work environment, higher quality information exchange, enhanced creativity, increased job satisfaction, intrinsic rewards, and even reduced turnover (Kram \& Isabella, 1985; Marks, 1994; Miller \& Jablin, 1991; Sias, 2005; Yager, 1997). Although workplace friendships tend to yield positive benefits, they may also have drawbacks, such as (but not limited to) issues associated with friendship deterioration (Sias, 2008, 2006; Sias, Heath, Perry, Silva, \& Fix, 2004), tensions inherent to working with a friend, and negative perceptions of others in the organization (Bridge \& Baxter, 1992). 
A workplace romance has been defined as "a non-platonic relationship between two members of an organization in which sexual attraction is present, affection is communicated, and both members recognize the relationship to be something more than just professional and platonic" (Horan \& Chory, 2011, p. 565). Positive implications of workplace romance include increased motivation, job involvement, and satisfaction with work (Pierce, 1998), improved relationships and communication with coworkers, and liking work more (Gillen \& Chory, 2014b). Negative implications include issues of sexual harassment (Boyd, 2010; Pierce, Aquinis, \& Adams, 2000; Pierce, Broberg, McClure, \& Aguinis, 2004, Pierce, Muslin, Dudley, \& Aguinis, 2007), coworkers’ negative perceptions (Horan \& Chory, 2009, 2011, 2013;

Malachowski, Chory, \& Claus, 2012), and decreased performance and conflict (Gillen \& Chory, 2014b).

In addition to the productive-destructive distinction in workplace relationship types, scholars have examined workplace relationships according to the status dynamic between the relationship partners. Specifically, researchers have distinguished between peer relationships and status differential workplace relationships.

Relationships between individuals at the same level of an organization who have no formal authority over one another are referred to as peer relationships. These relationships are the most common (Porter \& Roberts, 1973; Sias, Gallagher, Kopaneva, \& Pedersen, 2012) and some scholars argue the most important workplace relationships (Sias, 2009; Sias et al., 2012). Peer relationships vary in closeness (Kram \& Isabella, 1985) and include both positive implications, such as increased information exchange (e.g. Sias, 2005), and negative implications, such as bullying (e.g. Lutgen-Sandvik, 2007; Lutgen-Sandvik, \& Hood, 2009), for those involved. 
Status-differential relationships are those in which one partner (the superior or supervisor) holds direct formal authority over the other (Sias, 2009). As with peer relationships, these workplace relationships can vary in closeness. According to Leader-Member Exchange Theory (LMX), relationships between superiors and subordinates exist along a continuum, with high-quality dyadic relationships (the "in-group") on one end and low-quality dyadic relationships (the "out-group") on the other (Graen \& Uhl-Bien, 1995). Further, the quality of the status-differential relationship has been related to a number of outcomes. For instance, high quality relationships have been associated with supervisor attention and support, higher levels of confidence, increased clarity, and increased job satisfaction and commitment (Gerstner \& Day, 1997; Scandura, Graen, \& Novak, 1986). Alternatively, low quality relationships have been associated with a number of negative outcomes, including lower levels of satisfaction and commitment and higher turnover intentions (Gerstner \& Day, 1997).

Workplace relationships on the whole can have both benefits and drawbacks for the relational partners, other organizational members, and the organization. Benefits of workplace relationships include instrumental and emotional support, information exchange, higher levels of confidence, increased clarity, increased commitment, more job satisfaction and reduced turnover (Gerstner \& Day, 1997; Kram \& Isabella, 1985; Marks, 1994; Scandura et al., 1986; Sias, 2005; Yager, 1997). Drawbacks of workplace relationships include issues that arise when these relationships deteriorate, ostracism and bullying, and negative perceptions held by others in the organization (Gillen \& Chory, 2014a, 2014b; Lutgen-Sandvik, 2007; Lutgen-Sandvik, \& Hood, 2009; Sias et al., 2004).

The specific type of workplace relationship that is the focus of the dissertation presented here is the cross-sex workplace friendship, i.e., friendships between male and female 
organizational members. Whereas workplace friendship and workplace romance have been examined in communication studies research (e.g., Horan \& Chory, 2009, 2011, 2013;

Malachowski et al., 2012; Sias, 2008; Sias, Smith, \& Avdeyeva, 2003; Sias et al., 2004), platonic friendships between men and women in the workplace have received far less attention. Although cross-sex friendships have only been minimally examined in the organizational context (e.g., Doll, 2011; Elesser \& Peplau, 2006; Marks, 1994), they have been examined in non-work contexts (e.g., Afifi \& Burgoon, 1998; Baumgarte and Nelson, 2009; Dainton, Zelley, \& Langan, 2003; Fehr, 1996; Guerrero \& Chavez, 2005; Lenton \& Weber, 2006; Messman, Canary, \& Hause, 2000; Monsour, 2002; Werking, 1997).

Research suggests that there are benefits and drawbacks associated with being involved in a cross-sex workplace friendship. The benefits of cross-sex workplace friendships are especially salient for the women involved in these relationships. The most notable benefit is likely the ability to more easily advance in the organization due to increased networking opportunities provided by the male friend at work (Ignatius, 2013; Sias, 2008; Sias et al., 2003). The primary drawback of cross-sex workplace friendships concerns fear that the friendship will be perceived as romantic or potentially romantic. This includes both concerns that third-party coworkers will view the relationship as such and that the friendship partner will misinterpret friendliness as romantic advances (Elesser \& Peplau, 2006; Hurley, 1996; Sias et al., 2003).

As such, the studies presented here aim to better understand how organizational members view cross-sex friendships and their coworkers involved in cross-sex friendships. Specifically, it is theorized, based on prior research, that these relationships will be associated with perceptions that the individuals involved are in the friendship not for genuine companionship, but for unfair work advantages or organizational advancement. In addition, previous research suggests that 
others are likely to perceive these relationships as not platonic (or at least as including the possibility of romance or sexual behavior; Afifi \& Burgoon, 1998; Dainton et al., 2003; Elesser \& Peplau, 2006; Guerrero \& Chavez, 2005; Marks, 1994; Messman et al., 2000). Furthermore, workplace romance research suggests that cross-sex workplace friendships, if perceived as romantic, will be viewed negatively (Gillen \& Chory, 2014a, 2014b; Horan \& Chory, 2009, 2011, 2013; Malachowski et al., 2012; Sias, 2009), with perceptions of the female member of the friendship being perceived more negatively than the male member of the cross-sex workplace friendship (Dillard, 1987 in Pierce, Bryne, \& Aquinis, 1996; Gillen \& Chory, 2014a; Horan \& Chory, 2011, 2013; Jones, 1999; Malachowski et al., 2012; Sias, 2009). The study employs equity theory (Adams, 1965; Walster, Walster, \& Berscheid, 1978) and feminist organizational theorizing (Buzzanell, 1994) as frameworks within which to examine organizational members' perceptions of and responses to coworkers in cross-sex workplace friendships. It is hypothesized that individuals who observe cross-sex workplace friendships perceive an unequal input-tobenefit ratio for those in cross-sex workplace friendships, with the female friendship member being especially over-benefitted, leading to behaviors intended to restore equity.

\section{Literature Review}

\section{Workplace Friendships}

Interpersonal workplace relationships have garnered extensive attention from scholars in the fields of organizational communication and behavior, industrial/organizational psychology, and business management. Kram and Isabella (1985) identified three types of peer relationships that exist in the workplace: information peers, collegial peers, and special peers. An information peer is an individual with whom communication is primarily focused on exchanging workrelated information. A collegial peer is considered a coworker who is also a friend within the 
context of the workplace. Finally, a special peer is an individual who is a coworker, a friend at work, and a friend outside of the workplace. Employees who only have information peers demonstrate less communication openness (Myers, Knox, Pawlowski, \& Ropog, 1999), perceive less solidarity, trust, and self-disclosure (Myers \& Johnson, 2004), and tend to report lower information quality (Sias, 2005) than those who have collegial and/or special peers. Additionally, special peers use more open communication strategies than information peers and special peers and collegial peers tend to use affinity-seeking strategies with one another more often than do information peers (Gordon \& Hartman, 2009).

The special peer relationship is conceptually similar to a workplace friendship. A workplace friendship occurs when employees consider themselves friends, in addition to simply being coworkers (Sias, 2008). Sias et al. (2003) noted that workplace friendships are unique from other workplace relationships in two primary ways. First, these relationships are voluntary in that individuals do not choose with whom they work, but they do have a choice regarding with whom they become friends at work. Second, these relationships have a personal focus in that individuals in a workplace friendship begin to know each other as "whole" people. That is, they know each other beyond their roles in the organization.

In addition to being unique from other workplace relationships, workplace friendships are also notably different than friendships outside of work (Sias, 2008; Sias et al., 2003). First, if the workplace friendship ends, the individuals are "stuck" working together - they do not have the same option of physical distance that would occur in a deteriorated non-work friendship. Second, there are issues of power in workplace friendships that are not as salient in non-work friendships. Specifically, each party needs to negotiate his/her role (and related status or power) relative to one another in the workplace. That is, any status differentials in the relationship can 
impact how the individuals approach the friendship and one another. Many tensions inherent in workplace friendships concern navigating the issues that arise when an individual's friend at work is at a different level within the organization. Finally, workplace friendships are unique in the way that they form, as their development is often impacted by factors unique to the organizational context, such as shared organizational tasks and supervisor behavior (Sias \& Cahill, 1998).

A number of positive outcomes may result for individuals in workplace friendships. Individuals provide their friends at work with both instrumental and emotional support, in addition to helping them make sense of the work environment (Kram \& Isabella, 1985; Miller \& Jablin, 1991). Furthermore, workplace friendships have been linked with higher quality information exchange, enhanced creativity, increased job satisfaction, intrinsic rewards, and reduced turnover (Kram \& Isabella, 1985; Marks, 1994; Sias, 2005; Yager, 1997). It is clear that workplace friendships are often a site of both support and information exchange for the employees involved. Further, these relationships provide benefits related to the job and its tasks, in addition to providing personal or relational benefits.

Though the positive outcomes of workplace friendships have been examined, research has also identified a number of negative implications of friendships at work. One of these negative outcomes concerns the issues that arise when a friendship at work deteriorates. Due to the fact that individuals cannot as easily end contact with an "ex-friend" at work in the same way they could in a strictly interpersonal relationship (Sias, 2008), the deterioration of workplace friendships is unique.

Sias et al. (2004) identified a number of causes of workplace friendship deterioration. First, workplace friendships deteriorate due to conflicting expectations. If one individual, 
experiencing the tensions inherent to workplace friendships does not behave in a manner considered appropriate by the other member of the friendship, deterioration of the friendship is possible, if not likely. Workplace friendships also deteriorate due to one partner being perceived as having a "problem personality" (Sias et al., 2004, p. 327) or annoying personality characteristics. Third, distracting life events, such as one friend's personal problems or issues, lead to the deterioration of workplace friendships when they impede the friend's work-related performance. A fourth reason for the dissolution of workplace friendships is the promotion of one individual to a position of formal power over the other. A fifth cause of workplace friendship dissolution is a betrayal of trust by one or both members of the friendship. This betrayal often occurs when one partner shares information with others that was intended to be confidential, leading to feelings of distrust, anger, or doubt about the relationship.

In addition to workplace friendships deteriorating, a second concern with workplace friendships is the experience of dialectical tensions. Bridge and Baxter (1992) identified five dialectical tensions experienced in workplace friendships. These dialectical tensions occur when individuals who are both personal friends and coworkers "experience contradictory dilemmas posed by the friendship and work-association components of their relationship and the ways in which such dilemmas are communicatively managed" (p. 201). In other words, these tensions occur when individuals experience contradictions between the behaviors and roles desired and expected in the workplace and those desired and expected as a part of a friendship. The contradictions create tension and feelings of confusion or discomfort for the individual experiencing the contradictory expectations.

Drawing from a dialectical perspective on non-organizational friendships, Bridge and Baxter (1992) found that there were five tensions at play in workplace friendships. Equality- 
inequality refers to the tension experienced between the expectation of equality in a friendship and the hierarchy (and thus, inequality) inherent to the structure of most organizations. Impartiality-favoritism refers to the tension between the norm in organizations of fair treatment for all and the tendency for friends to favor each other (e.g., when giving information or benefits). Openness-closedness refers to the tension that exists between the expectation of honesty and open communication in a friendship and the confidentiality that is expected in private or classified organizational conversations. Autonomy-connection refers to the tension between one's desire to be autonomous or independent in the workplace and the benefits of being socially connected to others as a source of support and affiliation. Finally, judgmentacceptance refers to the tension created by the required critical evaluation in the workplace and the expectations for friends to be open and accepting of one another and their behaviors.

Finally, individuals in workplace friendships also deal with negative perceptions of others in the organization. Others, seeing that individuals are friends, may be inclined to assume that they will receive unfair advantages or an "upper hand" due to their friendship at work. The dialectical tensions of workplace friendship support this notion of receiving advantages at work due to a friendship. If organizational members observing the workplace friendship are aware that these tensions exist, they understand that the workplace friends are often faced with a dilemma in terms of whether or not to provide their friends with "inside" information or organizational benefits. Third-party coworkers' awareness of the impartiality-favoritism dialectical tension (Bridge \& Baxter, 1992) could lead them to be suspicious of their coworkers' motives for entering into the friendship. For instance, they may perceive the coworkers as entering into these friendships to somehow benefit on the job. 
This notion of receiving unfair advantages is evident in research on superior-subordinate organizational friendships. Lancaster and Chory (2013) found that organizational members who were friends with their supervisors were perceived as receiving more unfair advantages due to their relationship than were organizational peers who simply had working relationships with their supervisors. Furthermore, the perception of unfair advantages mediated the association between workplace relationship type (friendship or working) and communicating deception to the coworker involved in the relationship with the superior.

While extensive research has examined the unique type of workplace relationship that is a workplace friendship, less research has examined the impact of the sex makeup of this dyad. That is, limited research has explored workplace friendships that occur between men and women, as opposed to employees of the same sex.

\section{Male-Female Workplace Friendships}

Although workplace friendships and workplace romances have both been examined in communication studies research, platonic friendships between men and women in the workplace have received far less attention. A friendship between a man and woman is referred to as a crosssex friendship, and while not examined at length in the specific context of the workplace, crosssex friendships have been examined in non-work, interpersonal contexts. Furthermore cross-sex friendships appear to be becoming more common and even more significant within people's social networks (Fehr, 1996; Monsour, 2002). Despite this trend, research suggests that individuals still tend to have fewer cross-sex friendships than they do same-sex friendships (Lenton \& Webber, 2006, Reeder, 2003, Rose, 1985; Werking, 1997).

Research has examined the factors that may influence an individual's preference for a cross-sex or same sex friendship. For example, Baumgarte and Nelson (2009) found that 
individuals who reported that they preferred cross-sex friendships reported that those friendships were higher in closeness, trust, caring, having common interests, and providing narcissistic benefits than those respondents who reported having a preference for same-sex friends. Further, relationship commitment, perceptions of the benefits, gender role orientation, and sexism were independently found to predict participants' proportions of cross-sex friendships (Lenton \& Webber, 2006). Specifically, for individuals low in romantic relationship commitment, increasing commitment was associated with having more cross-sex friendships, but for individuals high in romantic relational commitment, increasing commitment was associated with having fewer cross-sex friendships. When the individual perceived that the benefits outweighed the costs, they were more likely to have cross-sex friendships. Among women, increasing masculinity and decreasing femininity was related to having more cross-sex friendships. Finally, in terms of sexism, among men, less benevolent sexism toward men was associated with having more cross-sex friendships.

As with workplace friendships in general, there are a wide variety of positive and negative outcomes of cross-sex friendships at work. The limited research on cross-sex workplace friendships, in addition to literature on women in the workplace, suggests that cross-sex workplace relationships are especially important for women. Existing research suggests that women have more difficulty moving upward in organizations, in part due to a phenomenon dubbed the "glass ceiling" (Davies-Netzley, 1998; Ignatius, 2013; Sias, 2008). This term, according to the United States Federal Glass Ceiling Commission, refers to "the unseen, yet unbreakable barrier that keeps minorities and women from rising to the upper rungs of the corporate ladder, regardless of their qualifications or achievements" (Wrigley, 2002, p. 4). The United States Department of Labor examined "the challenges presented by a lack of women and 
minorities in management" in their 1991 study, the "Glass Ceiling Initiative" (Wrigley, 2002).

In the foreword to her report documenting the findings of this federal study, U.S. Labor

Secretary Lynn Martin concluded that

The glass ceiling, where it exists, hinders not only individuals, but society as a whole. It effectively cuts our pool of potential corporate leaders by eliminating over one-half of our population. It deprives our economy of new leaders, new sources of creativity - the "would be" pioneers of the business world. If our end game is to compete successfully in today's global market, then we have to unleash the full potential of the American work force. The time has come to tear down, to dismantle - the "Glass Ceiling." (Women and the Workplace, 1991, p. 1)

The glass ceiling is still a concern facing many women in the contemporary US

workplace. Further, Sias (2008) argues that women, due to their propensity to hold positions in lower hierarchical levels than men, have fewer opportunities for mentoring relationships that could lead to advancement, and the "shattering" of the "glass ceiling." She further argues that cross-sex mentoring relationships could lead to women being able to advance more easily. As such, in many organizations it would benefit female employees to become friends with male employees as it could allow for access to men's networks.

Even though cross-sex workplace relationships, such as mentoring relationships, may be beneficial for the relational partners, research also suggests that functional cross-sex mentoring relationships are rare (Ignatius, 2013; Sias, 2008; Sias et al., 2003). According to Sheryl Sandberg, COO of Facebook.com, one reason for the lack cross-sex mentoring relationships is that men and women do not take the time to build the mentoring relationship and instead, women tend to "walk up to a virtual stranger" and ask if (s)he will mentor them (Ignatius, 2013, p. 87). However, when male and female organizational members do take the time to form close one-onone mentoring relationships, Sandberg notes that others in the organization perceive that something inappropriate is occurring. Nevertheless, Sandberg suggests that despite the 
difficulties, managers (both male and female) and organizations need to encourage cross-sex mentoring.

As indicated above, workplace friendships, whether same-sex or cross-sex, may be problematic in the workplace. However, scholars in both interpersonal and organizational communication have suggested unique factors that may cause individuals in cross-sex friendships to face more difficulties than individuals in same-sex friendships. Research suggests that, for a variety of reasons, male-female friendships may be suspect in the workplace. One reason for this could simply be that these relationships are not as socially accepted or even as expected as friendships between individuals of the same sex (Dainton, et al., 2003; Ignatius, 2013; Lenton \& Weber, 2006). Additionally, in the workplace these relationships may be even more removed from what is considered "normal," as men and women have historically occupied separate life spheres and occupations considered "masculine" or "feminine" (Bose \& Rossi, 1983; Reskin \& Hartmann, 1986).

Further, scholars argue that the public/work-private/sexuality split privileges masculinity over femininity and excludes and controls women in public spheres (Acker, 1990; Ashcraft, 2005; Burrell \& Hearn, 1989; Eisenberg, Goodall, \& Trethewey, 2007; Tracy \& Scott, 2006; Trethewey, 1999; Williams, Giuffre, \& Dellinger, 1999). Acker (1990) explains that the job and worker, organizational structures, and processes (though supposedly gender neutral) are male, and men and women view that perspective as representative of reality. As Buzzanell (1994) further asserts, both men and women, due to this unconscious perception of male-reality as reality, "devalue" women's (and/or feminine) contributions to organizational life, both consciously and unconsciously (p. 340). 
Additionally, women's bodies are seen as sexual and undisciplined because they, unlike male bodies, experience pregnancy, menstruation, and according to some, an increased expression of emotions (Trethewey, 1999). As such, women's behaviors and bodies are perceived as more sexual than men's. Further, in the workplace, masculinity is privileged; leading to specific forms of male (heterosexual) sexuality appearing to be legitimate organizational power (Acker, 1990), and the norm in professional realms (Ashcraft, 2005).

Additionally, observers of cross-sex friendships may believe that these relationships are strategic, that individuals are involved in these relationships in order to "get ahead" or to receive advantages beyond those of just having a friend. Coworkers may be inclined to believe that individuals enter into workplace friendships for motives of job advancement. In their evolutionally psychological model of workplace relationship development, Teboul, and Cole (2005) argue that individuals are evolutionarily predisposed to try to develop relationships with what they label "high-preference partners (p. 399)." These high-preference partners are often members in prestigious hierarchies, as it benefits individuals to be in close relationships with others who are well-situated in organizational hierarchies. As such, it would benefit individuals to be friends with organizational members who may be able to help them move up the hierarchy.

Therefore, it could be that cross-sex workplace friendships are perceived as strategic, or as a means of gaining an "upper hand" in the workplace. That is, third-party coworkers may perceive that coworkers who are friends at work receive unfair advantages from the friendship. This notion is supported by research conducted by Lancaster and Chory (2013). These perceptions may be especially strong for women who are not as easily positioned to move upward in the organization. 
While peers who were friends with a superior were perceived as receiving more unfair advantages and were trusted less than those who had a work relationship with their superior, trust and self-disclosure did not differ based on the type of relationship the peer had with a superior (Lancaster \& Chory, 2013). This stands in contrast to workplace romance literature, which indicates that individuals are less likely to trust and limit their self-disclosures to individuals dating superiors as opposed to peers (Horan \& Chory, 2009, 2013; Malachowski et al., 2012). It is suggested that individuals who are friends with their superior are still considered a separate entity from that superior, whereas an individual dating a superior is considered "an extension of that supervisor" (Lancaster \& Chory, 2013, p. 22) due to the intimacy of a romantic relationship. This difference may explain the differences observed for trust and honesty of self-disclosures. What is of particular interest to the current investigation is how cross-sex friendships may be viewed.

It is possible, then, that organizational members are inclined to believe that there are ulterior motives for individuals being involved in a friendship with a coworker of the opposite sex. That is, if coworkers do believe that unfair advantages come with being in a workplace friendship, it is possible that they also believe the individuals in these friendships enter into these relationships for that very reason. This may be especially true for the female participants, as women are likely perceived to benefit more from cross-sex workplace friendships than men are, based on workplace romance research (Dillard, 1987 in Pierce et al., 1996; Gillen \& Chory, 2014a; Horan \& Chory, 2011, 2013; Jones, 1999; Malachowski et al., 2012; Sias, 2009). This notion is supported by arguments forwarded by Buzzanell (1994) regarding competitive individualism and feminist theory. She states that the workplace is competitively oriented and requires "winners" and "losers," but that women, who are expected to fulfill traditional feminine 
gender roles, are othered and cast as losers. Further, women who attempt to enact traditionally masculine roles (such as behaving competitively) are perceived negatively, according to Buzzanell.

In addition to being suspect in terms of possible ulterior motives, research suggests that outside individuals often perceive cross-sex friendships as suspicious because they may not be entirely platonic. This claim has been examined in interpersonal communication research, with researchers noting that cross-sex friendships are often complicated and more difficult to maintain than same-sex friendships (Guerrero \& Chavez, 2005; Werking, 1997). Dainton et al. (2003) explain, "For heterosexual individuals, maintaining a cross-sex friendship involves the affection, companionship, intimacy, and assistance found in same-sex relationships, but it also involves downgrading sexuality" (p. 91). Individuals report engaging in less maintenance behavior in cross-sex friendships than same-sex friendships (Rose, 1985), and the maintenance behaviors in cross-sex friendships appear to depend on the "status" of the relationship. For example, Guerrero and Chavez (2005) found that individuals in cross-sex friendships in which both parties wanted the friendship to "turn romantic" tended to report the most maintenance behavior. Individuals who feared that their friend wanted the friendship to turn romantic, while they did not, and individuals in friendships that both parties viewed as strictly platonic tended to talk more to each other about outside romances, use less routine contact, and flirt less. When individuals were unsure of the status of their cross-sex friendships, they tended to talk less about the relationship, use less contact, talk more about outside romances, and use more instrumental support and humor. Finally, in terms of sex differences, women in cross-sex friendships tended to use more emotional support and positivity, more instrumental support, and talked more about outside romances than did men. It is clear, then, that individuals in cross-sex friendships are faced with 
the additional difficulty of navigating the possibility that one or more parties would like the relationship to be romantic. They manage this difficulty by flirting less (Messman et al., 2000) or avoiding sensitive discussions about the "state of the relationship" (Afifi \& Burgoon, 1998).

Like male-female relationships outside of the workplace, those within the workplace also may fall victim to perceptions of romance. For example, Sias et al. (2003) found that as same-sex workplace friendships became closer, the influence of workplace contextual factors (such as sharing tasks, proximity, and work-related problems) on the friendship decreased and the influence of extra organizational factors (such as life events) increased. However, in cross-sex workplace friendships, workplace contextual factors retained their importance over the development of the friendship. The authors argue that this is indicative of cross-sex workplace friends attempting to maintain a boundary between their personal and work lives with friends of the opposite sex. Reasons for this boundary include reducing the likelihood of rumors of romantic relationships or sexual harassment.

The notion of boundaries impacting cross-sex workplace friendships is supported by Elesser and Peplau's (2006) research that suggests specific obstacles exist in the formation of cross-sex friendships in the workplace. The authors label these unique obstacles the "glass partition," a play on the "glass ceiling (p. 1077)." Respondents reported being concerned that their cross-sex friends might interpret their relationship as indicative of romantic or sexual interest or that their coworkers might misinterpret the friendship as sexual. They were also concerned that certain types of humor or conversational topics might be perceived as sexually harassing by the friend. Furthermore, Marks (1994) found that when asked to name the coworkers with whom individuals confided personal information, coworkers who socialized outside of work named a same-sex coworker, whereas respondents who did not socialize outside 
of work with their confidant overwhelmingly chose to disclose to a member of the opposite sex. The author argues, "Evidently, if getting together with someone signals a special regard for them [Rook 1987], both the married and the non-married may want to avoid the impression that their interest in an opposite-sex person goes beyond friendship" (p. 853). The limited research on cross-sex workplace friendship, has, therefore, focused primarily on the individuals in the crosssex friendship, not the perceptions of others in the organization who observe the friendship.

Because cross-sex workplace friendships may be perceived as romantic, they can be understood in terms of workplace romance literature. One factor that appears to influence how workplace romances are perceived is the way in which the romance is disclosed to coworkers. Cowan and Horan (2014) found that, overall, when coworkers found out about a workplace romance through personal disclosures (the workplace romance partners telling the respondent) the reaction to or perception of the relationship was much more positive than when the workplace romance was discovered through impersonal revelations (such as overt and covert nonverbal behaviors, gossip, and "getting caught in the act"). Further, Doll (2011) found that relationship secrecy was negatively related to both projected life and job satisfaction. As such, cross-sex workplace friendships, if perceived as more than platonic, could be perceived negatively due to coworkers believing the parties involved are "hiding" the true nature of the relationship.

Observers having the suspicion that cross-sex workplace friendships are romantic is supported in research on cross-sex mentoring relationships. Two "dangers" of cross-sex mentoring are the difficulty managing appropriate levels of intimacy (occasionally crossing the line into sexual harassment) and others misinterpreting the relationship as romantic as opposed to platonic and work-focused (Hurley, 1996; Ignatius, 2013). 
If cross-sex workplace friendships are, in fact, perceived as romantic, it is therefore possible that they are perceived even more negatively by coworkers than same-sex friendships or romances that are "out in the open." Research suggests that workplace romances are generally perceived negatively, with women in workplace romances being perceived more negatively than men in these relationships.

\section{Workplace Romances}

A workplace romance has been defined as "a non-platonic relationship between two members of an organization in which sexual attraction is present, affection is communicated, and both members recognize the relationship to be something more than just professional and platonic" (Horan \& Chory, 2011, p. 565). One reason for the development of workplace romances is the close and/or repeated contact between members of an organization (Pierce et al., 1996). Other factors that influence the development of workplace romances include the culture or climate of the organization (Mainiero, 1989; Mano \& Gabriel, 2006), attitude similarity (Pierce et al., 1996), and one's personal attitude towards the acceptability of romances in the workplace (Doll, 2011; Haavio-Mannila, Kauppinen-Toropainen, \& Kandolin, 1988). Furthermore, an individual's willingness to engage in a workplace romance is predicted by the tolerance of the organizational policy (Karl \& Sutton, 2000) and his/her motives (job, ego, or love; Quinn, 1977). Additionally, Cowan and Horan (in press) identified the following motives for engaging in workplace romances: ease of opportunity, similarity, time, and "hook up." The authors explain that the motives of ease of opportunity, similarity, and time may be considered elements of interpersonal attraction. Interestingly, the "hook up" motive was only identified by coworkers who observed the romance, not the individuals actually involved in the romance. 
Furthermore, conscientiousness is negatively related to the willingness to engage in a workplace romance and is mediated by one's attitudes about workplace romances (Doll, 2011).

In addition to becoming increasingly common (Kiser, Coley, Ford, \& Moore, 2006; Pearce, 2010; Shellenbarger, 2005), it appears that workplace romances are also becoming more widely accepted. A 2010 Wall Street Journal article, reporting the results of a CareerBuilder survey, revealed that $67 \%$ of employees reported that they felt workplace romances were not something that needed to be hidden, a number which has risen 13\% since 2005 (Shellenbarger, 2005). Additionally, Parks (2006) reported that $40 \%$ of employees admitted that they personally had been involved in a romance at work.

Workplace romance effects. Workplace romantic relationships may yield positive outcomes for the relational partners, other organizational members, and the larger organization. These outcomes include increased motivation, job involvement, and satisfaction (Pierce, 1998). Furthermore, in their qualitative examination, Gillen and Chory (2014b) found that individuals in workplace romances identified benefits such as having more friends in the workplace or being liked more, improved romantic relationships or gaining knowledge about workplace romances, liking work more or feeling happier, and communication-related benefits (e.g., the ability to bounce ideas off one another). In contrast, nearly $40 \%$ of observers (third-party coworkers) of workplace romances identified no positive implications of the romance. The majority of positive effects they did identify were related to work, including romance participants' enhanced performance, a more positive work environment, romance participants receiving job help or advantages and honest feedback from their partner, and more honest and open communication with others. A small number reported personal benefits for the members of the romance, including increased affect. 
Although workplace romances may yield some positive organizational results, the majority of research suggests that the outcomes of workplace romances are neutral (Cole, 2009) or negative, for the individuals, coworkers, and organization. For example, Gillen and Chory (2014b) found that workplace romantic relationship partners and observers (third-party coworkers) of workplace romances noted awkwardness for others, gossip, turnover, scheduling issues, and conflict impacting work as negative effects. This demonstrates specific categories of implications that are perceived as existing for workplace romance participants, regardless of respondent role (observer or member).

One specific negative outcome of workplace romance concerns sexual harassment and legal concerns (Mainiero \& Jones, 2013; Pierce \& Aguinis, 1997, 2001; Pierce et al., 2000, 2004). Boyd (2010) explains that when a workplace romance ends, one partner may be inclined to try to win the other person back. If attempts at reconciliation continually occur in a work setting, they may be perceived by the relational partner or other organizational members as sexual harassment. In this case, "the employer may be held responsible for not protecting that employee from such harassment" (Boyd, 2010, p. 328).

Claims of sexual harassment in the workplace are also perceived differently, depending on the nature of the relationship between the accused harasser and alleged victim. Specifically, perceptions of a sexual harassment claim differ depending on whether the individuals had previously been involved in a workplace romance (Pierce et al., 2000, 2004, 2007). For example, in their content-analytic review of court cases involving sexual harassment and dissolved workplace romances, Pierce et al. (2007) found that unless the harassment was severe and witnessed by other individuals, the plaintiff in a sexual harassment case was less likely to win if (s)he and the defendant had been involved in a workplace romance. Clearly, there are a number 
of legal and procedural issues that can lead to overall negative views of romantic relationships in the workplace.

Many of the negative effects or implications of workplace romances include the perceptions held by others in the organization (Cowan \& Horan, 2014, in press; Gillen \& Chory, 2014a, 2014b; Horan \& Chory, 2009, 2011, 2013; Malachowski et al., 2012). Though various factors specific to the relationship may influence how an individual workplace romance is perceived, two overarching factors affecting third party perceptions of workplace romances are the status of the members involved in the romance and the sex of the relational partners.

Status dynamic of relational partners. Perhaps the most important factor impacting coworkers' perceptions of a workplace romance identified thus far is the status dynamic of the members of the relationship. According to Parks (2006), 60\% of employees and $80 \%$ of managers believe that a workplace romance between a superior and his or her organizational subordinate is a problematic and a situation that should be restricted (p. 5). One reason for this is the possibility of ulterior motives coworkers may perceive members of the relationship as having. Jones (1999) found that superiors were seen as more responsible for the workplace romance than subordinates, perhaps indicating that superiors are seen as "taking advantage" of subordinates by coercing them into a workplace romance. Additionally, employees may be inclined to view status differential relationships more negatively because they perceive them, quite simply, as unfair. Pierce et al., (1996) explain "Basically, members of the work group perceive organizational injustice as the result of boss-subordinate romances, thereby lowering their morale at work" (p. 20). This perceived sense of injustice can lead employees to view the relationship and both members involved less favorably. 
In terms of specific perceptions of the members involved in a superior-subordinate workplace romance, Malachowski et al. (2012) found that individuals who were dating a superior were perceived as being driven less by love motives and more by job motives than were individuals dating subordinates or organizational peers. In addition, individuals involved in a relationship with their superior were perceived as being more likely to receive unfair advantages in the workplace than those dating individuals of other status types. Participants also reported being less trusting of coworkers dating a superior than those dating individuals of other status types and engaged in more information manipulation with that individual than they did with those with romantic partners of other status types. Further supporting the notion that status differential relationships are perceived negatively, Horan and Chory (2011) discovered that employees who were dating a superior were perceived by coworkers as lower in both goodwill and trustworthiness than those employees dating organizational peers. Additionally, Horan and Chory (2009) found that when an employee was dating a superior as opposed to an organizational peer, coworkers reported that they trusted that coworker less, that they felt less interpersonal solidarity with that individual, and were less honest and accurate in their selfdisclosures to that individual. Furthermore, results indicated that trust in the individual involved in the workplace romance mediated the relationships between status of the individual's dating partner and solidarity, the honesty and accuracy of self-disclosure, and deception. This pattern of results was also observed for gay and lesbian workplace romances; peers dating superiors were trusted less, were deceived more, and were perceived as less credible than organizational peers dating other peers (Horan \& Chory, 2013).

In addition to the wide variety of negative implications addressed above, recent research also suggests that individuals involved in romantic workplace relationships do not fully 
understand the extent to which others view them negatively. Gillen and Chory (2014a) found that for the variables of trust, self-disclosure, unfair advantages, and workplace romance motives, workplace romance participants reported that they believed their coworkers' perceptions of the romance were more positive than workplace romance observers/coworkers reported they were actually perceived. For example, organizational members involved in a workplace romance perceived their coworkers as trusting them more than the coworkers actually reported. It seems then, that these negative implications not only exist, but that the individuals involved in the romantic relationships are not fully aware of the extent to which others' perceptions of the romance are negative.

If individuals believe that members of a workplace romance are in the romance for jobrelated motives and that they receive unfair advantages due to their relationship, coworkers may behave in ways that they believe will "level the playing field."

Sex of relational partners. Although research suggests that individuals in workplace romances tend to be viewed negatively, perceptions of workplace romances are especially problematic for the women involved in these relationships. Horan and Chory (2011) discovered that the status and sex of the members involved in a workplace romance interacted to affect perceptions of the peer member's trustworthiness and goodwill. Specifically, whereas male employees' status relative to their partner did not affect perceptions of their goodwill and trustworthiness, women dating a superior were perceived by coworkers as both less caring and less trustworthy than women dating male peers or men dating female peers or female superiors. In their examination of gay and lesbian workplace romances, Horan and Chory (2013) found that men were perceived as more competent and caring than women and that men were less likely to be deceived than women. 
Furthermore, overall perceptions of workplace romances are more negative if one or both members are married to someone else, but are the most negative when the female member of the relationship is married (Jones, 1999). Further, if a woman is perceived to be engaging in a relationship for the motive of sincere love, positive workplace gossip is generated, whereas if a woman is perceived to be engaging in a workplace romance for job-related reasons, there is an increase in negative gossip (Dillard, 1987 in Pierce et al., 1996; Sias 2009). Interestingly, though the bulk of sex-focused research on workplace romances has shown women tend to be perceived less favorably, Jones (1999) did find that in the instance of a female supervisor and a male subordinate, the woman was perceived as being driven by the motive of love.

Additionally, consistent with previous research demonstrating that women in workplace romances are viewed more negatively than are men, Gillen and Chory (2014a) found that male coworkers perceived female workplace romance participants as receiving more unfair advantages than did any other combination of coworker and workplace participant sex. Horan and Chory (2013) found that organizational peers are less likely to deceive gay and lesbian peers involved in workplace romances and more likely to perceive gay and lesbian peers in workplace romances as caring and of higher character than heterosexual individuals. This may be related to the unique relationship between men and women's positioning in the organizational hierarchy, with the same benefits of dating a man (who is likely perceived as more powerful in the organization) not relevant for women who are dating women at work.

Furthermore, in their review of strategic sexual performances at work, Watkins, Smith, and Aquino (2013) argued that men and women engage in different forms of strategic sexual performances in the workplace. The authors explain that due to the historical positions of men and women within organizations, women may use what they feel they can offer (their sexuality, 
flirting, etc.) in order to reach organizational goals. Men, alternatively, may use their organizational power (such as the ability to bestow tangible rewards) in order to gain the attention and liking of female employees. It is possible that women are perceived as using their sexual performances, flirting, and romance to gain tangible rewards to better position themselves in the organization, which could be interpreted as unfair advantages by others. Finally, women hold less favorable attitudes towards romance and sexual intimacy at work than do men (Pierce, 1998).

\section{Theoretical Rationale: Equity Theory}

Equity theory (Adams, 1965; Walster et al., 1978) explains that individuals assess their relationships by examining the contributions they make (such as time, effort, and "hard work") and the benefits they receive (such as praise, promotions, job security, and increased salary), and by comparing that ratio to the corresponding ratio of a comparison person or standard. Equity exists when employees receive what they believe they should, based on their inputs and the corresponding outcomes, compared to the inputs and outcomes of a comparison other. Alternatively, when an individual feels as if (s)he is not receiving the same benefits in comparison to his/her contributions as another individual, inequity exists. When individuals perceive inequity they may experience feelings of resentment, anger, and frustration, and they may be motivated to behave in ways that reduce the inequity (Adams, 1965; Deutsch, 1985; Homans, 1961; Walster et al., 1978). Inequity can be reduced and equity restored through antisocial organizational behavior and communication, including indirect interpersonal aggression, hostility, and deception (Chory \& Hubbell, 2008). These behaviors act as an attempt to put the individuals involved on a more equal level from the perspective of the individuals enacting the behaviors. This can be done through increasing the costs incurred by the individuals 
or by decreasing the benefits they receive, as both create a more equal ratio of costs and benefits between the individuals. For example, deception can lead to employees gaining inaccurate information, which could lead them to incorrectly or not fully enact their responsibilities, resulting in an increased workload or even disciplinary action.

Equity theory has been examined in a wide variety of communication contexts, including organizational (e.g., Carrell \& Dittrich, 1976, 1978; Goodboy, Chory, \& Dunleavy, 2008; Khalifa, 2011), interpersonal (e.g., Canary \& Stafford, 1993), family (e.g., Myers, Goodboy, and Members of COMM 201, 2013), cross-cultural (e.g., Bolino \& Turnley, 2008), and instructional (e.g., Chory-Assad \& Paulsel, 2004) contexts. In interpersonal relationships, examinations of equity theory have revealed that individuals in equitable relationships use relational maintenance behaviors at a higher rate than those in inequitable relationships (Canary \& Stafford, 1992, 2001; Dainton, 2003; Stafford \& Canary, 2006; Yum \& Canary, 2009). Further, individuals who are a part of an equitable relationship also assess those relationships more favorably than those in inequitable relationships (Canary \& Stafford, 1993). In organizational settings, equity theory has also been examined. For example, Goodboy et al. (2008) found that perceptions of organizational injustice were related to latent dissent, with individuals who perceived a lack of justice (a form of inequity) more likely to dissent to their coworkers, perhaps as an attempt to restore equity. Additionally, in their examination of equity theory in the context of the organizational performance appraisal, Chory and Hubbell (2008) found that employees respond to perceptions of inequity (specifically perceptions of unfairness) by engaging in indirect interpersonal aggressiveness, hostility, obstructionism, and deception toward the source of their inequity, i.e., supervisors. These antisocial behaviors are seen as a means of increasing the supervisors' costs, thus restoring equity to the employee-supervisor relationship.. In terms of workplace romance, 
Horan and Chory (2009) and Malachowski et al. (2012) assert that coworkers may deceive peers in workplace romances and/or be less honest and accurate in their self-disclosures to those peers in order to even the playing field, thus restoring equity.

In terms of the current investigation, equity theory will be employed in order to understand the perceptions organizational members have of coworkers in cross-sex workplace friendships and their behaviors towards these coworkers. Specially, the current investigation argues that, based on equity theory, specific variables will impact perceptions of equity and that these perceptions will lead to specific responses to restore equity.

Predictors of inequity perceptions. It is argued that the independent variables of workplace relationship type, sex composition of the relationship, sex of the peer being reported on, and status dynamic of the relationship will impact perceptions of inequity. In terms of relationship type, previous research has suggested that individuals in workplace romances are perceived as receiving unfair advantages (Gillen \& Chory, 2014a, 2014b; Malachowski et al., 2012). As such, it is likely that organizational members will perceive these types of relationships as causing more inequity than less intimate, more professional workplace relationships. Regarding sex composition of the relationship, research has suggested that cross-sex relationships are often perceived as romantic (Afifi \& Burgoon, 1998; Dainton et al., 2003; Elesser \& Peplau, 2006; Guerrero \& Chavez, 2005; Marks, 1994; Messman et al., 2000). As such, cross-sex relationships will likely be perceived as unequally benefiting partners compared to same-sex relationships. In terms of the sex of the peer being reported on, research has shown that women versus men are perceived as receiving more unfair advantages due to their workplace relationships (Gillen \& Chory, 2014a), likely leading to perceptions of inequity. Finally, in regards to the status dynamic, a wide variety of previous studies have indicated that individuals 
in relationships with organizational superiors are perceived as unfairly benefitting in the workplace (e.g., Malachowski et al., 2012), which again, is likely to lead to perceptions of inequity.

In addition to the variables noted above, the studies presented here consider the role of sexism in perceptions of equity (or lack thereof) in workplace relationships. As research has indicated that women are othered when the patriarchal worldview is normalized and reified (Buzzanell, 1994; Mumby \& Putnam, 1992), it is likely that more sexist individuals, who even more strongly believe women have a specific place and precise roles in organizations (and society), may be more inclined to believe that women are in workplace relationships in order to receive advantages, therefore perceiving inequity and in turn enacting certain antisocial behaviors as an attempt to restore equity.

Responses to inequity perceptions. In addition to the variables expected to impact perceptions of equity, the studies presented here also examine a series of responses to inequity, including a number of equity-restoration behaviors. First, non-behavioral responses to inequity examined in these studies include unfair advantages, credibility, and trust. It is argued, based on equity theory, that if individuals perceive inequity between themselves and coworkers (due to coworkers' workplace relationship type, sex of the peer, etc.), they will likely perceive those coworkers as receiving some sort of unfair advantage. Further, individuals that are perceived as receiving a benefit or unfair advantages in the workplace may be more likely to be seen as less credible and trustworthy. For example, Horan and Chory (2011) found that individuals dating a superior (a relationship with the possibility of perceived unfair advantages) were rated as lower in goodwill and trustworthiness than individuals in workplace romances with peers. 
Equity-restoration behaviors, which equity theory predicts will be motivated by perceptions of inequity, include obstructionism, information manipulation, and aggression. If individuals perceive that they are not receiving the benefits that they believe they should based on their contributions and the ratio of benefits to contributions of others, they will be inclined, according to equity theory, to behave in ways that restore equity. In the studies presented here, it is theorized that individuals who perceive inequity will respond with obstructionism of their coworkers' work, manipulation of the information they share with that coworker via deception and a lack of honest and accurate self-disclosure, and aggressive behavior towards that individual in the form of a lower rating and a lowered likelihood of considering that individual worthy of a promotion. Enacting these behaviors may be seen as either limiting or reducing the benefits individuals receive or directly increasing the costs that they experience, both of which will work to restore a sense of balance or equity. For example, organizational members may obstruct their coworkers' activities, making it more difficult for their coworkers to accomplish their goals, thus introducing costs into the coworkers' cost-benefit ratios.

Taken together, it appears that individuals may perceive that the certain factors (such as sex, status dynamic of the relationship, type of relationship, and sex composition of relationships) lead to individuals obtaining more benefits in the workplace. Drawing on equity theory, it is likely then, that individuals will feel that they are required to enact more active behaviors to "even things out." That is, in order to level the playing field, individuals may deceive those in cross-sex workplace friendships, be less honest and accurate in their selfdisclosures to these coworkers, obstruct the organizational functioning of those employees, and be aggressive toward them in order to counteract the benefits they believe those individuals receive by virtue of their friendship. Organizational members increase the costs for the 
individuals involved (such as through directly obstructing their work, thereby counteracting benefits they incur by virtue of the friendship) and/or decrease the benefits (such as by manipulating information so that information from their workplace friend that acts as a benefit is countered by incorrect information).

\section{Statement of Problem}

Taken together, research indicates that cross-sex workplace friendships are a rich area for examination from a Communication Studies perspective. First, research on cross-sex friendships (both inside and outside the workplace) indicates that these relationships are often perceived as romantic (Afifi \& Burgoon, 1998; Dainton et al., 2003; Elesser \& Peplau, 2006; Guerrero \& Chavez, 2005; Marks, 1994; Messman et al., 2000). Further, research has indicated that workplace romances are generally perceived negatively, including lower levels of credibility, increased perceptions of unfair advantages, and lower levels of trust and self-disclosure (Cowan \& Horan, 2014, in press; Gillen \& Chory, 2014a, 2014b; Horan \& Chory, 2009, 2011, 2013; Malachowski et al., 2012).

In addition to being perceived negatively, research has suggested that the way in which a romance is discovered impacts how others in the organization perceive the relationship. For example, Cowan and Horan (2014) found that workplace romances are perceived most negatively when they are discovered through gossip or "getting caught in the act," as opposed to through personal disclosures. That is, when workplace romances are believed to be "hidden" or kept secret, others in the organization tend to perceive them even more negatively than when they are openly exposed to others. Therefore, due to research suggesting that cross-sex friendships are often perceived as being romantic, and because workplace romances that are seen 
as hidden are perceived especially negatively, it is expected that individuals in cross-sex workplace friendships will be more likely to be perceived negatively by their coworkers.

In addition, female members of workplace romances are consistently perceived more negatively than male members (Gillen \& Chory, 2014a, 2014b; Horan \& Chory, 2009, 2011, 2013; Jones, 1999; Malachowski et al., 2012). One possible reason for this is the differing positions of men and women within many organizations. Because women have historically had more difficulty moving upward (or "breaking the glass ceiling”), they may be seen as having ulterior motives for being involved in the romance (or in the current investigation, workplace friendship), especially if they attempt to break free of traditional, constricting gender roles, such as attempting to become friends with men in the organization (Buzzanell, 1994). Further, individuals may believe that coworkers who claim to simply be friends are actually romantically involved and hiding it, leading to negative perceptions of even cross-sex workplace friendships. As such, it is hypothesized that female members of cross-sex workplace friendships, like female members of workplace romances, will be perceived more negatively than male members of the friendships.

In order to further understand perceptions of cross-sex workplace friendships, three studies were conducted. Whereas prior research has examined workplace friendships, cross-sex friendships, and workplace romances, there is a lack of research specifically examining perceptions of individuals in cross-sex workplace friendships. Therefore, the aim of Study 1 was to explore how individuals perceive (and the way they discuss) cross-sex workplace friendships and the men and women involved. The goal of Study 2, which employed hypothetical scenarios, was to gain a more holistic understanding of the differences in perceptions of various workplace relationships, including workplace romances, workplace friendships, and professional 
relationships, both cross-sex and same sex. Finally, the aim of Study 3 was to specifically examine organizational members' perceptions of their peers in cross-sex workplace friendships and organizational members' behavior toward these coworkers as reported by individuals who have personally observed a relationship of this type.

\section{Hypotheses and Research Questions}

In order to gain a basic understanding of the ways in which organizational members perceive and respond to cross-sex workplace friendships, an investigatory preliminary was conducted. As mentioned previously, existing research has not specifically examined the perceptions others hold regarding cross-sex workplace friendships and the individuals involved. As such, the research questions posed here aim to gain a general sense of these perceptions. As such, the following research questions are posed:

RQ1: How do organizational members describe cross-sex workplace friendships that they observe?

RQ2: What issues do organizational members report in regards to cross-sex workplace friendships they observe?

Further, equity theory (Adams, 1965) suggests that when employees feel like they are receiving what they should, based on their inputs and the corresponding inputs and outcomes of another employee, equity exists. When an individual feels as if, compared to the inputs and outcomes of another employee, (s)he is not receiving the same benefits relative to his/her contributions, inequity exists. As previously discussed, workplace friendships may provide benefits to those in the friendship (such as higher quality information or instrumental support) that others do not receive, creating inequity. Therefore, drawing on equity theory, the following research question is presented in an attempt to determine whether coworkers perceive any inequity between themselves and cross-sex workplace friendship partners. 
RQ3: Do organizational members perceive that coworkers in cross-sex workplace friendships receive unfair advantages due to their friendship?

Equity theory further claims that when inequity is perceived, individuals may experience negative feelings (such as resentment, anger and/or frustration). These negative feelings may motivate the individual to behave in ways that help reduce the inequity that they perceive (Adams, 1965; Deutsch, 1985; Homans, 1961; Walster et al., 1978). The following research questions are presented in an attempt to understand how organizational members generally behave toward cross-sex workplace friendship partners, and specifically, how they may behave in order to restore equity:

RQ4: How do organizational members behave around coworkers in cross-sex workplace friendships?

RQ5: In what ways do organizational members report behaving towards their coworkers in cross-sex workplace friendships in order to restore equity?

\section{Relationship Type: Romance, Friendship, and Professional Relationship. Research}

suggests that the type of workplace relationship impacts the way in which it is perceived.

Collegial peers share information about problems at work with each other and special peers share information on topics that are "virtually limitless" (Sias, 2008, p. 66). These topics may include their personal lives and intimate information about their work lives, such as problems with supervisors or peers. They may also communicate information needed for task accomplishment (Sias \& Cahill, 1998; Sias \& Jablin, 1995). Further, Kram and Isabella (1985) argued that collegial peers provide each another with information perceived to be more accurate, useful, and timely than information from other peer types. Research has also suggested that individuals with information peers experience less solidarity, trust, and self-disclosure (Myers \& Johnson, 2004), and tend to report lower information quality (Sias, 2005) than those with special or collegial 
peers. Drawing on equity theory (Adams, 1965), it is likely that individuals understand these benefits of workplace friendships and may be inclined to behave in ways that level the playing field. For example, coworkers may be aware of the fact that individuals in workplace friendships experience dialectical tensions and are continuously trying to determine if they should favor their friend or be objective in the workplace (Bridge \& Baxter, 1992). Further, research suggests that workplace romances may be perceived as even more likely than friendships to lead to these unfair benefits (Horan \& Chory, 2009, 2011, 2013; Malachowski et al., 2012; Sias, 2009). As Lancaster and Chory (2013) suggest, the intimacy of a romantic relationship may lead to the individuals involved being seen less as separate entities in the workplace and more as a pair, leading to an increase in shared information, and in turn, benefits. Accordingly, it is hypothesized that there will be differences in how professional workplace relationships, workplace friendships, and workplace romances are perceived, specifically regarding credibility, relationship motives, and unfair advantages. These differences are examined in Study 2.

Credibility includes perceptions of one's competence, trustworthiness/character, and goodwill/caring (McCroskey \& Teven, 1999). Relationship motives refer to the reasons individuals engage in a relationship and are based on Quinn's (1977) ego, love, and job motives. Unfair advantages relates to perceptions of organizational justice-perceptions of fairness and evaluations regarding the appropriateness of workplace outcomes or processes (Cropanzano \& Greenberg, 1997).

In addition, it is hypothesized that organizational members' trust in their coworkers will differ based on the type of workplace relationship in which the coworkers are involved. Trust is the "process of holding certain relevant, favorable perceptions of another person which engender certain types of dependent behaviors in a risky situation where the expected outcomes that are 
dependent upon the other person(s) are not known with certainty" (Wheeless \& Grotz, 1977, p. 251).

Finally, it is expected that, based on equity theory (Adams, 1965), organizational members' behaviors toward their coworkers will differ based on the type of relationship the observed coworkers are part of. The behaviors of interest are obstructionism, information manipulation, and aggression. Obstructionism refers to behaviors or actions in the workplace that are intended to interfere with another's ability to perform his or her job (Neuman \& Baron, 1998). Information manipulation includes forms of self-disclosure, the act of verbally communicating information to another person that (s)he would not have known otherwise, and deception, the act of controlling the information communicated in order to "convey a meaning that departs from the truth" as one knows it (Buller \& Burgoon, 1996, p. 205). Lastly, aggression refers to behaviors that are intended to harm another person (Anderson \& Bushman, 2002), such as recommendations for/against promotion and employment opportunities. As such, the following hypothesis is put forth:

H1: Organizational members in workplace romances will be a) perceived as the least credible, most driven by job and ego motives and least by sincere motives, and receiving the most unfair advantages; b) trusted the least; and c) most likely to be the targets of their coworkers' obstructionism, information manipulation, and aggression, followed by organizational members in workplace friendships, and then organizational members in professional workplace relationships.

Sexism refers to "an antipathy based upon a faulty and inflexible generalization" (Allport, 1954 quoted in Glick \& Fiske, 1996) towards a specific gender. Researchers have identified two forms of sexism. One form is hostile sexism, which refers to "traditional seething negative sexist attitude characterized by insults, disrespect, and intentional exclusion due to gender" (Jones et al., 2014, p. 172). For the purposes of this dissertation, hostile sexism directed at women is examined. The second form is benevolent sexism, or a "contemporary, seemingly positive form 
of sexism ... which reflects beliefs that women should be protected and revered" (p. 171).

Although more subtle than hostile sexism, benevolent sexism is still discriminatory and

potentially damaging. As such, sexism, including both hostility toward women and stereotypical

views of women in restricted roles, is likely to impact the association between workplace

relationship type and perceptions of coworkers, trust in them, and antisocial behavior toward

them. In terms of relationship type, it is possible that individuals who are more sexist will be

more likely to view individuals in more intimate workplace relationships more negatively and

behave more anti-socially towards these individuals. Individuals who are more sexist may be

inclined to believe that individuals, particularly women, in more intimate workplace

relationships are more likely to have ulterior motives for the relationship, leading to more

negative attitudes towards the individuals and the relationship. Accordingly, the following

hypothesis is proposed:

H2: Sexism will interact with relationship type to affect a) perceptions of credibility, motives, and unfair advantages; b) trust; and c) obstructionism, information manipulation, and aggression such that the differences in these outcomes among the three relationship types will be greater for more sexist versus less sexist individuals.

Sex Composition of Relationship: Cross-Sex and Same-Sex. Research suggests that cross-sex and same-sex relationships are perceived differently. One issue that arises with crosssex friendships is the perception that the friendship is romantic, which could lead to coworkers perceiving the individuals involved less as separate entities and more as connected intimates (Lancaster \& Chory, 2013), which may, in turn, lead to perceptions of more frequent and higher quality information exchange. This information could be seen as an unfair advantage or a benefit that creates an unequal situation. Additionally, individuals in cross-sex workplace friendships may receive benefits that are not as salient in same-sex relationships. Specifically, for women, 
cross-sex friendships in the workplace can lead to more easy advancement in the organization because of the increased networking opportunities provided by the male friend at work (Ignatuius, 2013; Sias, 2008; Sias et al., 2003). Equity theory (Adams, 1965) explains that this may lead to a sense of inequity, leading to behaviors intended to reduce that inequity. Further, the notion that cross-sex workplace relationships are perceived more negatively than same-sex relationships is supported by Horan and Chory's (2013) investigation of same- and cross-sex workplace romances. Specifically, they observed that organizational peers reported being less likely to deceive gay and lesbian peers involved in workplace romances and more likely to perceive gay and lesbian peers in workplace romances as caring and of higher character than individuals in heterosexual workplace romances. As such, the following hypothesis is presented and tested in Study 2:

H3: Organizational members in cross-sex workplace relationships will be a) perceived as less credible, more driven by job and ego motives and less by sincere motives, and receiving more unfair advantages; b) trusted less; and c) more likely to be the targets of their coworkers' obstructionism, information manipulation, and aggression than will organizational members in same-sex workplace relationships.

As with relationship type, sexism is expected to influence the relationship between sex composition of the relationship and perceptions, trust, and behaviors. Individuals who are more sexist may also be more likely to perceive individuals in cross-sex relationships more negatively as they believe that individuals should engage in relationships with individuals of their own sex exclusively That is, sexist individuals, by virtue of their negative views towards women may be inclined to believe that men should choose to associate and form friendships with other men, who are more equal to them. Accordingly, hypothesis four is as follows:

H4: Sexism will interact with relationship type to affect a) perceptions of credibility, motives, and unfair advantages; b) trust; and c) obstructionism, information manipulation, and aggression such that the differences in these outcomes between 
cross-sex and same-sex workplace relationships will be greater for more sexist versus less sexist individuals.

Sex of Peer. In addition to the type of workplace relationship and the sex composition of that relationship, research has demonstrated that the sex of the workplace relationship partner being reported on impacts the perceptions held by others. This impact is examined in Studies 2 and 3. Overwhelmingly, research has suggested that in workplace romances, female members are perceived more negatively than male members. For example, the most negative perceptions of workplace romance come when the female member is married (Jones, 1999). Further, women dating superiors are perceived by peer coworkers as both less caring and less trustworthy than women dating male organizational peers or men dating female peers or female superiors (Horan \& Chory, 2011). Women in workplace romances are also perceived as less competent and caring than men in workplace romances (Horan \& Chory, 2011, 2013). Additionally, research suggests that male coworkers perceive female workplace romance participants as receiving more unfair advantages (Gillen \& Chory, 2014a) than male workplace romance participants. These results may be due to women being perceived as benefiting more from workplace relationships than men, due to the potential for the relationship to help women break through the glass ceiling. According to equity theory (Adams, 1965), if individuals believe that women are benefitting unfairly from their workplace relationships with men, they will be inclined to behave in ways that reduce or counter those advantages, thus "leveling the playing field." As such, the following hypothesis is posed:

H5: Female organizational members in workplace relationships will be a) perceived as less credible, more driven by job and ego motives and less by sincere motives, and receiving more unfair advantages; b) trusted less; and c) more likely to be the targets of their coworkers' obstructionism, information manipulation, and aggression than will male organizational members in workplace relationships. 
It is likely that individuals, who are highly sexist towards women, by virtue of that sexism, will rate women less favorably, and be more including to enact negative behaviors towards them. Therefore, sexism is likely to influence relationships with perceptions, trust, and behaviors, as described in hypothesis six:

H6: Sexism will interact with organizational member sex to affect a) perceptions of credibility, motives, and unfair advantages; b) trust; and c) obstructionism, information manipulation, and aggression such that the differences in these outcomes between male and female organizational members will be greater for more sexist versus less sexist individuals.

Status Dynamic of Relationship. An additional aspect that has been shown to influence perceptions of workplace relationships is the status dynamic between the members involved. Having a quality relationship with a superior is associated with supervisor attention and support, higher levels of confidence, increased clarity, and increased job satisfaction and commitment (Gerstner \& Day, 1997; Scandura et al., 1986). In workplace romance research, individuals dating a superior are perceived as driven less by love motives and more by job motives, more likely to receive unfair advantages, and as lower in goodwill and trustworthiness than are individuals dating peers or subordinates. In addition, organizational members trust their peers who date superiors less, feel less solidarity with them, and engage in more information manipulation with these peers than they do with peers dating individuals of other status types (Horan \& Chory, 2009, 2011, 2013; Malachowski et al., 2012). Taken together, research suggests that individuals in relationships with a coworker of higher status are seen as receiving advantages that do not exist in relationships with peers or subordinates. As such, equity theory (Adams, 1965) suggests that if others in the organization believe these advantages are unfair and lead to a situation of inequity, they will be motivated to behave in ways to restore equity. Thus, the following hypothesis is posed (and tested in Study 3): 
H7: Organizational members in cross-sex workplace friendships with a superior will be a) perceived as less credible, more driven by job and ego motives and less by sincere motives, and receiving more unfair advantages; b) trusted less; and c) more likely to be the targets of their coworkers' obstructionism, information manipulation, and aggression than will organizational members in cross-sex workplace friendships with a peer or a subordinate.

Again, sexism is expected to moderate the relationships between status dynamic and perceptions, trust, and behaviors. Based on previous research indicating that status differential romantic relationships are viewed more negatively, especially for women (Horan \& Chory, 2011), it is possible that individuals who are sexist may be inclined to view status differential cross-sex friendships more negatively. Accordingly hypothesis eight is as follows:

H8: Sexism will interact with the status dynamic of cross-sex workplace friendships to affect a) perceptions of credibility, relationship motives, and unfair advantages; $b$ ) trust; and c) obstructionism, information manipulation, and aggression such that the differences in these outcomes between cross-sex workplace friendships with superiors versus peers or subordinates will be greater for more sexist versus less sexist individuals.

Interaction Effects. In addition to the above hypotheses, a research question is posed examining the effect of the interactions between relationship type, sex composition of the relationship, sex of the peer being reported on, the status dynamic of the relationship, and sexism on credibility, relationship motives, unfair advantages, trust, obstructionism, information manipulation, and aggression. As such, research question one is as follows:

RQ6: Will type of workplace relationship, sex composition of the relationship, sex of the peer being reported on, the status dynamic of the relationship, and sexism interact to affect perceptions of a) credibility, relationship motives, and unfair advantages; b) trust; and c) obstructionism, information manipulation, and aggression?

Relationships among Variables. Finally, a series of hypotheses and research questions are posed in order to understand the relationships between the variables being examined. These associations are examined in Studies 2 and 3. Trust and the belief that an individual is motivated 
to be in the relationship by love are expected to lead to less negative behavior, as research suggests that trust and perceptions of love motives are negatively related to outcomes such as information manipulation and decreased solidarity (Horan \& Chory, 2009; Malachowski et al., 2012). As such, the following hypothesis is posed:

H9: Trust and perceptions of love motives will be negatively related to obstructionism, information manipulation, and aggression.

Additionally, Malachowksi et al. (2012) found that individuals who believed their coworkers were in a workplace romance for job motives and who believed those individuals received more unfair advantages due to the relationship, were more likely to engage in information manipulation. This result supports equity theory (Adams, 1965), with individuals feeling that ulterior (that is insincere) motives and the unfair advantages that come from workplace relationships lead to an unequal situation, encouraging them to behave in ways that reduce inequity. As such, the tenth hypothesis is as follows:

H10: Perceptions of unfair advantages and ego and job motives will be positively related to obstructionism, information manipulation, and aggression.

Previous research has shown that trust and perceptions of the individuals in the workplace romance mediate the relationship between the status dynamic of the workplace romance and antisocial workplace behaviors toward the peer in the romance. For example, Horan and Chory (2009) found that trust in the peer mediated the relationships between peer's partner status and coworkers' solidarity and information manipulation with the peer. Similarly, Malachowski et al. (2012) found that trust, motives, and unfair advantages mediated the relationships between the status of the organizational peer's partner and coworker self-disclosure and deception. This research, coupled with the previous hypotheses, leads to the eleventh hypothesis: 
H11: Trust, motives, and unfair advantages will mediate the relationships between the independent variables (relationship type, sex composition, sex of peer reported on, status dynamic) and obstructionism, information manipulation, and aggression.

The relationship between perceived credibility and the antisocial workplace behaviors of obstructionism, information manipulation, and aggression will also be examined in Studies 2 and 3. Drawing on equity theory (Adams, 1965), it is possible that individuals who perceive coworkers in workplace relationships as lacking credibility will behave more negatively toward those individuals because they do not feel as if they deserve the benefits they obtain through the relationship. Alternatively, it is possible that individuals who are perceived as credible will be seen as a greater threat, leading to enacting more obstructionism, information manipulation, and aggressive behaviors. As such, the following research questions are posed:

RQ7: What are the relationships between credibility and obstructionism, information manipulation, and aggression?

RQ8: Does credibility mediate the relationships between the independent variables (relationship type, sex composition, sex of peer reported on, status dynamic) and obstructionism, information manipulation, and aggression?

The studies described in this chapter aim to jointly answer the series of hypotheses and research questions posed in the prior chapter. In using three studies, with three unique research methodologies, this dissertation takes a multimethod approach. The strategy of an approach such as this is "to attack a research problem with an arsenal of methods that have non-overlapping weaknesses in addition to their complementary strengths (Brewer \& Hunter, 2006, p. 4). As Brewer and Hunter (2006) further explain, this diversity of methods allows the researcher to gain the individual strengths of each method, while also allowing for the compensation of their individual weaknesses. As such, the methodologies of the three studies employed here each have unique strengths and weaknesses, but taken together, they allow for a holistic and diverse 
understanding of the phenomenon being examined. The hypotheses and research questions and the studies that address them can be found in Table 1. 
Table 1

Research Questions and Hypotheses Addressed by Study

\begin{tabular}{|c|c|c|c|}
\hline & $\begin{array}{c}\text { Study } \\
1\end{array}$ & $\begin{array}{c}\text { Study } \\
2\end{array}$ & $\begin{array}{c}\text { Study } \\
\mathbf{3}\end{array}$ \\
\hline RQ1: How do organizational members describe cross-sex workplace friendships that they observe? & $\checkmark$ & & \\
\hline $\begin{array}{l}\text { RQ2: What issues do organizational members report in regards to cross-sex workplace friendships they } \\
\text { observe? }\end{array}$ & $\checkmark$ & & \\
\hline $\begin{array}{l}\text { RQ3: Do organizational members perceive that coworkers in cross-sex workplace friendships receive } \\
\text { unfair advantages due to their friendship? }\end{array}$ & $\checkmark$ & & \\
\hline RQ4: How do organizational members behave around coworkers in cross-sex workplace friendships? & $\checkmark$ & & \\
\hline $\begin{array}{l}\text { RQ5: In what ways do organizational members report behaving towards their coworkers in cross-sex } \\
\text { workplace friendships in order to restore equity? }\end{array}$ & $\checkmark$ & & \\
\hline $\begin{array}{l}\text { H1: Organizational members in workplace romances will be a) perceived as the least credible, most } \\
\text { driven by job and ego motives and least by sincere motives, and receiving the most unfair advantages; b) } \\
\text { trusted the least; and c) most likely to be the targets of their coworkers' obstructionism, information } \\
\text { manipulation, and aggression, followed by organizational members in workplace friendships, and then } \\
\text { organizational members in professional workplace relationships. }\end{array}$ & & $\checkmark$ & \\
\hline $\begin{array}{l}\text { H2: Sexism will interact with relationship type to affect a) perceptions of credibility, motives, and unfair } \\
\text { advantages; b) trust; and c) obstructionism, information manipulation, and aggression such that the } \\
\text { differences in these outcomes among the three relationship types will be greater for more sexist versus } \\
\text { less sexist individuals. }\end{array}$ & & $\checkmark$ & \\
\hline $\begin{array}{l}\text { H3: Organizational members in cross-sex workplace relationships will be a) perceived as less credible, } \\
\text { more driven by job and ego motives and less by sincere motives, and receiving more unfair advantages; } \\
\text { b) trusted less; and c) more likely to be the targets of their coworkers' obstructionism, information } \\
\text { manipulation, and aggression than will organizational members in same-sex workplace relationships. }\end{array}$ & & $\checkmark$ & \\
\hline $\begin{array}{l}\text { H4: Sexism will interact with relationship type to affect a) perceptions of credibility, motives, and unfair } \\
\text { advantages; b) trust; and c) obstructionism, information manipulation, and aggression such that the } \\
\text { differences in these outcomes between cross-sex and same-sex workplace relationships will be greater } \\
\text { for more sexist versus less sexist individuals. }\end{array}$ & & $\checkmark$ & \\
\hline H5: Female organizational members in workplace relationships will be a) perceived as less credible, & & $\checkmark$ & \\
\hline
\end{tabular}




\begin{tabular}{|c|c|c|}
\hline $\begin{array}{l}\text { more driven by job and ego motives and less by sincere motives, and receiving more unfair advantages; } \\
\text { b) trusted less; and c) more likely to be the targets of their coworkers' obstructionism, information } \\
\text { manipulation, and aggression than will male organizational members in workplace relationships. }\end{array}$ & & \\
\hline $\begin{array}{l}\text { H6: Sexism will interact with organizational member sex to affect a) perceptions of credibility, motives, } \\
\text { and unfair advantages; b) trust; and c) obstructionism, information manipulation, and aggression such } \\
\text { that the differences in these outcomes between male and female organizational members will be greater } \\
\text { for more sexist versus less sexist individuals. }\end{array}$ & $\checkmark$ & $\checkmark$ \\
\hline $\begin{array}{l}\text { H7: Organizational members in cross-sex workplace friendships with a superior will be a) perceived as } \\
\text { less credible, more driven by job and ego motives and less by sincere motives, and receiving more unfair } \\
\text { advantages; b) trusted less; and c) more likely to be the targets of their coworkers' obstructionism, } \\
\text { information manipulation, and aggression than will organizational members in cross-sex workplace } \\
\text { friendships with a peer or a subordinate. }\end{array}$ & & $\checkmark$ \\
\hline $\begin{array}{l}\text { H8: Sexism will interact with the status dynamic of cross-sex workplace friendships to affect a) } \\
\text { perceptions of credibility, relationship motives, and unfair advantages; b) trust; and c) obstructionism, } \\
\text { information manipulation, and aggression such that the differences in these outcomes between cross-sex } \\
\text { workplace friendships with superiors versus peers or subordinates will be greater for more sexist versus } \\
\text { less sexist individuals. }\end{array}$ & & $\checkmark$ \\
\hline $\begin{array}{l}\text { RQ6: Will type of workplace relationship, sex composition of the relationship, sex of the peer being } \\
\text { reported on, the status dynamic of the relationship, and sexism interact to affect perceptions of a) } \\
\text { credibility, relationship motives, and unfair advantages; b) trust; and c) obstructionism, information } \\
\text { manipulation, and aggression? }\end{array}$ & $\checkmark$ & $\checkmark$ \\
\hline $\begin{array}{l}\text { H9: Trust and perceptions of love motives will be negatively related to obstructionism, information } \\
\text { manipulation, and aggression. }\end{array}$ & $\checkmark$ & $\checkmark$ \\
\hline $\begin{array}{l}\text { H10: Perceptions of unfair advantages and ego and job motives will be positively related to } \\
\text { obstructionism, information manipulation, and aggression. }\end{array}$ & $\checkmark$ & $\checkmark$ \\
\hline $\begin{array}{l}\text { H11: Trust, motives, and unfair advantages will mediate the relationships between the independent } \\
\text { variables (relationship type, sex composition, sex of peer reported on, status dynamic) and } \\
\text { obstructionism, information manipulation, and aggression. }\end{array}$ & $\checkmark$ & $\checkmark$ \\
\hline $\begin{array}{l}\text { RQ7: What are the relationships between credibility and obstructionism, information manipulation, and } \\
\text { aggression? }\end{array}$ & $\checkmark$ & $\checkmark$ \\
\hline $\begin{array}{l}\text { RQ8: Does credibility mediate the relationships between the independent variables (relationship type, } \\
\text { sex composition, sex of peer reported on, status dynamic) and obstructionism, information manipulation, } \\
\text { and aggression? }\end{array}$ & $\checkmark$ & $\checkmark$ \\
\hline
\end{tabular}




\section{CHAPTER II: STUDY ONE}

\section{Method}

Study one is formative research on the perceptions individuals hold of their coworkers in cross-sex workplace friendships. The method involves asking participants to respond to openended items in a questionnaire format. According to Ballou (2008), asking open-ended questions is ideal for gathering data on new topics, as it will help researchers understand what topics and issues are most salient for respondents. Second, qualitative data, in allowing respondents to expand on their responses, can provide more rich descriptions and details, which again, is beneficial when initially examining a previously under-examined topic.

Participants and procedures. After receiving IRB approval, individuals were recruited to participate in this study in four ways. Participants were recruited through snowball sampling in introductory communication courses at a large Mid-Atlantic University, an online announcement made through the same University, links posted on the researcher's personal Facebook page, and Amazon's Mechanical Turk crowd-sourcing service (www.mturk.com), which has been shown to be similar to other forms of sampling (Behrend, Sharek, Meade, \& Wiebe, 2011; Paolacci, Chandler, \& Ipeirotis, 2010; Sprouse, 2011). To participate, individuals had to be at least 25 years of age and be employed full time (at least 30 hours a week). Additionally, participants were required to have personally observed a cross-sex friendship in a current or previous workplace. Students in undergraduate courses were given a handout that included basic information on the study and information that directed them to identify an individual that they knew who fit the inclusion criteria. Students were instructed to have their identified participant email the coauthor, who provided them a link to the online questionnaire. The call for participants posted on the University online announcement system, researcher's 
Facebook page, and Amazon's Mechanical Turk included a direct link to the same online questionnaire. When participants clicked the link, they were first directed to a page that included the cover letter for the study and the researchers' contact information. Participants were instructed to click a button labeled "I agree to participate" if they agreed to participate and to exit the page if they decided not to proceed with the questionnaire. On the final page of the online questionnaire, individuals were thanked for their participation and provided the researchers' contact information a final time.

One hundred and forty one individuals completed questionnaires, though 45 participants were removed due to them being under 25 years of age $(n=7)$, working less than full time $(n=$ $20)$, reporting on their own workplace friendship $(n=12)$, or providing nonsensical answers or not answering the questions $(n=6)$. The final sample included responses from 96 working adults (50 women and 46 men). Thirty-nine participants accessed the survey via Mechanical Turk (40.6\%), while the remaining 59.4\% $(n=57)$ accessed the survey via Facebook, the University intranet, or recruitment from students in undergraduate courses. Participants ranged in age from 25 to 71 years old $(M=38.17, S D=11.66)$, worked/work 30 to 100 hours per week $(M=43.0$, $S D=9.17$, at the organization in which they observed the workplace friendship and had worked/been working at that organization from 4 months to 25.7 years $(M=79.46$ months, $S D=$ 9.17 months). The majority of respondents reported their race/ethnicity as Caucasian/White $(n=$ 60, 62.5\%), followed by Asian/Asian American $(n=24,25.0 \%)$, Hispanic/Latino $(n=5,5.2 \%)$, African American/Black $(n=2,2.1 \%)$, "Other" $(n=2,2.1 \%)$ and Native American $(n=1$, $1.0 \%)$. Two participants $(2.1 \%)$ did not report their race/ethnicity. The majority of participants $(n$ $=61,63.5 \%$ ) reported that they still worked at the organization at which they observed the crosssex workplace friendship. The most common occupational field reported by participants was 
managerial and professional ( $n=44,45.8 \%$ ), followed by technical, sales, and administrative support $(n=34,35.4 \%)$, service occupations $(n=10,10.4 \%)$, precision production, craft, and repair $(n=5,5.2 \%)$ and operators, fabricators, and laborers $(n=2,2.1 \%)$. One participant did not report his/her occupational field (1.0\%). The majority of participants $(n=20,20.8 \%)$ reported an annual salary of under $\$ 20,000$, followed by $\$ 20,000$ to $\$ 30,000(n=17,17.7 \%)$, $\$ 30,001$ to $\$ 40,000(n=13,13.5 \%), \$ 40,001$ to $\$ 50,000(n=12,12.5 \%), \$ 80,001$ to $\$ 90,000(n$ $=8,8.3 \%), \$ 50,001$ to $\$ 60,000(n=7,7.3 \%), \$ 60,001$ to $\$ 70,000(n=5,5.2 \%), \$ 70,001$ to $\$ 80,000(n=5,5.2 \%)$, over $\$ 100,000(n=4,4.2 \%)$, and $\$ 90,001$ to $\$ 100,000(n=2,2.1 \%)$. Three participants did not report their salary (3.1\%).

Instrumentation. The online questionnaire first featured the following definition of a cross-sex workplace friendship, drawn from existing research on workplace friendships (e.g., Sias, 2008; Sias et al., 2003):

A workplace friendship is a relationship between two people who work for the same organization. Although we don't always get to choose the people we work with, we do choose the people at work that we become friends with. Workplace friendships are voluntary relationships, they are not imposed - people choose employees they become friends with. Workplace friendships are more personal than other workplace relationships - workplace friends understand and communicate with each other as whole persons, not simply as work role occupants. Workplace friends choose to spend time together at work and away from the workplace. A cross-sex workplace friendship refers to a workplace friendship between individuals of the opposite sex (between a man and a woman).

Next, participants were given the following directions "We are interested in studying what people think about cross-sex friendships in their organization. We are asking you to report on a cross-sex friendship you observed in your current or former workplace that left an impression on you. We would appreciate any information you can offer that you think is relevant to our research." 
Respondents were then asked a series of questions. First, they were instructed to "Please describe the cross-sex workplace friendship you observed. Tell me a story about the friendship." The second item was "What do/did you think about the cross-sex workplace friendship and the man and woman involved?" followed by "Why did/do you feel this way?" Participants were then asked "How did/do you behave around the man and woman in the cross-sex workplace friendship?" The fifth question presented was "Have you changed your behavior toward either the man or the woman due to your knowledge of their cross-sex workplace friendship? Explain." Finally, participants were asked "Do you have any other thoughts about the cross-sex workplace friendship you reported on that you would like to share with us?” Additional items assessed demographic information, job and organizational information, and information regarding the organizational statuses of the individuals involved. The entire Study 1 questionnaire can be found in Appendix A.

\section{Data Analysis: Part 1}

A conventional qualitative content analysis (Hsieh \& Shannon, 2005) of the data was conducted. The individual response to a question/item was the unit of analysis. Responses to each question/prompt were coded separately for themes. For example, all responses to the first prompt "Please describe the cross-sex workplace friendship you observed. Tell me a story about the friendship" were examined for themes, then all responses to the second prompt "What do/did you think about the cross-sex workplace friendship and the man and woman involved?" were examined for themes. Specifically, the researcher and an undergraduate student research assistant blind to the purpose of the study open-coded and then axial coded the open-ended responses (Strauss \& Corbin, 1998). Open coding consisted of a line-by-line analysis of each open-ended response in which each coder identified major ideas or themes. Axial coding involved the 
researcher and research assistant jointly identifying larger themes and creating a codebook. Finally, the researcher and research assistant jointly coded $50 \%$ the data using the categories identified in the codebook. The criteria identified by Potter and Levine-Donnerstein (1999) were employed for the calculation of Scott's pi, the index of reliability. For the variable "Friendship Description," the coders achieved $77.1 \%$ agreement (Scott's pi $=.69)$, for "Thoughts on Friendship," the coders achieved $80.0 \%$ agreement (Scott's pi $=.73$ ), for "Reasons for Thoughts," the coders achieved 80.3\% agreement (Scott's pi $=.75)$, for "Respondent Behaviors," the coders achieved $80.7 \%$ agreement (Scott's pi $=.74)$, for "Changes in Respondent Behaviors," the coders achieved $81.0 \%$ agreement (Scott's pi $=.76)$, and for "Other Comments," the coders achieved $84.2 \%$ agreement $($ Scott's pi $=.82)$. The researcher and research assistant resolved discrepancies through discussion. The researcher then categorized the remaining $50 \%$ of the data. Examples of the categories and definitions for coding can be found in Appendix B.

\section{Results: Part 1}

Categories and examples for all questions posed to respondents can be found in Appendix C.

Research question 1: Descriptions. Research question one asked "How do organizational members describe cross-sex workplace friendships that they observe?" Participants' responses to the prompt, "Please describe the cross-sex workplace friendship you observed. Tell me a story about the friendship" consisted of four primary categories: benefits, friendship description, romantic nature, and detriments.

The most common category, benefits ( $n=57,51.4 \%$ ), included responses that discussed the personal or work benefits associated with the relationship, and the way in which the relationship was positive, "good," or no different than same sex friendships. Of the 40 responses 
that explicitly indicated benefits, 18 noted personal benefits for the individuals involved in the workplace friendship (e.g., "...enjoyed being around one another," "personal help on her vehicle"). Fifteen noted work benefits for the friendship partner, such as one respondent's story about how the female employee completed an assignment for her workplace friend, and seven concerned benefits for the organization as a whole. For example, one respondent commented that the "organization benefitted by their deep friendship."

The second most common category, friendship description $(n=27,24.3 \%)$, included 16 responses that primarily concerned the way in which the employees interacted at work or outside of work, such as "Hangin [sic] out together in and out of work, family get together, inside jokes." This category also included 11 discussions about how the individuals met or how the relationship developed from working together. For example, one respondent noted "...but ever since working on a project together, their bond has strengthened."

The third category, romantic nature $(n=20,18.0 \%)$, included both comments regarding suspicion of a romance $(n=12)$ and those that indicated the friendship was, in fact, romantic or developed into a non-platonic relationship $(n=8)$. An example of suspicion is a participant who noted individuals who seemed "a little too close," and an example of a confirmed romance includes a participant's story about her own husband leaving her for his 19-year-old coworker.

The final category, detriments $(n=7,6.3 \%)$, consisted of responses that indicated the friendship was negative for others $(n=4)$ and those who either noted it was negative for those involved or did not specify who the relationship negatively affected $(n=3)$. An example of when the friendship negatively affected others included "Some of us feel uneasy to carry that friendship so many hide it, which leads to many problems," while an example of negatively 
affecting the participant's personal life included a respondent noting that it can be a "killer for marriage."

Research question 2: Issues. Research question two asked "What issues do organizational members report in regards to cross-sex workplace friendships they observe?’ In general, a number of themes emerged across the prompts in regards to issues related to the observed friendships. First, it is important to note that in response to the prompts "What do/did you think about the cross-sex workplace friendship and the man and woman involved?" $(n=38)$ and "Why did/do you feel this way?" $(n=34)$, a total of 72 responses indicated that the relationships were a "non-issue" or did not cause any issues for the individuals involved, coworkers, or the organization itself. The remaining responses to these prompts did indicate a variety of issues.

In addition to non-issue, responses to the second question, "What do/did you think about the cross-sex workplace friendship and the man and woman involved?" and the third question "Why did/do you feel this way?" were categorized into three other categories: benefits, romantic nature, and detriments. Further, a final category of past experience was identified in response to the question "Why did/do you feel this way?" Twenty-five responses described people feeling the way they did because of "Personal Experience/Behavior," such as their own previous experiences with workplace friendships or the way in which the individuals involved in the friendship they reported on acted.

The category of benefits included a total of 52 responses (33 in response to "What do/did you think about the cross-sex workplace friendship and the man and woman involved?" and 19 in response to "Why did/do you feel this way?"). In addition to generally positive responses ( $n=$ $19)$, this category included those mentioning positive organizational benefits $(n=10)$, such as 
“...it benefitted our organization" and "both were helpful and made doing business easier," work benefits for the participants $(n=14)$, such as "He could have probably helped or guided her in ways he may not have done with other people because of their friendship," and personal benefits for the friendship participants $(n=9)$, such as those mentioning emotional support or one respondent describing the man giving "warm support and friendship" to his female workplace friend.

A total of 28 comments were categorized as romantic nature and included responses $(n=$ 24) that discussed feelings of suspicion or a belief that behavior had or might cross a line into something inappropriate, such as "I thought the woman was young and naïve and the man was married. Obviously I didn't like it." This category also included confirmed "inappropriate" behavior $(n=4)$, such as one respondent who noted (s)he felt it "crossed the limitations [...] because it is more than a friendship."

The final category found in response to both prompts two and three indicating issues was detriments $(n=19)$. In addition to generally negative responses $(n=5)$, such as "I thought it was inappropriate," this category included responses that discussed how the relationship was negative for others $(n=10)$ or for the workplace $(n=4)$. Examples of this category include "I knew from the beginning it would cause issues and a difficult work environment eventually" and "I felt this way because at times their relationship would often make myself or others feel out of place being around them when they were together."

Research question 3: Equity-related perceptions. Research question three asked "Do organizational members perceive that coworkers in cross-sex workplace friendships receive unfair advantages due to their friendship?" Although the majority of respondents did not explicitly note unfair advantages due to the workplace friendship, many responses indicated that 
the relationship led to benefits for the individuals involved in the friendship. Of the 109 individual responses that noted benefits ( 57 in response to the prompt "Please describe the crosssex workplace friendship you observed. Tell me a story about the friendship," 33 in response to the prompt "What do/did you think about the cross-sex workplace friendship and the man and woman involved?" and 19 in response to the prompt "Why did/do you feel this way?"), 29 noted work-related benefits for the individuals in the friendship. For example, one respondent explained "Since they talk so much, they tell each other about stuff that is happening, which I don't think other people get to know about. I guess that's true with anyone at work that are close." A second respondent noted "when people feel as 'someone has their back' supports them [sic], they are more likely to seek workplace success."

A summary of the response categories for research questions one, two, three, and six appear in Table 2. 
Table 2

Study 1: Frequency of Response Categories for Items \#1, \#2, \#3, and \#6

\begin{tabular}{|c|c|c|c|c|c|}
\hline & $\begin{array}{c}\text { Item } \# 1 \\
n\end{array}$ & $\begin{array}{c}\text { Item } \# 2 \\
n\end{array}$ & $\begin{array}{c}\text { Item } \# 3 \\
n\end{array}$ & $\begin{array}{c}\text { Item } \# 6 \\
n\end{array}$ & $\begin{array}{c}\text { Total } \\
N\end{array}$ \\
\hline Benefits/Positive & 57 & 33 & 19 & 16 & 125 \\
\hline Personal for Friend & 18 & 4 & 5 & 4 & 31 \\
\hline Work for Friend & 15 & 5 & 9 & 1 & 30 \\
\hline Organization & 7 & 5 & 5 & 4 & 21 \\
\hline in General & 17 & 19 & $\mathrm{n} / \mathrm{a}$ & 7 & 43 \\
\hline Non-Issue/Normally & $\mathrm{n} / \mathrm{a}$ & 38 & 34 & 7 & 79 \\
\hline Romantic Nature & 20 & 18 & 10 & 11 & 59 \\
\hline Suspicious & 12 & 16 & 8 & 8 & 44 \\
\hline Confirmed & 8 & 2 & 2 & 3 & 15 \\
\hline Detriments & 7 & 9 & 10 & 11 & 37 \\
\hline to Others & 4 & 3 & 6 & $\mathrm{n} / \mathrm{a}$ & 13 \\
\hline to Friends/in General & 3 & 2 & 4 & 5 & 14 \\
\hline Organization & $\mathrm{n} / \mathrm{a}$ & 4 & $\mathrm{n} / \mathrm{a}$ & 6 & 10 \\
\hline Friendship Description & 27 & $\mathrm{n} / \mathrm{a}$ & $\mathrm{n} / \mathrm{a}$ & $\mathrm{n} / \mathrm{a}$ & 27 \\
\hline Interaction & 16 & $\mathrm{n} / \mathrm{a}$ & $\mathrm{n} / \mathrm{a}$ & $\mathrm{n} / \mathrm{a}$ & 16 \\
\hline Development & 11 & $\mathrm{n} / \mathrm{a}$ & $\mathrm{n} / \mathrm{a}$ & $\mathrm{n} / \mathrm{a}$ & 11 \\
\hline Past Experience & $\mathrm{n} / \mathrm{a}$ & $\mathrm{n} / \mathrm{a}$ & 25 & $\mathrm{n} / \mathrm{a}$ & 25 \\
\hline Can be Positive or Negative & $\mathrm{n} / \mathrm{a}$ & $\mathrm{n} / \mathrm{a}$ & $\mathrm{n} / \mathrm{a}$ & 11 & 11 \\
\hline
\end{tabular}

Notes. Item \#1: "Please describe the cross-sex workplace friendship you observed. Tell me a story about the friendship." Item \#2: "What do/did you think about the cross-sex workplace friendship and the man and woman involved?" Item \#3: "Why did/do you feel this way?" Item \#6: "Do you have any other thoughts about the cross-sex workplace friendship you reported on that you would like to share with us?"

Research question 4: Behaviors. Research question four asked "How do organizational members behave around coworkers in cross-sex workplace friendships?" This research question 
was answered by analyzing responses to two items: "How did/do you behave around the man and woman in the cross-sex workplace friendship?" and "Have you changed your behavior toward either the man or the woman due to your knowledge of their cross-sex workplace friendship? Explain.” Responses to both questions were categorized into four primary categories: normally/no change, positively, mindfully, and negatively. The majority of respondents $(n=113)$ noted that they behaved normally or "No differently than before they were in the relationship."

Positive $(n=36)$ responses included those comments that noted the respondent was friendly or intentionally positive in his/her interactions, such as "Friendly, open, and respectful" or indicated that the individual changed his/her behavior in a positive manner, such as "Definitely. I have a huge respect to [sic] them."

A number of respondents $(n=32)$ discussed behaving more mindfully, such as one respondent who explained "I did my best not to bring anything personal up concerning them had no desire to be in the middle." Other comments in this category noted that organizational members would be careful not to be negative about the relationship or would try to be aware that the friends would probably share information with one another.

Finally, negative $(n=27)$ responses included generally negative behaviors or changes in behaviors in addition to respondents' descriptions of trying to avoid or leave the situation or interaction. For example, one respondent commented that s/he would “...often attempt to not approach the individuals when they were together because of the way [s/he] would feel when [s/he] was with the two of them together." A number of responses also indicated that participants felt as if they could not trust the individuals involved. As one respondent explained "I didn't trust either of them that much, seemed like they were always thinking some plot [sic]." 
Research question 5: Equity-restoration behaviors. Finally, research question five asked "In what ways do organizational members report behaving towards their coworkers in cross-sex workplace friendships in order to restore equity?" No responses explicitly noted any change in behavior as a means of equity restoration. That being said, respondents did mention that they did not trust the individuals involved, or noted that they understood that the individuals in the friendship would share information with one another. In response to the questions "Have you changed your behavior toward either the man or the woman due to your knowledge of their cross-sex workplace friendship? Explain" and "How did/do you behave around the man and woman in the cross-sex workplace friendship?," 17 and 15 responses, respectively, described respondents behaving more mindfully around the individuals involved in the friendship, with many even noting a lack of trust in the individuals $(n=8)$. For example, one respondent noted "Yes. I trust both of them less than I did previously, but I mistrust him much more than her. I still feel like I can tell her what I am thinking, but I also know that she will not listen to anything negative about him." The frequencies for the response categories used to answer research questions four and five appear in Table 3. 
Table 3

Study 1: Frequency of Response Categories for Items \#4 and \#5

\begin{tabular}{|c|c|c|c|}
\hline & $\begin{array}{c}\text { Item \#4 } \\
n\end{array}$ & $\begin{array}{c}\text { Item } \# 5 \\
n\end{array}$ & $\begin{array}{c}\text { Total } \\
N\end{array}$ \\
\hline Normally/No Change & 43 & 70 & 113 \\
\hline Positively & 28 & 8 & 36 \\
\hline Negatively & 14 & 13 & 27 \\
\hline in General/Avoid & 12 & 5 & 17 \\
\hline Less Trusting & 2 & 8 & 10 \\
\hline Mindfully & 15 & 17 & 32 \\
\hline
\end{tabular}

Notes. Item \#4: "How did/do you behave around the man and woman in the cross-sex workplace friendship?" Item \#5: "Have you changed your behavior toward either the man or the woman due to your knowledge of their cross-sex workplace friendship? Explain."

Additional respondent thoughts. In addition to the responses indicated in the research questions, respondents also provided final thoughts in response to the item "Do you have any other thoughts about the cross-sex workplace friendship you reported on that you would like to share with us?" The majority of respondents $(n=70,64.8 \%)$ noted that "no," they did not have anything further to share. The next most common category of response $(n=16,17.5 \%)$ was generally positive comments, including perceived positive implications or stories of the positive or happy nature of the friendship. Eleven responses (11.3\%) were categorized as generally negative, such as final notes about the negative implications of the friendship. A number of responses $(n=11,11.3 \%)$ noted that cross-sex workplace friendships can be positive or negative. This included comments about how these relationships work for some people and not for others, such as "While there are plenty of examples of these friendships being complicated for all involved, including them and co-workers, I have seen positive friendships where boundaries are maintained." An additional eleven (11.3\%) responses reiterated the potential or confirmed romantic nature of the friendships, with comments such as "People that do not know them tend 
to think there is something else going on. There isn't, but when you see cross-sex friendships at work, people do tend to assume they're more than just friends." Finally, a small group of responses discussed how the cross-sex friendships were "normal" or not an issue. These results appear in Table 2.

\section{Data Analysis: Part 2}

After coding the data by variable, the researcher grouped the categories into larger themes and analyzed the extent to which participants mentioned the themes in their responses. The larger themes were: Benefits, Detriments, Non-Issue/Normal, Romantic Nature, Mindful Behavior, Positive Behavior, and Negative Behavior. Using 10\% of the total data set, two research assistants, a male undergraduate student and a female graduate student, independently analyzed each participant's responses for the presence or absence of the themes. Coders identified whether each respondent mentioned the themes in any of his/her responses. Percent agreement between the coders and Scott's pi (using Potter and Levine-Donnerstein's, 1999 calculation) were: Benefits $(90 \%$ agreement, Scott's pi $=.80)$, Detriments $(100 \%$ agreement, Scott's pi $=1.0)$, Non-Issue/Normal $(70 \%$ agreement, Scott's pi $=.40)$, Romantic Nature $(80 \%$ agreement, Scott's pi $=.60)$, Mindful Behavior $(80 \%$ agreement, Scott's pi $=.60)$, Positive Behavior (80\% agreement, Scott's pi $=.60)$, and Negative Behavior $(80 \%$ agreement, Scott's pi $=.60$ ). The undergraduate research assistant then coded the remaining data.

\section{Results: Part 2}

Of the 96 participants, $48(50.0 \%)$ mentioned identified Benefits or positive aspects of cross-sex workplace friendships, $23(24.0 \%)$ identified Detriments or negative aspects, 73 $(76.0 \%)$ commented that the friendship was a Non-Issue/Normal, or that they behaved normally, $30(31.3 \%)$ mentioned the presence or possibility of the friendship having a Romantic Nature, 24 
(25\%) mentioned that they engaged in Mindful Behavior or were more aware of how they behaved, 46 (47.9\%) reported that they engaged in Positive Behavior, and 12 participants $(12.5 \%)$ reported that they engaged in Negative Behavior. The frequencies and percentages by theme can be found in Table 4.

Table 4

Study 1: Prevalence of Themes Among Participants

\begin{tabular}{|c|c|}
\hline Theme & $\begin{array}{l}\text { Percent of } \\
\text { Respondents } \\
\text { who Mentioned } \\
\text { the Theme }(N)\end{array}$ \\
\hline \multicolumn{2}{|c|}{ Perceptions of Cross-Sex Workplace Friendships } \\
\hline \begin{tabular}{l|l|} 
& Non-Issue/Normal \\
\end{tabular} & $76.0 \%(73)$ \\
\hline Benefits & $50.0 \%(48)$ \\
\hline Romantic Nature & $31.3 \%(30)$ \\
\hline \begin{tabular}{l|l|} 
Detriments \\
\end{tabular} & $24.0 \%(23)$ \\
\hline \multicolumn{2}{|c|}{ Behaviors toward Coworkers in Cross-Sex Workplace Friendships } \\
\hline \begin{tabular}{l|l} 
Positive Behavior \\
\end{tabular} & $47.9 \%(46)$ \\
\hline Mindful Behavior & $25.0 \%(24)$ \\
\hline Negative Behavior & $12.5 \%(12)$ \\
\hline
\end{tabular}

\section{Summary of Results}

In summary, the results of Study 1 provided a series of themes regarding coworkers' perceptions of cross-sex workplace friendships. First, respondents noted both benefits and detriments to these friendships, both of which affected individuals involved, coworkers, and the workplace in general. Second, participants discussed how the friendship may have had a romantic component, either confirmed, suspected, or simply was in danger of "crossing a line." A number of comments simply described the friendship, telling stories of how the individuals met or discussed how they behaved at work. Further, many respondents indicated that they felt the way that they did about the friendship due to past experience, either their own experiences 
with similar friendships or the past behavior of those involved. A number of respondents indicated that they did not change their behavior around those involved or that the friendship was a "non-issue." However, many respondents noted that they acted more mindfully around the individuals in the friendship, being more aware of what they said and how they behaved. Finally, participants indicated that cross-sex workplace friendships had risks, but could also be beneficial. Frequencies of each theme by item (i.e., the questions posed to participants in the questionnaire) can be found in Tables 2 and 3.

As the purpose of this study was to act as an exploratory, qualitative investigation of the perspectives of individuals who have observed a workplace friendship in order to inform Studies 2 and 3, two main implications are of note. First, many participants mentioned the possibility of the friendship being romantic/sexual in nature. This includes both the suspicion of romance and a number of responses indicating personal experiences with cross-sex workplace friendships that had become romantic relationships. Due to the relevance of this result to topics examined in Studies 2 and 3, a 5-item scale was developed to assess individuals' perceptions that a workplace relationship may be romantic. This measure can be found in Appendix L.

Additionally, as a number of responses noted either positive or negative implications of the friendship for others at work or the organization in general, a 4-item scale was developed to assess whether participants believed the relationships affected the workplace, such as others' work or the work environment. This measure will be used in Studies 2 and 3. This measure may be found in Appendix M.

\section{Discussion}

In addition to acting as an initial exploratory investigation, Study 1 aimed to garner responses regarding equity theory (Adams, 1965) as it relates to perceiving and responding to 
cross-sex workplace friendships. First, although respondents noted both positive and negative outcomes of these relationships, a large number of respondents emphasized that the relationships were normal and that they, in turn, behaved as they normally would around individuals in crosssex workplace friendships. Over two thirds of respondents commented that the relationship was normal (though the majority of the respondents did go on to indicate positive and/or negative implications as well). Second, overall, organizational members tended to discuss the positive aspects of these relationships more often than they did the negative aspects. That is, the majority of responses did not note that these relationships were explicitly negative for those involved or others in the organization, with half of participants noting some positive benefit as a result of the relationship. Although this could be due to a social desirability bias on behalf of the respondents, it is likely that these relationships are not perceived as inherently negative. This notion is further supported by the first major theme identified, the perceived benefits of cross-sex workplace friendships.

Organizational members seem to recognize benefits of cross-sex workplace friendships for the individuals involved, the organization as a whole, and other organizational members. That these relationships are perceived as providing benefits (both personal and work-related) for the individuals involved is also supported by existing workplace friendship literature. Previous research has indicated that these relationships not only help the individuals involved make sense of their work environment, they provide the workplace friends with both instrumental and emotional support (Kram \& Isabella, 1985; Miller \& Jablin, 1991). Results of Study 1 support this research, with respondents noting instrumental support with comments such as "they...would continually go out of their way to assist each other in work assignments" and emotional support, such as a story one respondent told of how s/he observed another coworker 
help her workplace friend "through the death of his wife from cancer and then finally overcoming that grief and finding and marrying another woman.” According to existing research, further benefits of workplace friendships for the individuals involved include higher quality information exchange, enhanced creativity, increased job satisfaction, intrinsic rewards, and reduced turnover (Kram \& Isabella, 1985; Marks, 1994; Sias, 2005; Yager, 1997). Respondents noted many of these benefits in the current study, with comments including "They often share their information" and a comment concerning increased creativity when working together, “...produced high quality, creative work." Therefore, consistent with previous research, the results uncovered here indicate that coworkers perceive that individuals in cross-sex workplace friendships specifically, like workplace friendships more generally, receive both personal and job-related benefits by virtue of their friendships.

In addition to benefits for those involved in workplace friendships, respondents also discussed benefits they perceived were reaped by the organization as a whole, with comments such as "These two brought out the best in each other's work and in workplace morale" and "our organization benefited by their deep friendship." The result that these friendships are perceived to lead to benefits for the organization is consistent with research indicating that these relationships can create a more positive working environment and have been associated with lower turnover (Gerstner \& Day, 1997, Kram \& Isabella, 1985, Sias et al., 2003). While previous research has noted benefits of workplace friendships, the results of Study 1 suggest that cross-sex workplace friendships can provide unique benefits. For example, while some respondents noted benefits that could apply to friendships in general, such as being fun to be around and improving the mood of the office, others noted workplace benefits that were specific to male-female friendships and their positive impact on the workplace. For instance, respondents made 
comments about how they perceived that men and women had different strengths and as a team they could accomplish more at work. This information is key for management, as it supports previous research that suggests male-female mentoring is advantageous, necessary, and should be encouraged (Ignatius, 2013; Sias, 2008; Sias et al., 2003).

Even though many participants noted the benefits or other positive aspects of cross-sex workplace friendships, a number of drawbacks or negative implications were also identified, with nearly one fourth of respondents noting negative implications. These negative implications support previous research on both friendships in general and cross-sex friendships. Previously identified drawbacks of workplace friendships in general include issues that arise when the friendship deteriorates (Sias et al., 2003, Sias, 2008), dialectical tensions experienced by the friends (Bridge and Baxter, 1992), and concerns of perceived unfair advantages due to the friendship (Lancaster \& Chory, 2013). The results of Study 1 are consistent with this research in that respondents in the present study noted drawbacks such as cliques of sorts forming and workers not part of the friendship being ostracized. In addition, Study 1 findings expand existing research by demonstrating how these negative aspects apply specifically to cross-sex workplace friends. For example, one issue mentioned by respondents was that the friends would not get their work done (causing the respondent to carry their load) because they were interacting, having fun, or in some cases "flirting." Flirting as a drawback is related to the next major theme, suspicion of romance between the individuals involved in the workplace friendship.

Though many respondents noted that the cross-sex workplace friendships they observed were "no different than other friendships," one third of respondents also indicated either confirmed or suspected romance between the cross-sex workplace friends. These romance suspicions support previous research on cross-sex friendships in both interpersonal and 
organizational contexts. Research suggests that romance suspicion occurs in many interpersonal cross-sex friendships (Dainton et al., 2003; Guerrero \& Chavez, 2005; Werking, 1997). Further, a primary concern of individuals involved in cross-sex friendships in the workplace is that others (either third-party observers or their cross-sex friend) will perceive the friendship as romantic or be suspicious that romance is or will be occurring (Elesser \& Peplau, 2006; Hurley, 1996; Sias et al., 2003).

Regarding the manner in which respondents report behaving towards individuals in crosssex workplace friendships, the majority of responses indicated "normal" behavior, with respondents reporting that they did not act differently around coworkers in cross-sex friendships than they did others in the organization. Additionally, most respondents noted that they did not behave any differently upon finding out about the friendship. Further, a number of respondents reported that they behaved in a positive manner around the friendship partners, noting that they were friendly to them or that they even respected them more by virtue of the relationship, with almost half of respondents noting some positive aspect to their behavior towards their coworkers in cross-sex workplace friendships.

Despite most respondents reporting that they behaved normally or positively, a number of responses did include admission of negative behavior. Of particular note are the responses that indicated that organizational members did not trust coworkers in cross-sex workplace friendships or that they knew they needed to be careful regarding what they shared with these coworkers for fear it would "get back" to the other individual. Considering equity theory (Adams, 1965), this result is especially interesting. While respondents did not report that they behaved antisocially, they did appear to believe that they needed to be aware of their behaviors around cross-sex workplace friends. This demonstrates an awareness that the individuals involved in the cross-sex 
friendship may share information with one another, creating unfair advantages. Further, it is certainly possible that individuals did behave more negatively, but due to a social desirability bias or a belief that their behavior was justified (and therefore not antisocial), did not report that they behaved antisocially.

Taken together, the results of Study 1 allow for an initial understanding of the perceptions held and behaviors enacted by organizational members who have observed a crosssex workplace friendship. Based on the results gathered here, it appears that although individuals tend to generally perceive these friendships as positive, negative perceptions are also indicated, including problems for the workplace or others involved. Further, a major implication of this investigative study is the number of respondents who noted the suspected or confirmed romantic nature of these relationships. This finding supports previous research in the interpersonal context demonstrating that cross-sex friendships are often perceived as romantic (e.g., Elesser \& Peplau, 2006; Hurley, 1996; Sias et al., 2003). Further, these responses regarding negative implications (including a lack of trust) and the suspicion of romance are of particular note and influenced areas of investigation for Studies 2 and 3. 


\section{CHAPTER III: STUDY TWO}

\section{Method}

Study 2 employs a $3 \times 2 \times 2$ experimental design using scenarios. This method was chosen for its strong contributions to the multimethod approach. By virtue of its experimental nature, Study 2 provides an element of control that does not exist in Studies 1 and 3. Additionally, with an experiment, causation can be tested, allowing for the assertion that the manipulated variables caused the differences observed. Further, as each condition was parallel with the exception of the variables being compared (i.e. relationship type, sex composition of the relationship, and sex of the peer being reported on), confounding issues such as personal issues with respondents are less likely to impact the results being observed.

Participants and procedures. After IRB approval was obtained, individuals were recruited to participate in the second study in four ways. Participants were recruited through snowball sampling in introductory communication courses at a large Mid-Atlantic University, two online announcements made through the same University, links posted on the researcher's personal Facebook pages, and Amazon's Mechanical Turk crowd-sourcing service (www.mturk.com). To participate, individuals had to be at least 25 years of age and work full time (at least 30 hours a week) in the United States. Students in undergraduate courses were given a handout that included basic information regarding the study and were then directed to identify an individual that they knew who fit the inclusion criteria, if they personally did not. Students were instructed to have their identified participant email the researcher, who randomly assigned the participant to 1 of the 12 conditions and provided him/her with a link to the appropriate version of the online questionnaire (one version for each of 12 unique scenarios). The call for participants posted on the University online announcement system, researcher's 
Facebook pages, and Mechanical Turk included a direct link to a website that had a link randomizer, which randomly assigned participants to 1 of the 12 conditions. When participants clicked the link, they were first directed to a page that included the cover letter for the study, in addition to the researchers' contact information. Participants were then instructed to click a button labeled "I agree to participate" if they agreed to participate and to exit the page if they decided not to proceed with the questionnaire. On the final page of the online questionnaire, individuals were thanked for their participation and provided the researchers' contact information a final time.

The final sample included responses from 314 working adults (157 women, 152 men, and 5 individuals who declined to report their sex). One hundred and forty nine participants accessed the survey via Mechanical Turk (47.5\%), while the remaining 52.5\% $(n=165)$ accessed the survey via Facebook, the University intranet, or recruitment from students in undergraduate courses. Participants ranged in age from 25 to 64 years old $(M=39.19, S D=11.58)$, reported that they worked 30 to 100 hours per week $(M=44.5, S D=8.96)$, and reported that they had been working at their organization from 1 month to 35 years $(M=87.8$ months, $S D=9.99$ months). The majority of respondents reported their race/ethnicity as Caucasian/White $(n=222$, 70.7\%), followed by Asian/Asian American $(n=38,12.1 \%)$, African American/Black $(n=22$, 7.0\%), Native American $(n=12,3.8 \%)$, Hispanic/Latino $(n=10,3.2 \%)$ and "Other" $(n=5$, $1.6 \%)$. Five participants (1.6\%) did not report their race/ethnicity. The majority of participants reported their occupational field as managerial and professional ( $n=144,45.9 \%)$, followed by technical, sales, and administrative support $(n=91,29.9 \%)$, service $(n=46,14.6 \%)$, precision production, craft, and repair $(n=13,4.1 \%)$, and operators, fabricators, and laborers $(n=10$, $3.2 \%)$. Ten (3.2\%) participants did not report their occupational field. The majority of 
participants $(n=60,19.1 \%)$ reported an annual salary of $\$ 30,001$ to $\$ 40,000$ followed by

$\$ 40,001$ to $\$ 50,000(n=48,15.3 \%), \$ 20,000$ to $\$ 30,000(n=42,13.4 \%), \$ 50,001$ to $\$ 60,000$ ( $n$

$=37,11.8 \%)$, over $\$ 100,000(n=33,10.5 \%), \$ 60,001$ to $\$ 70,000(n=27,8.6 \%)$, under $\$ 20,000$

( $n=19,6.1 \%), \$ 70,001$ to $\$ 80,000(n=17,5.4 \%), \$ 80,001$ to $\$ 90,000(n=13,4.1 \%)$, and

$\$ 90,001$ to $\$ 100,000(n=11,3.5 \%)$. Seven participants $(2.2 \%)$ declined to report their salary.

Experimental design and manipulation. Using a design similar to that used in recent

workplace relationship research (Horan \& Chory, 2009, 2011, 2013; Lancaster \& Chory, 2013;

Malachowski et al., 2012), scenarios were utilized in a $3 \times 2 \times 2$ experimental design. The

scenarios differed by the type of workplace relationship (workplace friendship, workplace

romance, or professional relationship), sex makeup of the workplace relationship (cross-sex or

same-sex), and sex of the peer coworker upon whom respondents reported (male or female). All

scenarios first read:

"Think of the organization you currently work in. [Male or female target name] and [male or female target name] are your coworkers at this organization. Both [male or female target name] and [male or female target name] are at the same job level you arethey are neither your superiors nor your subordinates. Imagine that [male or female target name] and [male or female target name] are in a professional relationship/are friends/are romantically involved with each other."

The friendship scenarios then included the following:

"As coworkers in a friendship, [Target Name 1] and [Target Name 2] understand and communicate with each other MORE as whole persons and LESS as work role occupants. They choose to spend time together outside of the workplace and generally communicate about work-related tasks, as well as personal topics. Their relationship is recognized by both of them to be nothing more than professional and platonic. Please respond to the following items based on your feelings about [male or female target name]."

The workplace romance scenarios then included the following:

"As coworkers in a professional relationship, [Target Name 1] and [Target Name 2] understand and communicate with each other LESS as whole persons and MORE as 
work role occupants. They choose not to spend time together outside of the workplace and generally communicate about work-related tasks, but not personal topics. Their relationship is recognized by both of them to be nothing more than professional and platonic. Please respond to the following items based on your feelings about [male or female target name]."

The professional relationship scenarios then included the following:

“As coworkers in a professional relationship, [Target Name 1] and [Target Name 2] understand and communicate with each other LESS as whole persons and MORE as work role occupants. They choose not to spend time together outside of the workplace and generally communicate about work-related tasks, but not personal topics. Their relationship is recognized by both of them to be nothing more than professional and platonic. Please respond to the following items based on your feelings about [male or female target name]."

Participants were randomly assigned to 1 of the 12 scenarios. Using the traditional $95 \%$ significance level and .80 power standards, 22 participants per condition were required to observe a moderate effect size (Cohen, 1988). In the present study, each condition had at least 25 participants: 25 participants reported on a woman in a same-sex romance, 25 on a man in a samesex romance, 28 on a woman in a cross-sex romance, 26 on a man in a cross-sex romance, 26 on a woman in a same-sex friendship, 26 on a man in a same-sex friendship, 26 on a woman in a cross-sex friendship, 30 on a man in a cross-sex friendship, 26 on a woman in a same-sex professional relationship, 25 on a man in a same-sex professional relationship, 26 on a woman in a cross-sex professional relationship, and 25 on a man in a cross-sex professional relationship. This sample size is consistent with previous research on workplace friendships and romances employing scenarios (Horan \& Chory, 2009, 2011, 2013; Malachowski et al., 2012; Sias \& Perry, 2004). After reading the scenario, participants completed a series of measures. The scenarios may be found in Appendix D.

Instrumentation. Credibility of the peer coworker in the scenario was assessed by McCroskey and Teven's (1999) measure. This measure includes three subscales assessing 
competence, trustworthiness/character, and goodwill/caring. Each subscale includes 6 items. Respondents were asked to respond to each item based on how they would feel about the target individual in the scenario if (s)he was their coworker. Responses to the items were solicited on 7point semantic differential scales, such as bright/stupid (competence), honest/dishonest (character), and insensitive/sensitive (caring). Previous studies have supported the reliability of this measure, with Cronbach's alphas ranging from .78 to .89 for competence, .86 to .92 for character, and .83 to .89 for caring (Horan \& Chory, 2011, 2013; McCroskey \& Teven, 1999). In the current study, the scales obtained acceptable Cronbach alphas of $.91(M=4.87, S D=1.10)$ for competence, $.92(M=4.81, S D=1.83)$ for character, and $.86(M=4.47, S D=1.25)$ for caring. Responses ranged from 1.00 to 7.00 for competence, 1.67 to 7.00 for character, and 1.00 to 7.00 for caring. The items for the credibility scales can be found in Appendix E.

Relationship motives were measured with 13 items. These items were revised versions of items employed by Malachowski et al. (2012), based on Quinn (1977). The original scale items used by Malachowski et al. (2012) assessed individuals' job, love, and ego motives for engaging in a workplace romance. The items in the current study measured the job (e.g., "for job enhancement," 6 items), ego (e.g., "for adventure," 4 items), and sincerity (e.g., "for sincere love/friendship," 3 items) motives for engaging in the workplace relationship depicted in the scenario. Participants were asked to respond to items based on their perceptions of the hypothetical peer coworker's likely motives for being involved in the target relationship (workplace friendship, workplace romance, or professional relationship). Individuals responded to items preceded by the stem, "I feel [target name] is involved in the workplace friendship/workplace romance/professional relationship at work ...” In Study 2, items for the sincere motive were only provided to respondents reporting on a workplace romance or 
workplace friendship. Items for the job and ego motives were provided to participants reporting on all relationship types. Responses were solicited using a 7-point Likert scale ranging from strongly disagree (1) to strongly agree (7). Previously obtained Cronbach's alphas for the original version of this measure ranged from .84 to .89 for job motives, .79 to .82 for ego motives, and .63 to 71 for love/sincerity motives (Gillen \& Chory, 2014a; Malachowski et al., 2012). Acceptable Cronbach's alpha reliabilities of .92 $(M=3.62, S D=1.36)$ for job motives, $.79(M=3.96, S D=1.91)$ for ego motives, and $.71(M=4.83, S D=1.07)$ for sincerity motives were obtained in the current study. Responses ranged from 1.00 to 7.00 for each of the motives. The items for the motives scales can be found in Appendix F.

Unfair advantages received by the coworker due to his/her workplace relationship were assessed with a 7-item measure originally intended to measure perceptions of unfair advantages of workplace romances (Malachowski et al., 2012). Respondents were presented with the stem "Due to his/her workplace friendship/workplace romance/professional relationship at work with [male or female name], I think [target name] would..." followed by a series of items concerning advantages at work (e.g., "receive special treatment at work," "be promoted over other organizational members"). Reponses for each item were recorded on a 7-point Likert scale ranging from strongly disagree (1) to strongly agree (7). Previous studies have supported the reliability of this measure, with Cronbach's alphas ranging from .95 to .97 to (Gillen \& Chory, 2014a; Lancaster \& Chory, 2013; Malachowski et al., 2012). In the current study, the measure obtained a Cronbach's alpha of $.94(M=3.65, S D=1.34)$ and responses ranged from 1.00 to 6.86. The items for the unfair advantages scale can be found in Appendix G.

Trust in the peer coworker featured in the scenario was measured using McCroskey and Richmond's (1996) Generalized Belief Measure. The belief stem read: “I would trust [target 
name] as a colleague.', Responses were solicited on five, 7-point semantic differential scales (e.g., yes/no, agree/disagree). Previously obtained Cronbach's alphas for the measure ranged from .87 to .98 (Horan \& Chory, 2009, 2013; McCroskey, 2006; Malachowski et al., 2012). A Cronbach's alpha of $.92(M=5.11, S D=1.36)$ was obtained in the current study. Responses ranged from 1.00 to 7.00. The items for the generalized belief measure can be found in Appendix H.

Obstructionism was measured using an instrument developed by Neuman and Baron (1998). This measure assesses actions intended to impede another organizational member's performance in the workplace. Respondents were directed to complete the items based on the peer coworker designated in their scenario. Participants were presented with the stem "If I had the opportunity I would..." followed by nine items, such as "interfere with or block the coworker's work." Responses to the items were solicited on a 7-point Likert scale with response options ranging from strongly disagree (1) to strongly agree (7). The obstructionism scale has demonstrated acceptable reliabilities in previous research, yielding Cronbach's alphas of .80 to .87 (Chory \& Hubbell, 2008; Hennessy, 2003). Cronbach’s alpha in the current study was 97 (M $=2.10, S D=1.31)$. Reponses ranged from 1.00 to 5.78 . The items for the obstructionism measure can be found in Appendix I.

Information manipulation was measured using scales assessing deception and honesty and accuracy of self-disclosure. To measure deception, eight items representing message ambiguity, complete message distortion, and partial message distortion were employed (Hubbell, Chory-Assad, \& Medved, 2005; McCornack, Levine, Solowczuk, Torres, \& Campbell, 1992). Participants were asked to respond to items based on how they would communicate with the person in the scenario if (s)he were a colleague. The following stem preceded the items: "If I had 
the opportunity I would ...” A sample item reads “tell [Target] 'white lies.' " Responses were solicited using a 7-point Likert scale ranging from strongly disagree (1) to strongly agree (7). Previously obtained Cronbach's alpha reliabilities for this scale ranged from .79 to .88 (Chory \& Hubbell, 2008; Horan \& Chory, 2009, 2013; Lancaster \& Chory, 2013; Malachowski et al., 2012). The current study obtained a Cronbach's alpha of .96 $(M=2.16, S D=1.33)$. Responses ranged from 1.00 to 6.00. The items for the deception scale can be found in Appendix J. Honesty and accuracy of self-disclosure was assessed with five items from Wheeless' (1978) Revised Self-Disclosure Scale, which measures the intimacy and amount of information disclosed. Participants were asked to respond to items based on how they would communicate with the person in the scenario if (s)he were a colleague. The following stem preceded the items: "If I had the opportunity I would ..." A sample item reads "reveal self-disclosures to [Target Name 1] that are completely accurate reflections of who I am." Responses were obtained using a 7-point Likert scale ranging from strongly disagree (1) to strongly agree (7). Past research supports the reliability of the scale, with Cronbach's alpha reliabilities ranging from .75 to .84 (Malachowski et al., 2012; Myers \& Johnson, 2004; Myers, 1998). In the current study Cronbach's alpha was .79 $(M=4.70, S D=1.20)$. Responses ranged from 1.60 to 7.00 . The items for the self-disclosure scale can be found in Appendix K.

Aggression was assessed using a revised version of a measure used in previous research (Chory, Goodboy, Hixson, \& Baker, 2006, 2007; Cicchirillo \& Chory-Assad, 2005; Skalski, Tamborini, Westerman, \& Smith, 2003; Tamborini et al., 2004). The measure is consistent with "most modern definitions of aggression that consider aggression as behavior intended to harm another person," such as Anderson and Bushman's (2002) definition (Cicchirillo \& ChoryAssad, 2005, p. 442). The original measure was framed as a work-study recommendation form in 
which participants were asked questions regarding whether the researcher should be granted a work-study position and financial support. For the current study, the measure was revised to assess the target individual's worthiness of receiving a promotion at work. The measure included two assessments of aggressive behavior. First, the participant was asked to rate the target's courtesy, competence, and deservedness of a promotion on 7-point semantic differential scales (such as "not at all courteous" and "extremely courteous"). The scale has obtained a Cronbach's alpha reliability of .83 to .93 in previous research (Chory et al., 2006, 2007; Tamborini et al., 2004). Cronbach's alpha in the current study was $.89(M=3.15, S D=1.05)$ after recoding. Responses ranged from 1.00 to 7.00 . All three items in this measure were reverse coded so that a higher score indicates more aggression. Second, participants were instructed to assign the target individual a rating of 0 to 100 . Ratings ranged from 8 to 100 . The mean rating was $72.84(S D=$ 17.6). The items for the aggression measure can be found in Appendix L.

Sexism was assessed by Glick and Fiske's (1996) Ambivalent Sexism Inventory (ASI). This measure includes two subscales, 11 items measuring "hostile sexism" and 11 items measuring "benevolent sexism." Hostile sexism refers to "those aspects of sexism that fit Allport's (1954) classic definition of prejudice (p. 491)" as "an antipathy based upon a faulty and inflexible generalization" (Allport, 1954 quoted in Glick \& Fiske, 1996). The subscale includes items such as "Women exaggerate problems they have at work." Benevolent sexism refers to attitudes that are sexist in that they view women in stereotypical and restricted roles, but "are subjectively positive in feeling tone (for the perceiver) and also tend to elicit behaviors typically categorized as prosocial" (Glick \& Fiske, 1996, p. 491). A sample benevolent sexism item is "Women, as compared to men, tend to have a more refined sense of culture and good taste." Responses to the sexism items were solicited on a 7-point Likert scale ranging from strongly 
disagree (1) to strongly agree (7). The measure has shown to be reliable in previous research, with Cronbach's alphas ranging from .80 to .92 for hostile sexism and .73 to .85 for benevolent sexism (Glick \& Fiske, 1996; Lenton \& Weber, 2006). In the current study, hostile sexism was reliable with a Cronbach's alpha of $.84(M=3.69, S D=1.01)$, as was benevolent sexism at .82 $(M=3.84, S D=1.00)$. Responses ranged from 1.00 to 6.00 and 1.00 to 7.00 for hostile and benevolent sexism, respectively. The items for the sexism measures can be found in Appendix M.

Perceptions of romance were assessed by a measure created for this study and based on open-ended responses to the exploratory examination of cross-sex workplace friendships in Study 1. Five items were created to assess respondents' perceptions that the relationship they were reporting on was romantic in nature. Responses were obtained using a 7-point Likert scale ranging from strongly disagree (1) to strongly agree (7). A sample item reads "I believe the relationship between [Target Name 1] and [Target Name 2] is actually romantic." The measure obtained an acceptable Cronbach's alpha reliability of $.86(M=3.64, S D=1.40)$. Responses ranged from 1.00 to 7.00 . The items for the perceptions of romance measure can be found in Appendix N.

Problems for the workplace were assessed by a measure created for this study and based on open-ended responses to the exploratory examination of cross-sex workplace friendships in Study 1. Four items were created in order to assess respondents' beliefs that the relationship they were reporting on caused problems for the workplace or others in the workplace. Responses were obtained using a 7-point Likert scale ranging from strongly disagree (1) to strongly agree (7). A sample item reads “[Target Name 1] and [Target Name 2]'s relationship negatively impacts the work environment." The scale obtained an acceptable Cronbach's alpha of $.80(M=$ 
$3.51, S D=1.20)$. Responses ranged from 1.00 to 7.00 . The items for the problems for the workplace scale can be found in Appendix O.

Finally, participants were asked to complete a series of manipulation checks, as well as items assessing demographics and information related to the job and their organization. The entire Study 2 questionnaire can be found in Appendix P.

\section{Results}

Pearson correlations among the variables appear in Table 5. Mean differences in the dependent variables according to relationship type, sex of the peer reported on, and sex composition of the relationship appear in Table 6, Table 7, and Table 8, respectively. 
Table 5

Study 2: Intercorrelations among Variables

\begin{tabular}{|c|c|c|c|c|c|c|c|c|c|c|c|c|c|c|c|c|c|}
\hline Variable & 1 & 2 & 3 & 4 & 5 & 6 & 7 & 8 & 9 & 10 & 11 & 12 & 13 & 14 & 15 & 16 & 17 \\
\hline 1. Comp. & & - & & & & & & & & & & & & & & & \\
\hline 2. Char. & $.85^{* * *}$ & - & & & & & & & & & & & & & & & \\
\hline 3. Car. & $.77^{* * *}$ & $-.83^{* * *}$ & - & & & & & & & & & & & & & & \\
\hline 4. Ego & $-.14^{*}$ & -.09 & -.07 & - & & & & & & & & & & & & & \\
\hline 5. Job & $-.25^{* * *}$ & $-.29^{* * *}$ & $-.37^{* * *}$ & $.22^{* * *}$ & - & & & & & & & & & & & & \\
\hline 6. Sincere & $.31^{* * *}$ & $.27^{* * *}$ & $.24^{* *}$ & $.42^{* * *}$ & $-.16^{*}$ & - & & & & & & & & & & & \\
\hline 7. Unfair Ad. & $-.23^{* *}$ & $-.29^{* * *}$ & $-.30^{* * *}$ & $.27^{* * *}$ & $.70^{* * *}$ & -.11 & - & & & & & & & & & & \\
\hline 8. Trust & $.69^{* * *}$ & $.69^{* * *}$ & $.69^{* * *}$ & $-.15^{*}$ & $-.36^{* * *}$ & $.35^{* * *}$ & $-.33^{* * *}$ & - & & & & & & & & & \\
\hline 9. Obstruct. & $-.21^{* * *}$ & $-.16^{* * *}$ & -.11 & $.41^{* * *}$ & $.48^{* * *}$ & -.10 & $.47^{* * *}$ & $-.27^{* * *}$ & - & & & & & & & & \\
\hline 10. Decept. & $-.23^{* * *}$ & $-.18^{* * *}$ & $-.13^{*}$ & $.44^{* *}$ & $.49^{* * *}$ & -.07 & $.47^{* * *}$ & $-.28^{* * *}$ & $.96^{* * *}$ & - & & & & & & & \\
\hline 11. Self-Discl. & $.33^{* * *}$ & $.32^{* * *}$ & $.35^{* * *}$ & -.10 & -.07 & $.17^{*}$ & $-.17^{* *}$ & $.37^{* * *}$ & $-.13^{*}$ & $-.15^{*}$ & - & & & & & & \\
\hline 12. Aggression & $-.64^{* * *}$ & $-.60^{* * *}$ & $-.57^{* * *}$ & .07 & $.20^{* * *}$ & $-33^{* * *}$ & $.22^{* * *}$ & $-.63^{* * *}$ & $.12^{* * *}$ & $.13^{*}$ & $-.32^{* * *}$ & - & & & & & \\
\hline 13. 1-100 Rating & $.47^{* * *}$ & $.44^{* * *}$ & $.39^{* * *}$ & $-.18^{*}$ & $-.23^{* * *}$ & $.15^{*}$ & $-.23^{* * *}$ & $.49^{* * *}$ & $-.24^{* * *}$ & $-.23^{* * *}$ & $.19^{* *}$ & $-.52^{* * *}$ & - & & & & \\
\hline 14. Romance & $-.21^{*}$ & $-.20^{* * *}$ & $-.16^{* *}$ & $.41^{* * *}$ & -.03 & -.07 & $.18^{* *}$ & $-.18^{* *}$ & $.26^{* * *}$ & $.23^{* * *}$ & $-.24^{* * *}$ & $.15^{*}$ & $-.17^{*}$ & - & & & \\
\hline 15. Problems & $-.38^{* * *}$ & $-.42^{* * *}$ & $-.36^{* * *}$ & $.38^{* * *}$ & $.28^{* * *}$ & $-.26^{* * *}$ & $.45^{* * *}$ & $-.46^{* * *}$ & $.43^{* * *}$ & $.42^{* * *}$ & $-.29^{* * *}$ & $.37^{* * *}$ & $-.30^{* * *}$ & $.54^{* * *}$ & - & & \\
\hline 16. Ben. Sexism & .08 & -.09 & -.09 & $.21^{* * *}$ & $.23^{* *}$ & -.08 & $.21^{* * *}$ & .09 & $.39^{* *}$ & $.35^{* * *}$ & -.05 & .01 & -.07 & $.15^{*}$ & $.20^{* * *}$ & - & \\
\hline 17. Hos. Sexism & -.10 & $-.11^{* *}$ & -.11 & $.29^{* * *}$ & $.22^{* * *}$ & $-.14^{*}$ & $.34^{* * *}$ & $-.21^{* * *}$ & $.41^{* * *}$ & $.40^{* * *}$ & $-.13^{*}$ & -.09 & $-.17^{*}$ & $.23^{* * *}$ & $.35^{* * *}$ & $.49^{* * *}$ & - \\
\hline
\end{tabular}

Note. ${ }^{*} p<.05 ; \stackrel{* *}{p}<.01 ;{ }^{* * *} p<.00$ 
Table 6

Study 2: Mean Differences Among Relationship Types

\begin{tabular}{|c|c|c|c|c|c|}
\hline & $\begin{array}{c}\text { Professional } \\
\text { Mean }(S D)\end{array}$ & $\begin{array}{l}\text { Friendship } \\
\text { Mean }(S D)\end{array}$ & $\begin{array}{c}\text { Romance } \\
\text { Mean }(S D)\end{array}$ & $\begin{array}{c}F \\
(\mathrm{df})\end{array}$ & $p$-value \\
\hline \multicolumn{6}{|l|}{ Credibility } \\
\hline Competence & $4.96(.955)$ & $4.91(1.18)$ & $4.74(1.16)$ & $\begin{array}{c}1.12 \\
(2,308)\end{array}$ & .327 \\
\hline Caring & $4.31(.911)$ & $4.67(1.22)$ & $4.43(1.19)$ & $\begin{array}{c}2.82 \\
(2,308)\end{array}$ & .061 \\
\hline Character & $4.78(.987)$ & $4.96(1.19)$ & $4.66(1.34)$ & $\begin{array}{c}1.69 \\
(2,308)\end{array}$ & .186 \\
\hline \multicolumn{6}{|l|}{ Motives } \\
\hline Job & $4.12_{\mathrm{a}}(1.27)$ & $3.50_{b}(1.45)$ & $3.26_{b}(1.20)$ & $\begin{array}{c}11.77 \\
(2,310)\end{array}$ & $.000^{*}$ \\
\hline Ego & $3.37_{\mathrm{b}}(1.38)$ & $4.22_{\mathrm{a}}(1.00)$ & $4.28_{\mathrm{a}}(.934)$ & $\begin{array}{c}21.63 \\
(2,310)\end{array}$ & $.000 *$ \\
\hline Sincere & $\mathrm{N} / \mathrm{A}$ & $5.03(1.11)$ & $4.61(.988)$ & $\begin{array}{c}8.12 \\
(1,210)\end{array}$ & $.005 *$ \\
\hline Unfair Advantages & $3.74(1.24)$ & $3.58(1.51)$ & $3.63(1.26)$ & $\begin{array}{c}.402 \\
(2,311)\end{array}$ & .669 \\
\hline Trust & $5.22(1.14)$ & $5.19(1.42)$ & $4.92(1.49)$ & $\begin{array}{c}1.49 \\
(2,306)\end{array}$ & .227 \\
\hline Obstructionism & $1.93(1.18)$ & $2.16(1.40)$ & $2.16(1.33)$ & $\begin{array}{c}1.11 \\
(2,311)\end{array}$ & .331 \\
\hline \multicolumn{6}{|l|}{$\begin{array}{l}\text { Information } \\
\text { Manipulation }\end{array}$} \\
\hline \begin{tabular}{|l|l} 
Self- \\
Disclosure
\end{tabular} & $4.93_{\mathrm{a}}(1.12)$ & $4.67_{b}(1.28)$ & $4.51_{b}(1.15)$ & $\begin{array}{c}3.34 \\
(2,311)\end{array}$ & $.037 *$ \\
\hline Deception & $1.99(1.19)$ & $2.24(1.44)$ & $2.24(1.34)$ & $\begin{array}{c}1.22 \\
(2,311)\end{array}$ & .297 \\
\hline \multicolumn{6}{|l|}{ Aggression } \\
\hline Aggression & $3.11(.953)$ & $3.11(1.07)$ & $3.22(1.14)$ & $\begin{array}{c}.441 \\
(2,294)\end{array}$ & .644 \\
\hline $\begin{array}{l}1-100 \\
\text { Rating }\end{array}$ & $74.7(15.3)$ & $72.5(18.5)$ & $71.1(19.0)$ & $\begin{array}{c}1.01 \\
(2,283)\end{array}$ & .365 \\
\hline $\begin{array}{l}\text { Suspected } \\
\text { Romance }\end{array}$ & $2.92_{b}(1.17)$ & $3.12_{b}(1.24)$ & $4.87 \mathrm{a}(.84)$ & $\begin{array}{c}97.56 \\
(2,308)\end{array}$ & $.000 *$ \\
\hline $\begin{array}{l}\text { Workplace } \\
\text { Problems }\end{array}$ & $3.00_{\mathrm{c}}(1.21)$ & $3.53_{b}(1.14)$ & $3.99_{a}(1.05)$ & $\begin{array}{c}18.93 \\
(2,309)\end{array}$ & $.000 *$ \\
\hline
\end{tabular}


Table 7

Study 2: Mean Differences Between Sex of Peer Reported on

\begin{tabular}{|c|c|c|c|c|}
\hline & $\begin{array}{c}\text { Male } \\
\text { Mean }(S D)\end{array}$ & $\begin{array}{c}\text { Female } \\
\text { Mean }(S D)\end{array}$ & $\begin{array}{c}t \\
(\mathrm{df})\end{array}$ & $p$-value \\
\hline \multicolumn{5}{|l|}{ Credibility } \\
\hline Competence & 4.85 (1.09) & $4.89(1.11)$ & $\begin{array}{l}-.356 \\
(309)\end{array}$ & .722 \\
\hline Caring & $4.44(1.17)$ & $4.51(1.07)$ & $\begin{array}{l}-.551 \\
(309)\end{array}$ & .582 \\
\hline Character & $4.80(1.17)$ & $4.80(1.98)$ & $\begin{array}{l}-.016 \\
(309)\end{array}$ & .987 \\
\hline \multicolumn{5}{|l|}{ Motives } \\
\hline Job & $3.52(1.31)$ & $3.73(1.40)$ & $\begin{array}{l}-1.41 \\
(311) \\
\end{array}$ & .159 \\
\hline Ego & $3.96(1.12)$ & $3.97(1.27)$ & $\begin{array}{l}-.043 \\
(311) \\
\end{array}$ & .966 \\
\hline Sincere & $4.85(1.11)$ & $4.81(1.04)$ & $\begin{array}{l}.235 \\
(210)\end{array}$ & .814 \\
\hline Unfair Advantages & $3.44(1.32)$ & $3.86(1.33)$ & $\begin{array}{l}-2.80 \\
(312)\end{array}$ & $.005 *$ \\
\hline Trust & $5.05(1.35)$ & $5.17(1.38)$ & $\begin{array}{l}-.803 \\
(307)\end{array}$ & .422 \\
\hline Obstructionism & $2.08(1.28)$ & $2.09(1.34)$ & $\begin{array}{l}-.107 \\
(312)\end{array}$ & .915 \\
\hline \multicolumn{5}{|l|}{$\begin{array}{l}\text { Information } \\
\text { Manipulation }\end{array}$} \\
\hline \begin{tabular}{l|l} 
Self- \\
Disclosure
\end{tabular} & $4.65(1.15)$ & $4.76(1.25)$ & $\begin{array}{l}-.797 \\
(312)\end{array}$ & .426 \\
\hline Deception & $2.12(1.29)$ & $2.20(1.38)$ & $\begin{array}{l}-.530 \\
(312)\end{array}$ & .596 \\
\hline \multicolumn{5}{|l|}{ Aggression } \\
\hline Aggression & $4.92(1.00)$ & $4.80(1.09)$ & $\begin{array}{l}.993 \\
(305) \\
\end{array}$ & .3222 \\
\hline \begin{tabular}{l|l}
$1-100$ \\
Rating
\end{tabular} & $72.05(18.3)$ & $73.61(17.1)$ & $\begin{array}{l}-.747 \\
(284) \\
\end{array}$ & .455 \\
\hline $\begin{array}{l}\text { Suspected } \\
\text { Romance }\end{array}$ & $3.65(1.38)$ & $3.63(1.43)$ & $\begin{array}{l}.091 \\
(309)\end{array}$ & .927 \\
\hline $\begin{array}{l}\text { Workplace } \\
\text { Problems }\end{array}$ & $3.47(1.22)$ & $3.55(1.19)$ & $\begin{array}{l}-.576 \\
(310)\end{array}$ & .565 \\
\hline
\end{tabular}


Table 8

Study 2: Mean Differences Between Same-Sex and Cross-Sex Relationships

\begin{tabular}{|c|c|c|c|c|}
\hline & $\begin{array}{l}\text { Same-Sex } \\
\text { Mean }(S D)\end{array}$ & $\begin{array}{l}\text { Cross-Sex } \\
\text { Mean }(S D)\end{array}$ & $\begin{array}{c}t \\
(\mathrm{df})\end{array}$ & $p$-value \\
\hline \multicolumn{5}{|l|}{ Credibility } \\
\hline Competence & $4.87(1.07)$ & $4.87(1.14)$ & $\begin{array}{l}.032 \\
(309)\end{array}$ & .974 \\
\hline Caring & $4.42(1.12)$ & $4.52(1.13)$ & $\begin{array}{l}-.836 \\
(309) \\
\end{array}$ & .404 \\
\hline Character & $4.78(1.18)$ & $4.83(1.18)$ & $\begin{array}{l}-.379 \\
(309) \\
\end{array}$ & .813 \\
\hline \multicolumn{5}{|l|}{ Motives } \\
\hline Job & $3.75(1.36)$ & $3.50(1.36)$ & $\begin{array}{l}1.64 \\
(311)\end{array}$ & .102 \\
\hline Ego & $3.98(1.18)$ & $3.95(1.21)$ & $\begin{array}{l}.221 \\
(311) \\
\end{array}$ & .825 \\
\hline Sincere & $4.86(1.02)$ & $4.80(1.13)$ & $\begin{array}{l}.339 \\
(210)\end{array}$ & .735 \\
\hline Unfair Advantages & $3.83(1.34)$ & $3.47(1.33)$ & $\begin{array}{l}2.44 \\
(312)\end{array}$ & $.015^{*}$ \\
\hline Trust & $5.03(1.26)$ & $5.19(1.45)$ & $\begin{array}{l}-1.00 \\
(307)\end{array}$ & .316 \\
\hline Obstructionism & $2.06(1.34)$ & $2.11(1.28)$ & $\begin{array}{l}-.361 \\
(312) \\
\end{array}$ & .718 \\
\hline \multicolumn{5}{|l|}{$\begin{array}{l}\text { Information } \\
\text { Manipulation }\end{array}$} \\
\hline \begin{tabular}{|l|l} 
Self- \\
Disclosure
\end{tabular} & $4.67(1.23)$ & $4.87(1.14)$ & $\begin{array}{l}-.237 \\
(312)\end{array}$ & .813 \\
\hline Deception & $2.11(1.34)$ & $2.21(1.32)$ & $\begin{array}{l}-.668 \\
(312) \\
\end{array}$ & .505 \\
\hline \multicolumn{5}{|l|}{ Aggression } \\
\hline Aggression & $4.89(1.01)$ & $4.84(1.07)$ & $\begin{array}{c}.474 \\
(305) \\
\end{array}$ & .635 \\
\hline $\begin{array}{l}1-100 \\
\text { Rating }\end{array}$ & $73.55(17.1)$ & $72.15(18.3)$ & $\begin{array}{l}.669 \\
(284) \\
\end{array}$ & .504 \\
\hline $\begin{array}{l}\text { Suspected } \\
\text { Romance }\end{array}$ & $3.50(1.41)$ & $3.77(1.39)$ & $\begin{array}{l}-1.69 \\
(309) \\
\end{array}$ & .092 \\
\hline $\begin{array}{l}\text { Workplace } \\
\text { Problems }\end{array}$ & $3.48(1.20)$ & $3.54(1.20)$ & $\begin{array}{l}-.491 \\
(310) \\
\end{array}$ & .624 \\
\hline
\end{tabular}


Hypotheses 1 and 2: Relationship type. Hypothesis one predicted that organizational members in workplace romances would be a) perceived as the least credible, most driven by job and ego motives and least by sincere motives, and receiving the most unfair advantages; b) trusted the least; and c) most likely to be the targets of their coworkers' obstructionism, information manipulation, and aggression, followed by organizational members in workplace friendships, and then organizational members in professional workplace relationships. Hypothesis two predicted that sexism would interact with relationship type to affect a) perceptions of credibility, motives, and unfair advantages; b) trust; and c) obstructionism, information manipulation, and aggression such that the differences in these outcomes among the three relationship types would be greater for more sexist versus less sexist individuals. To analyze hypotheses one and two, a Multivariate analysis of variance (MANOVA) was conducted with competence, character, caring, ego motives, job motives, unfair advantages, trust, obstructionism, self-disclosure, deception, the measure of aggression, and the single-item rating entered as dependent variables. Relationship type, benevolent sexism, hostile sexism and the interaction terms for relationship type and benevolent sexism and relationship type and hostile sexism were entered as fixed factors. Only participants in the workplace romance and friendship conditions assessed the sincere motive, therefore, a multiple linear regression was conducted with relationship type (romance or friendship), benevolent sexism, hostile sexism, and the interaction terms for relationship type and benevolent sexism and relationship type and hostile sexism entered as predictors. The sincere motive was entered as the criterion variable in the regression.

For the MANOVA, results indicate that the models were statistically significant for relationship type, Wilks' lambda $=.34, F(24,80)=2.38, p=.002, \eta_{p}{ }^{2}=.42$; but not for 
hostile sexism, Wilks' lambda $=.00, F(684,516)=1.02, p=.40, \eta_{p}{ }^{2}=57$; benevolent sexism, Wilks' lambda $=.00, F(660,515)=1.04, p=.32, \eta_{p}{ }^{2}=.56:$ the interaction between hostile sexism and relationship type, Wilks' lambda $=.00, F(504,505)=1.14, p=.07, \eta_{p}{ }^{2}=.52$; or the interaction between benevolent sexism and relationship type, Wilks' lambda $=.00, F(480,503)$ $=1.03, p=.38, \eta_{p}{ }^{2}=.48$. For the sincere motive, results of the regression analysis indicate that relationship type predicted perceptions of sincere motives, $\beta=-.17, p=.013, F(5,209)=2.38$, $R^{2}=.06, p=.04$

Regarding hypothesis one, results indicate that perceptions of ego motives, sincere motives, and job motives $(p=.063)$ differed by relationship type. Pairwise comparisons showed that organizational members in professional relationships were perceived as being more motivated by the job and less motivated by ego than were coworkers in friendships or romantic relationships and perceptions of sincere motives were lower for more intimate relationships. As such, hypothesis one was not supported.

Regarding hypothesis two, relationship type and hostile sexism interacted to predict perceptions of the ego motive and aggression at a statistically significant level. Relationship type and benevolent sexism interacted to predict perceptions of competence at $p<.07$. All results for hypotheses one and two can be found in Table 9. 
Table 9

Study 2: Results for Hypotheses 1 and 2

\begin{tabular}{|c|c|c|c|c|c|c|c|c|c|c|c|c|c|}
\hline & \multicolumn{3}{|c|}{ Credibility } & \multicolumn{3}{|c|}{ Relationship Motives } & \multirow[b]{2}{*}{$\begin{array}{c}\text { Unfair } \\
\text { Adv. } \\
F\end{array}$} & \multirow[b]{2}{*}{$\begin{array}{c}\text { Trust } \\
F\end{array}$} & \multirow[b]{2}{*}{$\begin{array}{c}\text { Obstr. } \\
F\end{array}$} & \multicolumn{2}{|c|}{$\begin{array}{c}\text { Information } \\
\text { Manipulation }\end{array}$} & \multicolumn{2}{|c|}{ Aggression } \\
\hline & $\begin{array}{l}\text { Comp. } \\
\qquad F\end{array}$ & $\begin{array}{l}\text { Caring } \\
\quad F\end{array}$ & $\begin{array}{c}\text { Char. } \\
F\end{array}$ & $\begin{array}{c}\text { Job } \\
F\end{array}$ & $\begin{array}{c}\text { Ego } \\
F\end{array}$ & $\begin{array}{c}\text { Sincere } \\
\beta\end{array}$ & & & & $\begin{array}{c}\text { Self- } \\
\text { Disclsr. } \\
F \\
\end{array}$ & $\begin{array}{c}\text { Decep. } \\
\qquad F\end{array}$ & $\underset{F}{\text { Agg. }}$ & $\begin{array}{c}1-100 \\
\text { Rating } \\
F\end{array}$ \\
\hline $\begin{array}{l}\text { Relationship } \\
\text { Type }\end{array}$ & 1.41 & .46 & .15 & $2.92^{\dagger}$ & $6.46^{* *}$ & $-.17^{*}$ & .92 & .80 & 1.74 & .56 & 1.13 & 2.22 & .55 \\
\hline $\begin{array}{l}\text { Hostile } \\
\text { Sexism }\end{array}$ & $1.52^{\dagger}$ & $1.68^{*}$ & 1.50 & 1.16 & .90 & -.15 & $1.57^{\dagger}$ & 1.48 & 1.19 & 1.23 & 1.19 & $1.80^{*}$ & .96 \\
\hline $\begin{array}{l}\text { Benevolent } \\
\text { Sexism }\end{array}$ & 1.25 & $1.70^{*}$ & 1.46 & .87 & $1.69^{*}$ & .01 & 1.42 & 1.33 & .85 & .14 & .92 & $1.78^{*}$ & .94 \\
\hline $\begin{array}{l}\text { Hostile } \\
\text { Sexism X } \\
\text { Relationship } \\
\text { Type }\end{array}$ & 1.53 & 1.26 & 1.54 & 1.16 & $1.68^{*}$ & -.06 & 1.45 & 1.69 & 1.06 & 1.49 & .97 & $1.69^{*}$ & .97 \\
\hline $\begin{array}{l}\text { Benevolent } \\
\text { Sexism X } \\
\text { Relationship } \\
\text { Type }\end{array}$ & $1.57^{\dagger}$ & .97 & 1.20 & 1.00 & 1.47 & .01 & 1.20 & 1.12 & .77 & .98 & .84 & 1.49 & .79 \\
\hline Adjusted $R^{2}$ & .22 & .23 & .25 & .17 & $.42^{* *}$ & .05 & $.33^{*}$ & .18 & .19 & .20 & .19 & $.40^{* *}$ & .07 \\
\hline
\end{tabular}

Note. ${ }^{* * *} p<.001 ;{ }^{* *} p<.01 ;{ }^{*} p<.05 ;{ }^{\dagger} p<.07 ;$ The sincere motive only contains the groups Friendship and Romance. 
Hypotheses 3 and 4: Sex composition of the relationship. Hypothesis three predicted that organizational members in cross-sex workplace relationships would be a) perceived as less credible, more driven by job and ego motives and less by sincere motives, and receiving more unfair advantages; b) trusted less; and c) more likely to be the targets of their coworkers' obstructionism, information manipulation, and aggression than would organizational members in same-sex workplace relationships. Hypothesis four predicted that sexism would interact with sex composition of the relationship (cross-sex or same-sex) to affect a) perceptions of credibility, motives, and unfair advantages; b) trust; and c) obstructionism, information manipulation, and aggression such that the differences in these outcomes between cross-sex and same-sex workplace relationships would be greater for more sexist versus less sexist individuals.

To analyze hypotheses three and four, a series of multiple linear regressions were run with sex composition of the relationship (cross-sex or same-sex), benevolent sexism, hostile sexism, and the interaction terms for sex composition of the relationship and benevolent sexism and sex composition and hostile sexism entered as predictors. Competence, character, caring, ego motives, job motives, sincere motives, unfair advantages, trust, obstructionism, selfdisclosure, deception, the measure of aggression, and the single-item rating measure were entered as criterion variables in the regressions.

Regarding hypothesis three, results indicate that the sex composition of the relationship predicted perceptions of unfair advantages at a statistically significant level, $\beta=-.15, p=.005, F$ $(5,311)=10.23, R^{2}=.14, p<.001$, with individuals in same-sex relationships perceived as receiving more unfair advantages. As such, hypothesis three was not supported.

Regarding hypothesis four, the sex composition of the relationship and sexism did not interact to predict any of the criterion variables. As such, hypothesis four was not supported. In 
general, results indicate that although 7 of the 12 multiple regression models were statistically significant, hostile sexism was the primary predictor of the criterion variables. All results for hypotheses three and four can be found in Table 10. 
Table 10

Study 2: Results for Hypotheses 3 and 4

\begin{tabular}{|c|c|c|c|c|c|c|c|c|c|c|c|c|c|}
\hline & \multicolumn{3}{|c|}{ Credibility } & \multicolumn{3}{|c|}{ Relationship Motives } & \multirow[b]{2}{*}{$\begin{array}{c}\text { Unfair } \\
\text { Adv. } \\
\beta\end{array}$} & \multirow[b]{2}{*}{$\begin{array}{c}\text { Trust } \\
\beta\end{array}$} & \multirow[b]{2}{*}{$\begin{array}{c}\text { Obstr. } \\
\beta\end{array}$} & \multicolumn{2}{|c|}{$\begin{array}{l}\text { Information } \\
\text { Manipulation }\end{array}$} & \multicolumn{2}{|c|}{ Aggression } \\
\hline & $\underset{\beta}{\operatorname{Comp} .}$ & $\begin{array}{c}\text { Caring } \\
\beta\end{array}$ & $\underset{\beta}{\text { Char. }}$ & $\begin{array}{c}\text { Job } \\
\beta\end{array}$ & $\underset{\beta}{\text { Ego }}$ & $\begin{array}{c}\text { Sincere } \\
\beta\end{array}$ & & & & $\begin{array}{c}\text { Self- } \\
\text { Disclsr } \\
\beta\end{array}$ & $\underset{\beta}{\text { Decep. }}$ & $\underset{\beta}{\text { Agg. }}$ & $\begin{array}{c}1-100 \\
\text { Rating } \\
\beta\end{array}$ \\
\hline $\begin{array}{l}\text { Sex } \\
\text { Composition } \\
\text { of } \\
\text { Relationship }\end{array}$ & .00 & .05 & .02 & -.10 & -.23 & -.03 & $-.15^{*}$ & -.06 & .00 & .01 & .02 & .02 & -.03 \\
\hline $\begin{array}{l}\text { Hostile } \\
\text { Sexism }\end{array}$ & -.07 & -.08 & -.08 & $.14^{*}$ & $.25^{* * *}$ & -.14 & $.31^{* * *}$ & $-.20^{* *}$ & $.29^{* * *}$ & $-.20^{* *}$ & $.30^{* * *}$ & .11 & $-.19^{* *}$ \\
\hline $\begin{array}{l}\text { Benevolent } \\
\text { Sexism }\end{array}$ & -.04 & -.06 & -.05 & $.16^{* *}$ & .10 & -.01 & .06 & -.01 & $.25^{* * *}$ & $.14^{*}$ & $.21^{* * * *}$ & -.05 & .03 \\
\hline $\begin{array}{l}\text { Hostile } \\
\text { Sexism X } \\
\text { Relationship } \\
\text { Makeup }\end{array}$ & .03 & .05 & .07 & .00 & .10 & .10 & -.01 & -.08 & .03 & .04 & .03 & -.09 & -.08 \\
\hline $\begin{array}{l}\text { Benevolent } \\
\text { Sexism X } \\
\text { Relationship } \\
\text { Makeup }\end{array}$ & .04 & -.07 & .01 & .03 & -.09 & .10 & -.06 & .06 & -.03 & .03 & -.02 & -.03 & .02 \\
\hline $\begin{array}{l}F \\
\text { (df) }\end{array}$ & $\begin{array}{l}.91 \\
(5,308)\end{array}$ & $\begin{array}{l}1.24 \\
(5,308)\end{array}$ & $\begin{array}{l}1.26 \\
(5,308)\end{array}$ & $\begin{array}{l}5.22^{* * *} \\
(5,311)\end{array}$ & $\begin{array}{l}6.70^{* * *} \\
(5,311)\end{array}$ & $\begin{array}{l}2.08 \\
(5,209)\end{array}$ & $\begin{array}{l}10.23^{* * *} \\
(5,311)\end{array}$ & $\begin{array}{l}3.36^{* *} \\
(5,306)\end{array}$ & $\begin{array}{l}17.34^{* * *} \\
(5,311)\end{array}$ & $\begin{array}{l}2.30^{*} \\
(5,311)\end{array}$ & $\begin{array}{l}14.65^{* * *} \\
(5,311)\end{array}$ & $\begin{array}{l}1.34 \\
(5,304)\end{array}$ & $\begin{array}{l}2.04 \\
(5,283)\end{array}$ \\
\hline$R^{2}$ & .02 & .02 & .02 & $.08^{* * *}$ & $.10^{* * *}$ & $.05^{*}$ & $.12^{* * *}$ & $.05^{* *}$ & $.22^{* * *}$ & $.04^{*}$ & $.19^{* * *}$ & .02 & .04 \\
\hline
\end{tabular}

Note. ${ }^{* * *} p<.001 ;{ }^{* *} p<.01 ;{ }^{*} p<.05 ;$ Sex Composition of the Relationship was coded as: $1=$ Same-sex, $2=$ Cross-sex 
Hypotheses 5 and 6: Sex of peer in relationship. Hypothesis five predicted that female organizational members in workplace relationships would be a) perceived as less credible, more driven by job and ego motives and less by sincere motives, and receiving more unfair advantages; b) trusted less; and c) more likely to be the targets of their coworkers' obstructionism, information manipulation, and aggression than would male organizational members in workplace relationships. Hypothesis six predicted that sexism would interact with organizational member sex to affect a) perceptions of credibility, motives, and unfair advantages; b) trust; and c) obstructionism, information manipulation, and aggression such that the differences in these outcomes between male and female organizational members would be greater for more sexist versus less sexist individuals. To analyze hypotheses five and six a series of multiple linear regressions were conducted, with coworker sex, benevolent sexism, hostile sexism, and the interaction terms for coworker sex and benevolent sexism and coworker sex and hostile sexism entered as predictors. Competence, character, caring, ego motives, job motives, sincere motives, unfair advantages, trust, obstructionism, self-disclosure, deception, the measure of aggression and the single-item employee rating score were entered as criterion variables in the regressions.

Regarding hypothesis five, results indicate that coworker sex predicted unfair advantages at a statistically significant level in the direction of the hypothesis, $\beta=.15, p=.007, F(5,311)=$ $10.08, R^{2}=.14, p<.001$. That is, results suggest that respondents perceived that female organizational members received more unfair advantages due to their workplace relationships than did male organizational members. No other relationships were statistically significant. As such, hypothesis five was partially supported. 
Regarding hypothesis six, benevolent sexism interacted with coworker sex to predict trust, $\beta=.15, p=.021, F(5,306)=4.21, R^{2}=.07, p=.001$. For female coworkers $(n=157)$, the relationship between benevolent sexism and trust was not statistically significant, but for male coworkers $(n=157)$, results indicate a negative relationship between benevolent sexism and trust $(r=-.24, p=.004)$. Although the models for competence and caring were not statistically significant, the interaction of benevolent sexism and peer sex predicted both competence and caring. No other relationships were statistically significant. As such, hypothesis six was not supported. In general, results indicate that although 8 of the 12 multiple regression models were statistically significant, hostile sexism was the primary predictor of the criterion variables. All results for hypotheses five and six can be found in Table 11. 
Table 11

Study 2: Results for Hypotheses 5 and 6

\begin{tabular}{|c|c|c|c|c|c|c|c|c|c|c|c|c|c|}
\hline & \multicolumn{3}{|c|}{ Credibility } & \multicolumn{3}{|c|}{ Relationship Motives } & \multirow[b]{2}{*}{$\begin{array}{c}\text { Unfair } \\
\text { Adv. } \\
\beta\end{array}$} & \multirow[b]{2}{*}{$\begin{array}{c}\text { Trust } \\
\beta\end{array}$} & \multirow[b]{2}{*}{$\begin{array}{c}\text { Obstr. } \\
\beta\end{array}$} & \multicolumn{2}{|c|}{$\begin{array}{l}\text { Information } \\
\text { Manipulation }\end{array}$} & \multicolumn{2}{|c|}{ Aggression } \\
\hline & $\underset{\beta}{\text { Comp. }}$ & $\underset{\beta}{\text { Caring }}$ & $\begin{array}{c}\text { Char. } \\
\beta\end{array}$ & $\begin{array}{c}\text { Job } \\
\beta\end{array}$ & $\begin{array}{c}\text { Ego } \\
\beta\end{array}$ & $\begin{array}{c}\text { Sincere } \\
\beta\end{array}$ & & & & $\begin{array}{c}\text { Self- } \\
\text { Disclsr } \\
\beta\end{array}$ & $\underset{\beta}{\text { Decep. }}$ & $\underset{\beta}{\text { Agg. }}$ & $\begin{array}{c}1-100 \\
\text { Rating } \\
\beta\end{array}$ \\
\hline Peer Sex & .02 & .03 & .00 & .07 & -.01 & -.03 & $.15^{*}$ & .05 & -.01 & .04 & .02 & .05 & .05 \\
\hline $\begin{array}{l}\text { Hostile } \\
\text { Sexism }\end{array}$ & -.08 & -.09 & -.09 & $.14^{*}$ & $.24^{* * *}$ & $-.16^{*}$ & $.31^{* * *}$ & $-.22^{* *}$ & $.29^{* * *}$ & $-.20^{* *}$ & $.30^{* * *}$ & .12 & $-.19^{* *}$ \\
\hline $\begin{array}{l}\text { Benevolent } \\
\text { Sexism }\end{array}$ & -.03 & -.04 & -.04 & $.15^{*}$ & .10 & .03 & .04 & .01 & $.25^{* * *}$ & $.15^{*}$ & $.21^{* * *}$ & -.06 & .04 \\
\hline $\begin{array}{l}\text { Hostile } \\
\text { Sexism X } \\
\text { Peer Sex } \\
\end{array}$ & -.08 & -.05 & -.06 & .02 & .06 & .13 & -.02 & -.03 & -.00 & -.04 & .01 & .04 & .06 \\
\hline $\begin{array}{l}\text { Benevolent } \\
\text { Sexism X } \\
\text { Peer Sex }\end{array}$ & $.14^{*}$ & $.15^{*}$ & .11 & -.06 & .01 & .14 & -.06 & $.15^{*}$ & .01 & .0 &.-00 & -.07 & -.01 \\
\hline $\begin{array}{l}F \\
\text { (df) }\end{array}$ & $\begin{array}{l}1.71 \\
(5,308)\end{array}$ & $\begin{array}{l}2.03 \\
(5,308)\end{array}$ & $\begin{array}{l}1.49 \\
(5,308)\end{array}$ & $\begin{array}{l}4.94^{* * *} \\
(5,311)\end{array}$ & $\begin{array}{l}6.37^{* * *} \\
(5,311)\end{array}$ & $\begin{array}{l}3.27^{* *} \\
(5,209)\end{array}$ & $\begin{array}{l}10.08^{* * *} \\
(5,311)\end{array}$ & $\begin{array}{l}4.21^{* *} \\
(5,306)\end{array}$ & $\begin{array}{l}17.26^{* * *} \\
(5,311)\end{array}$ & $\begin{array}{l}2.61^{*} \\
(5,311)\end{array}$ & $\begin{array}{l}14.59^{* * *} \\
(5,311)\end{array}$ & $\begin{array}{l}1.00 \\
(5,304)\end{array}$ & $\begin{array}{l}2.00 \\
(5,283)\end{array}$ \\
\hline$R^{2}$ & .03 & .03 & .02 & $.08^{* * *}$ & $.09^{* * *}$ & $.07^{* *}$ & $.14^{* * *}$ & $.07^{* *}$ & $.22^{* * *}$ & $.04^{*}$ & $.19^{* * * *}$ & .02 & .04 \\
\hline
\end{tabular}

Note. ${ }^{* * *} p<.001 ;{ }^{* *} p<.01 ;{ }^{*} p<.05 ;$ Peer sex coded as: $1=$ Male, $2=$ Female 
Research question 6: Interactions. Research question six asked if the type of workplace relationship, sex composition of the relationship, sex of the peer being reported on, the status dynamic of the relationship, and sexism would interact to affect perceptions of a) credibility, relationship motives, and unfair advantages; b) trust; and c) obstructionism, information manipulation, and aggression. Because status dynamic did not vary in Study 2 (all relationships were peer relationships), effects of this variable were not assessed here. To answer research question six, a multiple regression was conducted with a single interaction term (type of workplace relationship X sex composition of the relationship X sex of the peer being reported on $\mathrm{X}$ benevolent sexism $\mathrm{X}$ hostile sexism) entered as a predictor. Competence, character, caring, job motives, ego motives, sincere motives, unfair advantages, trust, obstructionism, deception, selfdisclosure, the 1-item aggression rating and the aggression measure were entered as the criterion variables. Results indicate that the interaction between type of workplace relationship, sex composition of the relationship, sex of the peer being reported on, and sexism did not predict any of the criterion variables. Results of the regressions can be found in Table 12. 
Table 12

Study 2: Results for Research Question 6

\begin{tabular}{|c|c|c|c|c|c|c|c|c|c|c|c|c|c|}
\hline & \multicolumn{3}{|c|}{ Credibility } & \multicolumn{3}{|c|}{ Relationship Motives } & \multirow[b]{2}{*}{$\begin{array}{c}\text { Unfair } \\
\boldsymbol{\beta}\end{array}$} & \multirow[b]{2}{*}{$\underset{\beta}{\text { Trust }}$} & \multirow[b]{2}{*}{$\begin{array}{c}\text { Obstr. } \\
\beta\end{array}$} & \multicolumn{2}{|c|}{$\begin{array}{l}\text { Information } \\
\text { Manipulation }\end{array}$} & \multicolumn{2}{|c|}{ Aggression } \\
\hline & $\underset{\beta}{\operatorname{Comp} .}$ & $\begin{array}{c}\text { Caring } \\
\beta\end{array}$ & $\underset{\beta}{\text { Char. }}$ & $\begin{array}{c}\text { Job } \\
\beta\end{array}$ & $\begin{array}{c}\text { Ego } \\
\beta\end{array}$ & $\begin{array}{c}\text { Sincere } \\
\beta\end{array}$ & & & & $\begin{array}{c}\text { Self- } \\
\text { Dis. } \\
\beta\end{array}$ & $\begin{array}{c}\text { Decept. } \\
\beta\end{array}$ & $\underset{\beta}{\text { Agg. }}$ & $\begin{array}{c}1-100 \\
\text { Rating } \\
\beta\end{array}$ \\
\hline $\begin{array}{l}\text { Peer Sex X } \\
\text { Relationship } \\
\text { Type X Sex } \\
\text { Composition } \\
\text { of } \\
\text { Relationship } \\
\text { X Benevolent } \\
\text { Sexism X } \\
\text { Hostile } \\
\text { Sexism }\end{array}$ & .05 & .02 & -.03 & .07 & .08 & .13 & .02 & -.00 & .05 & .11 & .06 & -.05 & .06 \\
\hline $\begin{array}{l}F \\
(d f)\end{array}$ & $\begin{array}{l}.89 \\
(1,308)\end{array}$ & $\begin{array}{l}.11 \\
(1,308)\end{array}$ & $\begin{array}{l}.24 \\
(1,308)\end{array}$ & $\begin{array}{l}1.65 \\
(1,153)\end{array}$ & $\begin{array}{l}1.86 \\
(1,311)\end{array}$ & $\begin{array}{l}3.80 \\
(1,209)\end{array}$ & $\begin{array}{l}.17 \\
(1,311)\end{array}$ & $\begin{array}{l}.00 \\
(1,306)\end{array}$ & $\begin{array}{l}.76 \\
(1,311)\end{array}$ & $\begin{array}{l}3.69 \\
(1,311)\end{array}$ & $\begin{array}{l}.98 \\
(1,311)\end{array}$ & $\begin{array}{l}.85 \\
(1,304)\end{array}$ & $\begin{array}{l}1.08 \\
(1,283)\end{array}$ \\
\hline
\end{tabular}

Note. ${ }^{* * *} p<.001 ;{ }^{* *} p<.01 ;{ }^{*} p<.05$ 


\section{Hypotheses 9 and 10: Trust, motives, and unfair advantages correlations. Hypothesis}

nine predicted that trust and perceptions of sincere motives would be negatively related to obstructionism, information manipulation, and aggression. Results of Pearson correlations (see Table 4) indicate no statistically significant relationships between the sincere motive and obstructionism or deception, though the sincere motive and the aggression measure $(r=-.33, p<$ $.001)$, aggression rating $(r=.15, p<.05)$, and self-disclosure $(r=.17, p<.05)$ were correlated at a statistically significant level. Trust in the coworker was related to obstructionism $(r=-.27, p<$ $.001)$, self-disclosure $(r=.37, p<.001)$, deception $(r=-.28, p<.001$, and the aggression measure $(r=-.63, p<.001)$ and rating $(r=.49, p<.001)$. Hypothesis nine was partially supported.

Hypothesis ten predicted that perceptions of unfair advantages and ego and job motives would be positively related to obstructionism, information manipulation, and aggression. Results of Pearson correlations (see Table 4) indicate that although the ego and job motives were not related to self-disclosure, job and ego motives were positively correlated with obstructionism, deception, and aggression. Unfair advantages were positively correlated with obstructionism, information manipulation, and aggression, and negatively related to the employee rating.

Overall, hypothesis ten was supported for 13 of the 15 relationships tested.

Additionally, for hypotheses 9 and 10, a series of multiple linear regressions were conducted in order to understand the role of each motive in predicting obstructionism, information manipulation, and aggression. In these regressions, job motives, ego motives, and sincere motives were entered as predictors and obstructionism, self-disclosure, deception, the measure of aggression, and the single-item rating measure each served as separate criterion variables. Results of these multiple linear regressions can be found in Table 13. 
Table 13

Study 2: Results of Hypotheses 9 and 10

\begin{tabular}{|c|c|c|c|c|c|}
\hline & & \multicolumn{2}{|c|}{$\begin{array}{l}\text { Information } \\
\text { Manipulation }\end{array}$} & \multicolumn{2}{|c|}{ Aggression } \\
\hline & $\begin{array}{c}\text { Obstructionism } \\
\beta\end{array}$ & $\begin{array}{c}\text { Self- } \\
\text { Disclosure } \\
\beta\end{array}$ & $\begin{array}{c}\text { Deception } \\
\beta\end{array}$ & $\begin{array}{c}\text { Aggression } \\
\text { Measure } \\
\beta\end{array}$ & $\begin{array}{c}1-100 \\
\text { Rating } \\
\beta\end{array}$ \\
\hline Job Motive & $.55^{* * *}$ & -.05 & $.54^{* * *}$ & $.19^{*}$ & $-.18^{*}$ \\
\hline Ego Motive & $.16^{*}$ & -.14 & $.19^{* *}$ & .06 & -.18 \\
\hline Sincere Motive & -.08 & $.22^{* *}$ & -.07 & $-.34^{* * * *}$ & $.21^{* *}$ \\
\hline $\begin{array}{l}F \\
(d f)\end{array}$ & $\begin{array}{l}47.06^{* * *} \\
(3,210)\end{array}$ & $\begin{array}{l}3.83^{*} \\
(3,210)\end{array}$ & $\begin{array}{l}49.17^{* * *} \\
(3,210)\end{array}$ & $\begin{array}{l}13.72^{* * *} \\
(3,203)\end{array}$ & $\begin{array}{l}7.41^{* * *} \\
(3,186)\end{array}$ \\
\hline$R^{2}$ & $.40^{* * *}$ & $.05^{*}$ & $.42^{* * * *}$ & $.17^{* * *}$ & $.11^{* * *}$ \\
\hline
\end{tabular}

Note. ${ }^{* * *} p<.001 ;{ }^{* *} p<.01 ; \stackrel{*}{p}<.05$

Further, a series of regression analyses were conducted with job, ego and sincere motives, trust, and unfair advantages entered as predictors and obstructionism, self-disclosure, deception, the aggression scale, and the single item aggression rating entered as criterion variables. For results of these regressions, see Table 14. Results indicate that obstructionism was predicted primarily by the job motive, with the ego motive also a statistically significant predictor. Unfair advantages was the strongest predictor of self-disclosure, with the job motive, ego motive, and trust also statistically significant predictors. Deception was predicted primarily by the job motive, with the ego motive also a statistically significant predictor. Finally, for both measures of aggression, trust was the strongest predictor, with the sincere motive also a statistically significant predictor of aggression. 
Table 14

Study 2: Results of Hypotheses 9 and 10 Supplementary Regression Analyses

\begin{tabular}{|l|l|l|l|l|l|}
\hline & & \multicolumn{2}{|c|}{$\begin{array}{c}\text { Information } \\
\text { Manipulation }\end{array}$} & \multicolumn{2}{c|}{\begin{tabular}{c} 
Aggression \\
\hline
\end{tabular}} \\
\hline
\end{tabular}

Note. $\stackrel{* * *}{p}<.001 ;{ }^{* *} p<.01 ; \stackrel{*}{p}<.05$

Hypothesis 11: Mediation. Hypothesis 11 predicted that trust, motives, and unfair advantages would mediate the relationships between the independent variables (relationship type, sex composition, sex of peer reported on, status dynamic) and obstructionism, information manipulation, and aggression. Because status dynamic did not vary in Study 2 (all relationships were peer relationships), mediation concerning this variable was not assessed here. For the other independent variables, path analyses were conducted using the AMOS software package. Model fit was assessed through the chi-square statistic, as well as the Root Mean Square Error of Approximation (RMSEA), and the Bentler and Bonett normed fit index (NFI), comparative fit index (CFI), and relative fit index (RFI). Models with non-statistically significant chi-squares, 
RMSEAs above .08, and/or NFI, CFI, and/or RFI values in excess of .90 were considered good fits to the data.

Results of hypothesis one indicated that relationship type was related to the job, ego, and sincere motives. Correlations indicate that the job motive was related to obstructionism, deception, and both measures of aggression. The ego motive was related to obstructionism, deception, and the single-item aggression rating. The sincere motive was related to selfdisclosure, the aggression measure, and the one-item aggression rating. To determine if the perceived motives mediated the relationships between relationship type and obstructionism, deception, self-disclosure, and both measures of aggression, separate sets of path analyses, one set for each motive as the mediating variable, were computed.

Results indicate that the job motive mediated the relationship between relationship type and the aggression measure, as the model provided an acceptable, albeit not strong, fit for the data, $\chi^{2}(1)=3.52, p=.061, \mathrm{RMSEA}=.09, \mathrm{NFI}=.91, \mathrm{CFI}=.92, \mathrm{RFI}=.45$. The job motive did not mediate the relationship between relationship type and obstructionism, $\chi^{2}(1)=17.43, p$ $<.000, \mathrm{RMSEA}=.23, \mathrm{NFI}=.86, \mathrm{CFI}=.86, \mathrm{RFI}=.14$; deception, $\chi^{2}(1)=18.33, p<.000$, $\mathrm{RMSEA}=.24, \mathrm{NFI}=.85, \mathrm{CFI}=.85, \mathrm{RFI}=.11$; or the 1 -item aggression rating measure $\chi^{2}(1)=$ $6.29, p=.01, \mathrm{RMSEA}=.13, \mathrm{NFI}=.84, \mathrm{CFI}=.86, \mathrm{RFI}=.13$. These results suggest that organizational members perceive relationships characterized by more intimacy (romances more intimate than friendships, which are more intimate than professional relationships) as being less driven by job motives, which is associated with them behaving less aggressively toward coworkers in these relationships.

Results indicate that the ego motive mediated the relationship between relationship type and the outcome variables, as all three models provided good fits for the data, $\chi^{2}(1)=1.32, p=$ 
$.25, \mathrm{RMSEA}=.03, \mathrm{NFI}=.99, \mathrm{CFI}=.99, \mathrm{RFI}=.91($ obstructionism$) ; \chi^{2}(1)=1.51, p=.22$, RMSEA $=.04, \mathrm{NFI}=.99, \mathrm{CFI}=1.00, \mathrm{RFI}=.91$ (deception); and $\chi^{2}(1)=1.68, p=.68$, RMSEA $=.00, \mathrm{NFI}=1.00, \mathrm{CFI}=1.00, \mathrm{RFI}=.98$ (aggression rating). These results suggest that organizational members perceive more intimate workplace relationships as being more driven by ego motives, which is associated with engaging in more obstructionism and deception with coworkers in more intimate relationships and more aggression toward them by giving them lower employee ratings (1-item aggression measure).

Regarding the sincere motive, results indicate that it mediated the relationships between relationship type and self-disclosure, $\chi^{2}(1)=2.01, p=.14$; $\mathrm{RMSEA}=.06, \mathrm{NFI}=.89, \mathrm{CFI}=.92$, and $\mathrm{RFI}=.35$; aggression, $\chi^{2}(1)=.50, p=.48 ; \mathrm{RMSEA}=.00, \mathrm{NFI}=.98, \mathrm{CFI}=1.00$, and RFI $=$ .91 ; and the 1-item aggression rating, $\chi^{2}(1)=.41, p=.52, \mathrm{RMSEA}=.00, \mathrm{NFI}=.97, \mathrm{CFI}=1.0$, and $\mathrm{RFI}=.83$. These results suggest that more intimate relationships are perceived as being less driven by sincere motives, which is related to coworkers reporting that they are less honest and accurate in their self-disclosures to individuals in more intimate relationships, behave more aggressively toward them, and assign them lower ratings.

Results for hypothesis three indicated that sex composition of the relationship was related to perceptions of unfair advantages. Correlations indicate that unfair advantages were related to all outcome variables (obstructionism, information manipulation, and aggression). To determine if unfair advantages mediated the relationship between sex composition of the relationship and the outcome variables, a set of path analyses with unfair advantages as the mediator was conducted.

Results of these analyses indicate that while the model for deception did not provide an acceptable fit for the data, $\chi^{2}(1)=4.33, p=.37$; RMSEA $=.10, \mathrm{NFI}=.95, \mathrm{CFI}=.96, \mathrm{RFI}=.85$; 
the models for obstructionism, $\chi^{2}(1)=2.91, p=.90 ;$ RMSEA $=.08, \mathrm{NFI}=.97, \mathrm{CFI}=.98, \mathrm{RFI}=$ .90 ; self-disclosure, $\chi^{2}(1)=.03, p=.86 ; \mathrm{RMSEA}=.00, \mathrm{NFI}=1.0, \mathrm{CFI}=1.0, \mathrm{RFI}=.99$, aggression, $\chi^{2}(1)=.96, p=.34 ; \mathrm{RMSEA}=.00, \mathrm{NFI}=.96, \mathrm{CFI}=1.0, \mathrm{RFI}=.96$; and the singleitem aggression rating, $\chi^{2}(1)=1.75, p=.19 ; \mathrm{RMSEA}=.05, \mathrm{NFI}=.92, \mathrm{CFI}=.96, \mathrm{RFI}=.54 ; \mathrm{did}$ provide acceptable fits for the data. These results suggest that organizational members in samesex versus opposite-sex workplace relationships are perceived as receiving more unfair advantages, which is associated with receiving more obstructionism and aggression, lower employee ratings, and less honest and accurate self-disclosure.

Hypothesis five indicated that sex of the peer was related to perceptions of unfair advantages. Correlations indicate that unfair advantages were related to all outcome variables (obstructionism, information manipulation, and aggression). To determine if perceived unfair advantages mediated the relationship between sex of the peer and the outcome variables, path analyses with unfair advantages as the mediator were conducted.

Results of these analyses indicated that perceptions of unfair advantages mediated the relationships between sex of the peer reported on and obstructionism, $\chi^{2}(1)=1.85, p=.17$; $\mathrm{RMSEA}=.05, \mathrm{NFI}=.98, \mathrm{CFI}=.99, \mathrm{RFI}=.94 ;$ deception, $\chi^{2}(1)=.80, p=.37 ; \mathrm{RMSEA}=.00$, $\mathrm{NFI}=.99, \mathrm{CFI}=1.0, \mathrm{RFI}=.97$; self-disclosure, $\chi^{2}(1)=1.68, p=.20 ; \mathrm{RMSEA}=.05, \mathrm{NFI}=.91$, $\mathrm{CFI}=.96, \mathrm{RFI}=.73$; aggression, $\chi^{2}(1)=.18, p=.67 ; \mathrm{RMSEA}=.00, \mathrm{NFI}=.99, \mathrm{CFI}=1.0, \mathrm{RFI}$ $=.95$; and the single-item aggression rating, $\chi^{2}(1)=1.89, p=.17$; $\mathrm{RMSE}=.05, \mathrm{NFI}=.92$, CFI $=.95, \mathrm{RFI}=.56$. These results suggest that female organizational members in workplace relationships are perceived as receiving more unfair advantages than male organizational members in workplace relationships, which is associated with receiving more obstructionism, deception, and aggression, lower employee ratings, and less honest and accurate self-disclosure. 


\section{Research questions 7 and 8: Credibility correlations and mediation. Research}

question seven concerned the relationships between credibility and obstructionism, information manipulation, and aggression. Results of Pearson correlations (see Table 4) indicate that, with the exception of obstructionism's [lack of] relationship with caring, the three dimensions of credibility (competence, character and caring) were negatively related to obstructionism, information manipulation, and both measures of aggression.

Additionally, for research question seven, a series of multiple linear regression analyses were conducted in order to understand the role of each dimension of credibility in predicting obstructionism, information manipulation, and aggression. In these regressions, competence, character, and caring were entered as predictors and obstructionism, self-disclosure, deception, the measure of aggression, and the single-item rating measure were separate criterion variables in each regression. Results of these multiple linear regressions can be found in Table 15. 
Table 15

Study 2: Results of Research Question 7

\begin{tabular}{|c|c|c|c|c|c|}
\hline & & \multicolumn{2}{|c|}{$\begin{array}{l}\text { Information } \\
\text { Manipulation }\end{array}$} & \multicolumn{2}{|c|}{ Aggression } \\
\hline & $\begin{array}{c}\text { Obstructionism } \\
\beta\end{array}$ & $\begin{array}{c}\text { Self- } \\
\text { Disclosure } \\
\beta\end{array}$ & $\begin{array}{c}\text { Deception } \\
\beta\end{array}$ & $\begin{array}{c}\text { Aggression } \\
\text { Measure } \\
\beta\end{array}$ & $\begin{array}{c}1-100 \\
\text { Rating } \\
\beta\end{array}$ \\
\hline Competence & $-.32^{* *}$ & .14 & $-.29^{* *}$ & $-.43^{* * *}$ & $.36^{* * *}$ \\
\hline Character & -.00 & .01 & -.03 & -.11 & .10 \\
\hline Caring & .14 & $.23^{*}$ & .11 & -.15 & .04 \\
\hline $\begin{array}{l}F \\
(d f)\end{array}$ & $\begin{array}{l}5.72^{* *} \\
(3,310)\end{array}$ & $\begin{array}{l}15.44^{* * *} \\
(3,310)\end{array}$ & $\begin{array}{l}5.91^{* *} \\
(3,310)\end{array}$ & $\begin{array}{l}76.72^{* * *} \\
(3,306)\end{array}$ & $\begin{array}{l}27.59^{* * *} \\
(3,285)\end{array}$ \\
\hline$R^{2}$ & $.05^{* *}$ & $.13^{* * *}$ & $.06^{* *}$ & $.43^{* * *}$ & $.23^{* * *}$ \\
\hline
\end{tabular}

Note. $* * * p<.001 ; * * p<.01 ; * p<.05$

Research question eight asked if credibility mediated the relationships between the independent variables (relationship type, sex composition, sex of peer reported on, status dynamic) and obstructionism, information manipulation, and aggression. Because status dynamic did not vary in Study 2 (all relationships were peer relationships), mediation concerning this variable was not assessed here. As results for hypotheses one, three, and five indicate, the independent variables were not related to credibility, mediation could not have occurred.

Post-hoc analyses. The results of Study 1 lead to the creation of measures assessing suspected romance and workplace problems. As such, the analyses conducted for the research questions and hypotheses were conducted with suspected romance and workplace problems where relevant. 
Results of a multivariate analysis of variance (MANOVA) indicate that both suspected romance and workplace problems differed among the relationship types. Specifically, individuals in workplace romances faced higher romance suspicion than did those in professional relationships and friendships, however, suspicion of romance did not differ between friendships and professional relationships. Regarding workplace problems, results indicate that all groups differed from one another, with workplace romances being perceived as leading to the most problems, followed by workplace friendships, and then professional relationships. Results also indicate that benevolent sexism interacted with relationship type to affect workplace problems. Results for these post-hoc analyses can be found in Table 16.

Table 16

Study 2: Effect of Relationship Type on Suspected Romance and Workplace Problems

\begin{tabular}{|l|l|l|}
\hline & \multicolumn{1}{|c|}{$\begin{array}{c}\text { Suspected } \\
\text { Romance }\end{array}$} & \multicolumn{1}{|c|}{$\begin{array}{c}\text { Workplace } \\
\text { Problems }\end{array}$} \\
\hline Relationship Type & $24.48^{* * *}$ & $17.59^{* * *}$ \\
\hline Hostile Sexism & .83 & 1.45 \\
\hline Benevolent Sexism & .75 & $1.88^{*}$ \\
\hline Hostile Sexism X Relationship Type & 1.28 & 1.25 \\
\hline Benevolent Sexism X Relationship Type & .93 & $1.59^{*}$ \\
\hline Adjusted $\boldsymbol{R}^{2}$ & $.43^{* * *}$ & $.47^{* * *}$ \\
\hline
\end{tabular}

Note. ${ }^{* * *} p<.001 ;{ }^{* *} p<.01 ; \stackrel{*}{p}<.05$ 
Results indicate that sex composition of the relationship did not predict suspected romance or workplace problems. Hostile sexism interacted with sex composition of the relationship to predict suspected romance, $\beta=-.16, p=.014$, and benevolent sexism interacted with sex composition of the relationship to predict suspected romance, $\beta=-.15, p=.02, F(5$, $308)=5.58, R^{2}=.08, p<.001$. A closer examination of the relationships indicate that within the same-sex sample, benevolent sexism was positively related to suspected romance $(r=.50, p<$ .000 ), although hostile sexism was not. Within the cross-sex sample, hostile sexism was positively related to suspected romance $(r=.30, p<.000)$, although benevolent sexism was not. Results for these post-hoc analyses can be found in Table 17. 
Table 17

Study 2: Sex Composition of the Relationship as a Predictor of Suspected Romance and Workplace Problems

\begin{tabular}{|l|l|l|}
\hline & $\begin{array}{c}\text { Suspected } \\
\text { Romance }\end{array}$ & $\begin{array}{c}\text { Workplace } \\
\text { Problems }\end{array}$ \\
\hline Sex Composition of Relationship & $\boldsymbol{\beta}$ & \multicolumn{1}{|c|}{$\boldsymbol{\beta}$} \\
\hline Hostile Sexism & .09 & .02 \\
\hline Benevolent Sexism & $.21^{* *}$ & $.34^{* * *}$ \\
\hline Hostile Sexism X Sex Composition of Relationship & $-.15^{* *}$ & .04 \\
\hline Benevolent Sexism X Sex Composition of Relationship & $.16^{* *}$ & .06 \\
\hline $\boldsymbol{F}$ & $5.58^{* * *}$ & $9.06^{* * *}$ \\
\hline$(d f)$ & $(5,308)$ & $(5,309)$ \\
\hline $\boldsymbol{R}^{2}$ & $.08^{* * *}$ & $.13^{* * *}$ \\
\hline
\end{tabular}

Note. ${ }^{* * *} p<.001 ;{ }^{* *} p<.01 ;{ }^{*} p<.05$; Sex Composition of Relationship coded as: $1=$ Same-sex, $2=$ Cross-sex

Results indicate that coworker sex did not predict suspected romance or workplace problems and sexism did not interact with coworker sex to predict suspected romance or workplace problems. Results for these post-hoc analyses can be found in Table 18 . 
Table 18

Study 2: Coworker Sex as a Predictor of Suspected Romance and Workplace Problems

\begin{tabular}{|l|l|l|}
\hline & \multicolumn{1}{|c|}{$\begin{array}{c}\text { Suspected } \\
\text { Romance }\end{array}$} & $\begin{array}{c}\text { Workplace } \\
\text { Problems }\end{array}$ \\
\hline Coworker Sex & -.01 & .02 \\
\hline Hostile Sexism & $.20^{* *}$ & $.34^{* * *}$ \\
\hline Benevolent Sexism & .04 & .02 \\
\hline Hostile Sexism X Coworker Sex & -.07 & -.09 \\
\hline Benevolent Sexism X Coworker Sex & .03 & -.04 \\
\hline $\boldsymbol{F}$ & $3.68^{* *}$ & $9.87^{* * *}$ \\
\hline$(d f)$ & $(5,308)$ & $(5,309)$ \\
\hline $\boldsymbol{R}^{2}$ & $.06^{* *}$ & $.14^{* * *}$ \\
\hline
\end{tabular}

Note. ${ }^{* * *} p<.001 ;{ }^{* *} p<.01 ;{ }^{*} p<.05$; Coworker sex coded $1=$ Male; $2=$ Female

Results indicate that the interaction between relationship type, sex composition of the relationship, sex of the peer being reported on, and benevolent and hostile sexism was not a statistically significant predictor of either suspected romance or workplace problems. Results of the regressions can be found in Table 19. 
Table 19

Study 2: The Interaction of Coworker Sex, Relationship Type, and Sexism as a Predictor of Suspected Romance and Workplace Problems

\begin{tabular}{|l|l|l|}
\hline & $\begin{array}{c}\text { Suspected } \\
\text { Romance } \\
\boldsymbol{\beta}\end{array}$ & $\begin{array}{c}\text { Workplace } \\
\text { Problems } \\
\boldsymbol{\beta}\end{array}$ \\
\hline $\begin{array}{l}\text { Peer Sex X Relationship Type X } \\
\text { Sex Composition of Relationship X } \\
\text { Benevolent Sexism X } \\
\text { Hostile Sexism }\end{array}$ & .07 & .11 \\
\hline $\boldsymbol{F}$ & & \\
$(\mathbf{d f})$ & 1.60 & 3.57 \\
$\boldsymbol{R}^{2}$ & $(1,308)$ & $(1,309)$ \\
\hline
\end{tabular}

Note. ${ }^{* * *} p<.001 ;{ }^{* *} p<.01 ;{ }^{*} p<.05$

Results of Pearson correlations indicate that suspected romance was related to trust, unfair advantages, and the ego workplace relationship motive. Perceptions that the relationship caused workplace problems was related to trust, unfair advantages, and all three workplace relationship motives. Correlations can be found in Table 4. Results of a series of linear regressions indicate that the ego motive was the strongest predictor of suspected romance, with the sincere motive also a statistically significant predictor. The job motive was the strongest predictor of workplace problems, with the sincere motive also a statistically significant predictor. Results of these linear regressions can be found in Table 20. 
Table 20

Study 2: Relationship Motives as Predictors of Suspected Romance and Workplace Problems

\begin{tabular}{|l|l|l|}
\hline & \multicolumn{1}{|c|}{$\begin{array}{c}\text { Suspected } \\
\text { Romance } \\
\boldsymbol{\beta}\end{array}$} & $\begin{array}{c}\text { Workplace } \\
\text { Problems } \\
\boldsymbol{\beta}\end{array}$ \\
\hline Job Motive & -.13 & $.42^{* * *}$ \\
\hline Ego Motive & $.43^{* * *}$ & .13 \\
\hline Sincere Motive & $-.27^{* *}$ & $-.25^{* * *}$ \\
\hline $\boldsymbol{F}$ & $\begin{array}{l}\text { (df) } \\
(3,208)\end{array}$ & $\begin{array}{l}29.95^{* * *} \\
(3,208)\end{array}$ \\
\hline $\boldsymbol{R}^{2}$ & $.12^{* * *}$ & $.31^{* * *}$ \\
\hline
\end{tabular}

Note. $\stackrel{* * *}{p}<.001 ;{ }^{* *} p<.01 ;{ }^{*} p<.05$

Results of a series of regressions with job, ego, and sincere motives, trust, and unfair advantages entered as predictors indicate that suspected romance was most strongly predicted by the ego and job motives, with the sincere motive and unfair advantages also statistically significant predictors. Workplace problems were predicted primarily by trust and unfair advantages, with the ego and sincere motives also statistically significant predictors. For results of these regressions, see Table 21. 
Table 21

Study 2: Relationship Motives, Trust, and Unfair Advantages as Predictors of Suspected Romance and Workplace Problems

\begin{tabular}{|c|c|c|}
\hline & $\begin{array}{c}\text { Suspected } \\
\text { Romance } \\
\beta\end{array}$ & $\begin{array}{c}\text { Workplace } \\
\text { Problems } \\
\boldsymbol{\beta} \\
\end{array}$ \\
\hline Job Motive & $-.42^{* * * *}$ & .10 \\
\hline Ego Motive & $.46^{* * *}$ & $.15^{*}$ \\
\hline Sincere Motive & $-.26^{* * *}$ & $-.18^{*}$ \\
\hline Trust & -.09 & $-.28^{* * *}$ \\
\hline Unfair Advantages & $.33^{* *}$ & $.28^{* *}$ \\
\hline $\begin{array}{l}F \\
\text { (df) }\end{array}$ & $\begin{array}{l}8.24^{* * *} \\
(5,206)\end{array}$ & $\begin{array}{l}26.88^{* * *} \\
(5,206)\end{array}$ \\
\hline$R^{2}$ & $.17^{* * *}$ & $.40^{* * *}$ \\
\hline
\end{tabular}

Note. ${ }^{* * *} p<.001 ;{ }^{* *} p<.01 ;{ }^{*} p<.05$

With regard to relationship type, results of hypothesis one indicate that relationship type was related to the ego motive, the job motive, and the sincere motive. Post hoc analyses also revealed that all three motives were related to suspected romance and to perceptions of workplace problems. Therefore, motives as mediators of the associations between relationship type and suspected romance and relationship type and workplace problems were tested via separate path analyses.

Results of these analyses indicated that the job motive did not mediate the relationships between relationship type and suspected romance, $\chi^{2}(1)=125.08, p<.000$; RMSEA $=.47$, NFI 
$=.15, \mathrm{CFI}=.12, \mathrm{RFI}=4.11$; or relationship type and workplace problems, $\chi^{2}(1)=65.10, p$ $<.000 ; \mathrm{RMSEA}=.45, \mathrm{NFI}=.42, \mathrm{CFI}=.40, \mathrm{RFI}=2.49$. The ego motive did not mediate the relationships for suspected romance, $\chi^{2}(1)=90.89, p<.000$; $\mathrm{RMSEA}=.54, \mathrm{NFI}=.50, \mathrm{CFI}=$ $.48, \mathrm{RFI}=2.02$; or workplace problems, $\chi^{2}(1)=18.44, p<.000$; RMSEA $=.24, \mathrm{NFI}=.81, \mathrm{CFI}$ $=.81, \mathrm{RFI}=.11$. The sincere motive also did not mediate the relationships between relationship type and suspected romance, $\chi^{2}(1)=108.54, p<.000$; RMSEA $=.59$, NFI $=.15, \mathrm{CFI}=.12$, RFI $=4.08$; or relationship type and workplace problems, $\chi^{2}(1)=16.53, p<.000 ;$ RMSEA $=.22$, NFI $=.70, \mathrm{CFI}=.69, \mathrm{RFI}=.79$.

Regarding sex composition of the relationship, results of hypothesis three indicated that sex composition of the relationship was related to unfair advantages. Additionally, post hoc analyses revealed that unfair advantages were related to workplace problems and suspected romance. Therefore, unfair advantages as the mediator of the association between sex composition of the relationship and suspected romance, as well as the association between sex composition of the relationship and workplace problems, was tested via two separate path analyses.

Results of these analyses indicated that while the model for suspected romance was not an acceptable fit for the data, $\chi^{2}(1)=4.88, p=.03$; RMSEA $=.11, \mathrm{NFI}=.77, \mathrm{CFI}=.74, \mathrm{RFI}=$ .38 ; the model for workplace problems was, $\chi^{2}(1)=3.35, p=.07$; RMSEA $=.09, \mathrm{NFI}=.96$, CFI $=.97, \mathrm{RFI}=.74$. These results suggest that organizational members in same-sex versus oppositesex workplace relationships are perceived as receiving more unfair advantages, which is associated with beliefs that same-sex workplace relationships cause more workplace problems than do cross-sex workplace relationships. 
Regarding sex of the peer, results of hypothesis five indicated that peer sex was related to unfair advantages. Additionally, post hoc analyses revealed that unfair advantages was related to workplace problems and suspected romance. Therefore, unfair advantages was tested as a mediator of the association between sex of the peer and both suspected romance and workplace problems via two separate path analyses.

Results of these analyses indicate that unfair advantages mediated the relationships between sex of the peer and suspected romance, $\chi^{2}(1)=.36, p=.55$; RMSEA $=.00, \mathrm{NFI}=.98$, $\mathrm{CFI}=1.0, \mathrm{RFI}=.88 ;$ and workplace problems, $\chi^{2}(1)=.53, p=.47$ RMSEA $=.00, \mathrm{NFI}=.99$, $\mathrm{CFI}=1.0, \mathrm{RFI}=.96$. These results suggest that female organizational members in workplace relationships are perceived as receiving more unfair advantages than male organizational members in workplace relationships, which is associated with organizational members suspecting female versus male coworkers' workplace relationships to be romantic to a greater extent and to cause more workplace problems.

Results of Pearson correlations (see Table 4) indicate that all three dimensions of credibility (competence, character and caring) were negatively related to both suspected romance and workplace problems. However, results of multiple linear regressions indicate that while the credibility model as a whole predicted suspected romance, none of the individual credibility dimensions were statistically significant predictors of suspected romance. The credibility model did predict workplace problems. Only character was a statistically significant predictor of workplace problems. Perceptions of coworker character negatively predicted workplace problems caused by the coworker's friendship. Results of these multiple linear regressions can be found in Table 22 . 
Table 22

Study 2: Credibility as a Predictor of Suspected Romance and Workplace Problems

\begin{tabular}{|c|c|c|}
\hline & $\begin{array}{c}\text { Suspected } \\
\text { Romance } \\
\beta\end{array}$ & $\begin{array}{c}\text { Workplace } \\
\text { Problems } \\
\beta\end{array}$ \\
\hline Competence & .05 & -.01 \\
\hline Character & -.14 & -.06 \\
\hline Caring & -.12 & $-.36^{* *}$ \\
\hline $\begin{array}{l}F \\
\text { (df) }\end{array}$ & $\begin{array}{l}4.83^{* *} \\
(3,309)\end{array}$ & $\begin{array}{l}23.53^{* * *} \\
(3,310)\end{array}$ \\
\hline$R^{2}$ & $.05^{* *}$ & $.18^{* * *}$ \\
\hline
\end{tabular}

Note. ${ }^{* * *} p<.001 ; * * p<.01 ; * p<.05$

Results indicate that peer sex, relationship type, and sex composition were not related to credibility, therefore, mediation was not tested.

Summary of results. The data in Study 2 were used to examine hypotheses 1, 2, 3, 4, 5, $6,9,10$, and 11 , as well as research questions 6,7 , and 8 . Results indicate that hypothesis one was partially supported, with perceptions of ego motives higher for workplace relationships that were more intimate (romance was more intimate than friendship, which was more intimate than professional relationships), and perceptions of job and sincere motives lower for more intimate relationships. Hypothesis two was partially supported, with more hostile sexist individuals reporting that they behaved more aggressively toward coworkers in romances but not toward coworkers in friendships or professional relationships. Further, hostile sexism was positively related to perceptions of the ego motive for both workplace romances and professional 
workplace relationships, but not for friendships. Hypothesis three was not supported, as the only statistically significant relationship (organizational members in same-sex workplace relationships were perceived as receiving more unfair advantages) was opposite the direction hypothesized. Hypothesis four, which concerned the interaction of sexism and relationship type to affect the outcome variables, was not supported. Hypothesis five was partially supported, with respondents perceiving that female organizational members receive more unfair advantages from their workplace relationships than male organizational members do. Hypothesis six, which concerned the interaction of sexism and peer sex to affect the outcome variables, was not supported. Hypothesis nine was partially supported, with 8 of the 10 tested relationships reaching statistical significance and hypothesis 10 was partially supported, with 13 of the 15 tested relationships reaching statistical significance. Relationships that did not achieve statistical significance included the associations between the sincere motive and obstructionism, the sincere motive and deception, the ego motive and self-disclosure, and the job motive and self-disclosure. Hypothesis 11 was partially supported, with mediation occurring in 16 of the 20 tested relationships. Results of research question six indicate that the interaction between type of workplace relationship, sex composition of the relationship, sex of the peer being reported on, and sexism did not predict any of the criterion variables. Results of research question seven indicate that, in the main, credibility was negatively related to obstructionism, information manipulation, and aggression. For research question eight, the independent variables were not related to credibility, therefore, mediation could not have occurred.

Finally, results of post-hoc analyses suggest that relationship type predicted both suspected romance and workplace problems, with workplace romances being seen as the most romantic and most likely to cause workplace problems. Additionally, benevolent sexism 
interacted with relationship type to predict workplace problems. Sex composition of the relationship did not predict suspected romance or workplace problems, though both hostile and benevolent sexism interacted with sex composition of the relationship to predict suspected romance. Coworker sex did not predict suspected romance or workplace problems, sexism did not interact with coworker sex to predict suspected romance or workplace problems, and the interaction between relationship type, sex composition of the relationship, sex of the peer being reported on, and benevolent and hostile sexism was not a statistically significant predictor of either suspected romance or workplace problems. Post-hoc analyses also revealed that suspected romance was related to trust, unfair advantages, and the ego workplace relationship motive, while perceptions that the relationship caused workplace problems was related to trust, unfair advantages, and all three workplace relationship motives. Unfair advantages mediated the relationship between sex composition of the relationship and workplace problems, as well as the relationships between sex of the peer being reported on and both suspected romance and workplace problems. Additionally, all three dimensions of credibility (competence, character and caring) were negatively related to both suspected romance and workplace problems.

\section{Discussion}

Relationship type. In terms of relationship type, results indicated that perceptions of ego motives increased and perceptions of job and sincere motives decreased as the relationships moved from professional, through friendships, to romances. One explanation for this is that individuals who are in romances are perceived as looking for excitement in a relationship. Although workplace romances are becoming more common (Kiser, Coley, Ford, \& Moore, 2006; Pearce, 2010; Shellenbarger, 2005), they are still somewhat taboo, with a 2010 Wall Street Journal article, reporting the results of a CareerBuilder survey, revealing that $33 \%$ of employees 
felt workplace romances were something that needed to be hidden (Shellenbarger, 2005). In terms of the result for job motives, it is possible that individuals in professional relationships may be perceived as being more motivated by job motives as the job motive items included items such as "for job advancement." That is, individuals may consider a professional relationship, due to its lack of ego or sincere motives, to be motivated purely by job-related reasons. Regarding the sincere motive, it seems that organizational members are suspicious of the motives of coworkers in workplace romances, perhaps thinking they may be in the romance, as previous research would suggest, in order to receive unfair advantages or to advance in the organization (Gillen \& Chory 2014a, 2014b; Malachowski et al., 2012).

Further, post-hoc analyses indicated that workplace romances were more likely to be seen as romantic than were professional relationships and workplace friendships. Additionally, workplace romances were seen as causing more workplace problems than friendships or professional relationships were perceived to cause. While the result that more intimate relationships (including admitted romances) are considered not surprising (and perhaps simply acts as a manipulation check for the scenarios), the result that relationships that are more intimate lead to more perceived workplace problems is worth noting. This result is consistent with previous research that suggests that workplace romances are often perceived negatively (Cowan \& Horan, 2014, in press; Gillen \& Chory, 2014a, 2014b; Horan \& Chory, 2009, 2011, 2013; Malachowski, et al., 2012).

Sex composition of the relationship. Organizational members generally did not perceive differences between coworkers in cross-sex workplace relationships and those in same-sex workplace relationships. The one point on which respondents did note a difference was unfair advantages. Organizational members in same-sex versus cross-sex workplace relationships are 
perceived as receiving more unfair advantages by virtue of that relationship. Although this is counter to the hypothesized relationship that individuals in cross-sex relationships would be perceived as receiving more unfair advantages, a number of possible explanations exist.

First, both men and women may be perceived as being more willing to help coworkers of the same sex than they are coworkers of the opposite sex (perhaps a sense of "having each others' backs" due to their shared sex). Previous research suggesting that men and women tend to have more friendships with individuals of the same sex as opposed to those of the opposite sex (Lenton \& Webber, 2006, Reeder, 2003, Werking, 1997), in addition to even preferring these friendships (Rose, 1985), lends support to this explanation.

A related possibility stems from the previously mentioned research suggesting that crosssex friendships are often perceived as romantic. It is possible, then, that organizational members in cross-sex workplace relationships are aware of their coworkers' romance-related suspicions and may be hesitant to help their cross-sex friends, coworkers, or romantic partners. They may at least be more secretive in doing so, for fear of others assuming the gesture is a sign of a more intimate, more than platonic, relationship between the two. Therefore, if employees are more disposed to help their same-sex coworkers at work (and more wary of openly helping cross-sex coworkers), third-party coworkers may perceive more unfair advantages being gained in samesex, as opposed to opposite-sex, relationships.

Additionally, unfair advantages were found to mediate the relationships between sex composition of the relationship and obstructionism, self-disclosure, and aggression. Therefore, because of the unfair advantages they perceive same-sex coworkers receiving, individuals report that they behave in a variety of antisocial ways towards those individuals. This relationship supports equity theory (Adams, 1965). Individuals believe that their coworkers in same-sex 
relationships receive more unfair advantages, which creates a sense of inequity. Perhaps as a means of restoring equity, respondents behave in aggressive ways towards these coworkers, obstruct their work, and are dishonest and/or inaccurate in their self-disclosures to them.

Further, post-hoc analyses suggest that organizational members perceive coworkers in same-sex versus opposite-sex workplace relationships as receiving more unfair advantages due to their relationships, which leads organizational members to report that these same-sex workplace relationships cause more workplace problems than do cross-sex workplace relationships. While the relationship between same-sex relationships and unfair advantages is counter to the hypothesis, the result regarding unfair advantages and increased workplace problems is consisting with workplace romance research that individuals in workplace relationships that include the perception of unfair advantages are also perceived more negatively by their coworkers (Gillen \& Chory, 2014a).

Sex of the peer reported on. In terms of the sex of the coworker in the cross-sex workplace relationship being reported on by the respondent, results indicated that for all but one variable, perceptions of men and women did not differ. Results did indicate that female organizational members are perceived as receiving more unfair advantages by virtue of their workplace relationships than are male organizational members. This result is consistent with previous research (Gillen \& Chory, 2014a) and the proposed hypothesis. As theorized, these results may be due to the fact that women, having to break through the glass ceiling, may be perceived by coworkers as needing these relationships in order to advance, and in turn, receiving more benefits from them than men do.

Further, unfair advantages were found to mediate the relationships between the sex of the peer being reported on and obstructionism, deception, self-disclosure, and aggression. That is, 
female organizational members are perceived to receive more advantages by virtue of their workplace relationships, which is associated with respondents behaving in a variety of antisocial ways towards the female coworkers. As with the mediating role of unfair advantages for the relationships with sex composition, this relationship supports equity theory (Adams, 1965). That is, respondents believe that female organizational members in workplace relationships receive more unfair advantages, which creates a sense of inequity. It is because of these unfair advantages or perceived inequity that respondents report behaving in aggressive ways towards the female coworkers, obstructing their work, and being dishonest and/or inaccurate in their selfdisclosures. These actions may serve as ways to restore the equity they feel was damaged through the female coworkers receiving unfair advantages.

Sexism. In study 2, both hostile and benevolent sexism interacted with independent variables to predict outcomes. First, regarding relationship type, hostile sexism interacted with relationship type to affect the employee rating only for coworkers in workplace romances. That is, hostile sexism is associated with higher aggression towards coworkers in workplace romances, but not of coworkers in other types of workplace relationships. This is consistent with the hypothesized relationship and the assertion that organizational members who are more sexist against women may be more inclined to believe that individuals who are in workplace romances have ulterior motives for those relationships, and as such, think less highly of them as a fellow employee. Further, as hostile sexism concerns negative and biased discrimination of women, it is likely that romances, which bring the notion of sex (and the sexualized woman) into the workplace, make negative perceptions increasingly intense.

Additionally, hostile sexism interacted with relationship type to impact perceptions of ego motives for engaging in the relationship. More hostile sexist organizational members tended 
to perceive coworkers in professional relationships and workplace romances as being more motivated by ego, whereas hostile sexism was not related to perceptions of the ego motives of coworkers in friendships.

Second, regarding sex composition of the workplace relationships, post hoc analyses indicated that hostile sexism interacted with sex composition of the relationship to predict suspected romance and benevolent sexism interacted with sex composition of the relationship to predict suspected romance. Results suggest that organizational members high in benevolent sexism tend to believe same-sex workplace relationships are secretly romantic, whereas more hostile sexist organizational members tend to believe that cross-sex relationships are likely to be secretly romantic. This could be due to the (seemingly) positive and negative stereotypes held by individuals who are benevolent sexist and hostile sexist, respectively. Perhaps individuals who are hostile sexist, since they are more likely to subscribe to beliefs regarding traditional gender roles, are more likely to assume that men and women will be romantically involved.

Third, regarding sex of the coworker, benevolent sexism interacted with coworker sex to predict character and caring, as well as trust. It appears that benevolent sexism is only related to trust in male coworkers. Benevolent sexism and trust in men in workplace relationships are negatively related. This notion is counter to the hypothesis, but may be due to the fact that benevolent sexism is, at least on the surface, seemingly positive. That is, individuals who believe women "have a quality of purity that few men possess" and "compared to men, tend to have a superior moral sensibility" (Glick \& Fisk, 1996), are perhaps not only more inclined to believe that they can trust women, but also more likely to believe that men should not be trusted. 


\section{CHAPTER IV: STUDY THREE}

\section{Method}

Study 3 employed a cross-sectional design with a questionnaire consisting of quantitative measures. Participants in Study 3 were required to have personally observed a cross-sex workplace friendship. Study 3 provides insight on cross-sex workplace friendships from employees who have actually worked with people involved in such relationships. This method lends ecological validity to the investigation.

Participants and procedures. Once IRB approval had been obtained, individuals were recruited to participate in this study in four ways. Participants were recruited through snowball sampling in introductory communication courses at a large Mid-Atlantic University, an online announcement made through the same University, links posted on the researcher's personal Facebook pages, and Amazon's Mechanical Turk crowd-sourcing service (www.mturk.com). To participate, individuals had to be at least 25 years of age and employed full time (at least 30 hours a week) in the United States. Participants were also required to have personally observed a cross-sex friendship in a current or previous workplace. Students who were recruited in undergraduate courses were given a handout that included basic information on the study and directed them to identify an individual that they knew who fit the inclusion criteria. Students were instructed to have their identified participant email the researcher, who provided that participant a link to the online questionnaire. The call for participants posted on the University online announcement system, researcher's Facebook pages, and Amazon Mechanical Turk included a direct link to the same online questionnaire. When participants clicked the link, they were first directed to a page that included the cover letter for the study, in addition to the researchers' contact information. Participants were then instructed to click a button labeled 'I 
agree to participate" if they agreed to participate and to exit the page if they decided not to proceed with the questionnaire. On the final page of the online questionnaire, individuals were thanked for their participation and provided the researchers' contact information a final time.

The final sample included responses from 183 working adults ( 79 women, 81 men, and 19 individuals who declined to report their sex). Fifty-nine participants accessed the survey via Amazon's Mechanical Turk (32.2\%), while the remaining 67.8\% $(n=124)$ accessed the survey via Facebook, the University intranet, or recruitment from students in undergraduate courses. Participants ranged in age from 25 to 73 years old $(M=40.90, S D=12.33)$. The majority of respondents reported their race/ethnicity as Caucasian/White $(n=120,65.6 \%)$, followed by Asian/Asian American $(n=18,9.8 \%)$, African American/Black $(n=12,6.6 \%)$, Native American ( $n=4,2.2 \%)$, Hispanic/Latino $(n=3,1.6 \%)$ and "Other" $(n=3,1.6 \%)$. Twenty-three participants (12.6\%) did not report their race/ethnicity. The most common occupational field reported was managerial and professional $(n=92,50.3 \%)$, followed by technical, sales, and administrative support $(n=41,22.4 \%)$, service occupations ( $n=18,9.8 \%)$, operators, fabricators, and laborers $(n=5,2.7 \%)$, and precision production, craft, and repair $(n=4,2.2 \%)$, with 23 participants not reporting occupational field (12.6\%). The majority of participants $(n=$ $26,14.2 \%)$ reported an annual salary of $\$ 40,001$ to 50,000 followed by over $\$ 100,000(n=21$, $11.5 \%), \$ 30,001$ to $\$ 40,000(n=20,10.9 \%), \$ 20,000$ to $\$ 30,000(n=19,10.4 \%), \$ 50,001$ to $\$ 60,000(n=19,10.4 \%)$, under $\$ 20,000(n=14,7.7 \%), \$ 60,001$ to $\$ 70,000(n=13,7.1 \%)$, $\$ 90,001$ to $\$ 100,000(n=8,4.4 \%), \$ 70,001$ to $\$ 80,000(n=6.3 .3 \%)$, and $\$ 80,001$ to $\$ 90,000(n$ $=9,1.6 \%)$, while 34 participants declined to report their salary $(18.6 \%)$. Respondents reported they had been employed at their current organization from 1 to 36 years $(M=4.77$ years, $S D=$ 5.52 years) and worked an average of 43.76 hours a week (range of 30 to 100 hours, $S D=9.61$ ). 
Regarding the organization in which they had observed the workplace friendship, respondents reported having worked there from 1 month to 36 years $(M=5.49$ years, $S D=5.99$ years) and working/having worked an average of 44.13 hours per week $(S D=10.30)$ at that organization. The majority of participants $(n=121,66.1 \%)$ reported that they still worked at the organization where they had observed the workplace friendship.

Instrumentation. Participants were first given a definition of a cross-sex workplace friendship. The definition was drawn from existing research on workplace friendships (e.g., Sias, 2008; Sias et al., 2003) and reads:

A workplace friendship is a relationship between two people who work for the same organization. Although we don't always get to choose the people we work with, we do choose the people at work that we become friends with. Workplace friendships are voluntary relationships, they are not imposed - people choose employees they become friends with. Workplace friendships are more personal than other workplace relationships - workplace friends understand and communicate with each other as whole persons, not simply as work role occupants. Workplace friends choose to spend time together at and away from the workplace.

Next, participants were given the definition of a cross-sex workplace friendship as "a workplace friendship between individuals of the opposite sex (between a man and a woman)."

After reading the definition of a cross-sex workplace friendship, participants were instructed to "respond to the following questions based on a workplace friendship between a man and woman you have personally observed in the workplace." Respondents then completed a series of quantitative measures based on their "communication with the coworker in the crosssex workplace friendship with whom you have/had the most work-related contact." These criteria, which have been employed in previous research (e.g., Gillen \& Chory, 2014a, 2014b) were used for two primary reasons. First, it allowed participants to report on an individual with whom they interact(ed) regularly in a workplace setting (as opposed to a friendship partner 
assigned by the researcher whom the respondent may not know well), allowing for more accurate assessments. Further, by indicating that the individual the respondent was reporting on was the member of the relationship (s)he has/had the most "work-related" contact with, respondents were not able to choose the individual they liked more or less than the other, which could have led to responses based on personal issues beyond the scope of this study. Respondents reported on 89 men (48.6\%) and 93 women (50.8\%) in cross-sex workplace friendships, with one respondent not identifying the sex of his/her coworker. The majority of respondents $(n=121,66.1 \%)$ reported on an individual who was friends with a peer, 46 respondents reported on an individual who was friends with a subordinate, $(25.1 \%)$, and $16(8.7 \%)$ reported on an individual who was friends with a superior.

Participants then completed the measures employed in Study 2 assessing credibility, motives for entering into the friendship, perceptions of unfair advantages, trust, obstructionism, information manipulation, aggression, sexism, perceptions of romance, and perceptions of workplace problems. See Appendices E through O for these measures.

For McCroskey and Teven's (1999) measures assessing credibility, Cronbach's alphas of $.87(M=5.76, S D=1.07)$ for competence, $.91(M=5.15, S D=1.39)$ for caring, and $.96(M=$ $5.67, S D=1.38$ ) for character were obtained. Responses ranged from 2.67 to 7.00 for competence, 1.00 to 7.00 for caring, and 1.50 to 7.00 for character. The scales assessing perceptions of motives for entering into the friendship (based on Malachowski et al., 2012) obtained Cronbach's alphas of $.85(M=3.55, S D=1.50), .76(M=3.92, S D=1.30)$, and $.89(M$ $=2.81, S D=1.46)$ for ego, sincere, and job motives, respectively. Responses ranged from 1.00 to 7.00 for ego, sincere, and job motives. The measure of unfair advantages (based on Malachowski et al., 2012) obtained a Cronbach's alpha of .95 $(M=2.59, S D=1.60)$ yielded 
responses ranging from 1.00 to 7.00. The Cronbach's alpha of McCroskey and Richmond's (1996) measure of trust was $.95(M=2.59, S D=1.60)$. Responses ranged from 1.00 to 7.00 . The scale measuring obstructionism (Neuman \& Baron, 1998) was reliable with a Cronbach's alpha of $.97(M=1.68, S D=1.13)$ and responses that ranged from 1.00 to 6.11 . The scales of information manipulation, which included deception (Hubbell et al., 2005; McCornack et al., 1992) and self-disclosure (Wheeless, 1978) were reliable, with Cronbach's alphas of .94 $(M=1.76, S D=1.12)$ for deception and $.87(M=4.92, S D=1.37)$ for self-disclosure. Responses ranged from .88 to 6.25 for deception and from 2.00 to 7.00 for self-disclosure. The semantic differential measure of aggression (Cicchirillo \& Chory-Assad, 2005) obtained an acceptable Cronbach's alpha of .87 (after reverse-scoring: $M=3.39, S D=1.29$ ) and responses ranged from 1.00 to 7.00 . For the single-item measure assessing respondents' rating of workplace friendship participants, scores ranged from 1 to $100(M=79.29, S D=23.25)$.

The sexism measure (Glick \& Fiske, 1996) was reliable with a Cronbach's alpha of .84 $(M=3.58, S D=0.97)$ for hostile sexism and $.83(M=3.76, S D=1.00)$ for benevolent sexism. Responses ranged from 1.36 to 7.00 for hostile sexism and 1.00 to 6.00 for benevolent sexism. The measures of suspected romance and workplace problems had Cronbach's alphas of $.90(M=$ $2.75, S D=1.73)$ and $.86(M=2.64, S D=1.43)$, respectively. Responses ranged from 1.00 to 6.80 for suspected romance and 1.00 to 7.00 for workplace problems.

The directions for all measures reminded participants to respond based on their "communication with the coworker in the cross-sex workplace friendship with whom you have/had the most work-related contact." Finally, participants were asked to complete a series of items assessing demographics and information related to the job, their organization, and the sex and statuses of those in the friendship. The Study 3 questionnaire can be found in Appendix Q. 


\section{Results}

Correlations between all variables in the study can be found in Table 23. Mean differences in the dependent variables based on the status dynamic of the cross-sex workplace

friendship and the sex of the peer in the cross-sex workplace friendship appear in Table 24 and Table 25, respectively. 
Table 23

Study 3: Intercorrelations among Variables

\begin{tabular}{|c|c|c|c|c|c|c|c|c|c|c|c|c|c|c|c|c|}
\hline Variable & 1 & 2 & 3 & 4 & 5 & 6 & 7 & 8 & 9 & 10 & 11 & 12 & 13 & 14 & 15 & 16 \\
\hline \multicolumn{17}{|l|}{ 1. Competence - } \\
\hline 2. Character & $.73^{* * *}$ & - & & & & & & & & & & & & & & \\
\hline 3. Caring & $.59^{* * *}$ & $-.85^{* * *}$ & - & & & & & & & & & & & & & \\
\hline 4. Ego Motive & $-.16^{* * *}$ & $-.23^{* *}$ & $-.24^{* * *}$ & - & & & & & & & & & & & & \\
\hline 5. Job Motive & $-.44^{* * *}$ & $-.48^{* * *}$ & $-.36^{* * *}$ & $.37^{* * *}$ & - & & & & & & & & & & & \\
\hline 6. Sinc. Motive & .15 & .13 & .06 & $.63^{* * *}$ & -.03 & - & & & & & & & & & & \\
\hline 7. Unfair Adv. & $-.47^{* *}$ & $-.52^{* * *}$ & $-.46^{* * *}$ & $.27^{* * *}$ & $.70^{* * *}$ & -.07 & - & & & & & & & & & \\
\hline 8. Trust & $.69^{* * *}$ & $.81^{* * *}$ & $.74^{* * *}$ & -.18 & $-.45^{* * *}$ & $.16^{*}$ & $-.48^{* * *}$ & - & & & & & & & & \\
\hline 9. Obstruction. & $-.44^{* * *}$ & $-.43^{* * *}$ & $-.35^{* * *}$ & $.26^{* *}$ & $.55^{* * *}$ & -.80 & $.64^{* * *}$ & $-.45^{* * *}$ & - & & & & & & & \\
\hline 10. Deception & $-.50^{* * *}$ & $-.49^{* * *}$ & $-.41^{* * *}$ & $.23^{* *}$ & $.55^{* * *}$ & -.13 & $.66^{* * *}$ & $-.52^{* * *}$ & $.93^{* * *}$ & - & & & & & & \\
\hline 11. Self-Dis. & $.44^{* * *}$ & $.46^{* * *}$ & $.52^{* * *}$ & $-.19^{*}$ & $-.32^{* * *}$ & .13 & $-.38^{* * *}$ & $.48^{* * *}$ & $-.34^{* * *}$ & $-.37^{* * *}$ & - & & & & & \\
\hline 12. Agg. Scale & $-.67^{* * *}$ & $-.78^{* * *}$ & $-.75^{* * *}$ & .09 & $.40^{* * *}$ & $-.23^{* *}$ & $.42^{* * *}$ & $-.78^{* * *}$ & $.38^{* * *}$ & $.47^{* * *}$ & $-.53^{* * *}$ & - & & & & \\
\hline 13. 1-100 Rating & $\lg .45^{* * *}$ & $.41^{* * *}$ & $.45^{* * *}$ & $-.20^{* *}$ & $-.35^{* * *}$ & .01 & $-.32^{* * *}$ & $.49^{* * *}$ & $-.30^{* * *}$ & $-.35^{* * *}$ & $.24^{* *}$ & $-.55^{* * *}$ & - & & & \\
\hline 14. Romance & $-.19^{*}$ & $-.17^{*}$ & $-.22^{* *}$ & $.56^{* *}$ & $.31^{* * *}$ & $.24^{* *}$ & $.26^{* *}$ & $-.18^{*}$ & $.32^{* * *}$ & $.28^{* * *}$ & $-.27^{* *}$ & .14 & -.12 & - & & \\
\hline 15. Problems & $-.49^{* * *}$ & $-.49^{* * *}$ & $-.48^{* * *}$ & $.42^{* *}$ & $.59^{* * *}$ & .01 & $.53^{* * *}$ & $-.54^{* * *}$ & $.55^{* * *}$ & $.57^{* * *}$ & $-.40^{* * *}$ & $.50^{* * *}$ & $-.41^{* * *}$ & $.52^{* * *}$ & - & \\
\hline 16. Ben. Sex. & .01 & -.07 & -.01 & .09 & $.27^{* *}$ & $-.17^{*}$ & .04 & .01 & $.24^{* *}$ & $.19^{*}$ & -.01 & .05 & -.05 & $.23^{* *}$ & .84 & - \\
\hline 17. Hos. Sex. & $-.17^{*}$ & -.15 & $-.19^{*}$ & .14 & $.33^{* * *}$ & -.13 & $.22^{* *}$ & $.20^{* *}$ & $.37^{* * *}$ & $.36^{* * *}$ & $-.16^{*}$ & $.21^{* *}$ & $-.24^{* *}$ & $.28^{* * *}$ & $.39^{* * *}$ & $.53^{* * *}$ \\
\hline
\end{tabular}


Table 24

Study 3: Mean Differences Between Cross-Sex Workplace Friendships with a Superior and with a Peer or Subordinate

\begin{tabular}{|c|c|c|c|c|}
\hline & $\begin{array}{l}\text { Superior } \\
\text { Mean }(S D)\end{array}$ & $\begin{array}{c}\text { Peer or Subordinate } \\
\text { Mean }(S D)\end{array}$ & $\begin{array}{c}t \\
(\mathrm{df})\end{array}$ & $p$-value \\
\hline \multicolumn{5}{|l|}{ Credibility } \\
\hline Competence & $5.54(1.07)$ & $5.77(1.07)$ & $\begin{array}{l}-.782 \\
(169)\end{array}$ & .436 \\
\hline Caring & $5.11(1.45)$ & $5.15(1.39)$ & $\begin{array}{l}-.119 \\
(171)\end{array}$ & .905 \\
\hline Character & $5.41(1.56)$ & $5.69(1.36)$ & $\begin{array}{l}-.704 \\
(169) \\
\end{array}$ & .482 \\
\hline \multicolumn{5}{|l|}{ Motives } \\
\hline Job & $3.26(1.59)$ & $2.78(1.45)$ & $\begin{array}{l}1.24 \\
(167)\end{array}$ & .217 \\
\hline Ego & $2.86(1.58)$ & $3.89(1.46)$ & $\begin{array}{l}-2.58 \\
(167)\end{array}$ & $.011 *$ \\
\hline Sincere & $4.09(1.12)$ & $4.75(1.37)$ & $\begin{array}{l}-1.82 \\
(168) \\
\end{array}$ & .070 \\
\hline Unfair Advantages & $3.49(1.90)$ & $2.50(1.54)$ & $\begin{array}{c}2.30 \\
(166) \\
\end{array}$ & $.022 *$ \\
\hline Trust & $5.80(1.76)$ & $5.83(1.56)$ & $\begin{array}{l}-.070 \\
(175) \\
\end{array}$ & .944 \\
\hline Obstructionism & $1.53(.934)$ & $1.69(1.15)$ & $\begin{array}{l}-.527 \\
(179)\end{array}$ & .599 \\
\hline \multicolumn{5}{|c|}{ Information Manipulation } \\
\hline Self-Disclosure & $4.69(1.41)$ & $4.95(1.37)$ & $\begin{array}{l}-.723 \\
(178) \\
\end{array}$ & .471 \\
\hline Deception & $1.64(.748)$ & $1.77(1.15)$ & $\begin{array}{l}-.418 \\
(181)\end{array}$ & .677 \\
\hline \multicolumn{5}{|l|}{ Aggression } \\
\hline Aggression & $2.35(1.27)$ & $2.39(1.29)$ & $\begin{array}{l}-.113 \\
(178)\end{array}$ & .910 \\
\hline $1-100$ Rating & $82.63(23.2)$ & $78.98(23.3)$ & $\begin{array}{l}.599 \\
(181)\end{array}$ & .550 \\
\hline Suspected Romance & $1.96(1.42)$ & $2.83(1.46)$ & $\begin{array}{l}-1.82 \\
(160) \\
\end{array}$ & .070 \\
\hline Workplace Problems & $2.47(1.08)$ & $2.65(1.45)$ & $\begin{array}{l}-.447 \\
(162)\end{array}$ & .550 \\
\hline
\end{tabular}


Table 25

Study 3: Mean Differences Between Sex of Peer Reported On

\begin{tabular}{|c|c|c|c|c|}
\hline & $\begin{array}{c}\text { Male } \\
\text { Mean }(S D)\end{array}$ & $\begin{array}{c}\text { Female } \\
\text { Mean }(S D)\end{array}$ & $\begin{array}{c}t \\
(\mathrm{df})\end{array}$ & $p$-value \\
\hline \multicolumn{5}{|l|}{ Credibility } \\
\hline Competence & $5.72(1.10)$ & $5.78(1.06)$ & $\begin{array}{l}-.361 \\
(169) \\
\end{array}$ & .718 \\
\hline Caring & $4.95(1.39)$ & $5.34(1.37)$ & $\begin{array}{l}-1.885 \\
(170)\end{array}$ & .061 \\
\hline Character & $5.59(1.31)$ & $5.75(1.45)$ & $\begin{array}{l}-.795 \\
(168)\end{array}$ & .428 \\
\hline \multicolumn{5}{|l|}{ Motives } \\
\hline Job & $2.79(1.51)$ & $2.82(1.43)$ & $\begin{array}{l}-.114 \\
(166)\end{array}$ & .909 \\
\hline Ego & $4.00(1.58)$ & $3.64(1.40)$ & $\begin{array}{c}1.42 \\
(166)\end{array}$ & .158 \\
\hline Sincere & $4.84(1.42)$ & $4.58(1.29)$ & $\begin{array}{l}1.26 \\
(167)\end{array}$ & .208 \\
\hline Unfair Advantages & $2.58(1.57)$ & $2.59(1.64)$ & $\begin{array}{l}-.026 \\
(165)\end{array}$ & .979 \\
\hline Trust & $5.70(1.60)$ & $5.96(1.54)$ & $\begin{array}{l}-1.07 \\
(174)\end{array}$ & .286 \\
\hline Obstructionism & $1.74(1.17)$ & $1.61(1.10)$ & $\begin{array}{c}.758 \\
(178)\end{array}$ & .450 \\
\hline \multicolumn{5}{|l|}{$\begin{array}{l}\text { Information } \\
\text { Manipulation }\end{array}$} \\
\hline \begin{tabular}{l|l} 
Self- \\
Disclosure
\end{tabular} & $4.89(1.45)$ & $4.96(1.30)$ & $\begin{array}{l}-.349 \\
(177)\end{array}$ & .727 \\
\hline Deception & $1.85(1.13)$ & $1.67(1.11)$ & $\begin{array}{c}1.09 \\
(180) \\
\end{array}$ & .277 \\
\hline \multicolumn{5}{|l|}{ Aggression } \\
\hline Aggression & $2.59(1.34)$ & $2.20(1.22)$ & $\begin{array}{l}2.03 \\
(177)\end{array}$ & $.044^{*}$ \\
\hline $\begin{array}{ll}1-100 \\
\text { Rating }\end{array}$ & $76.8(23.9)$ & $81.6(22.5)$ & $\begin{array}{l}-1.41 \\
(180)\end{array}$ & .161 \\
\hline $\begin{array}{l}\text { Suspected } \\
\text { Romance }\end{array}$ & $2.97(1.78)$ & $2.55(1.67)$ & $\begin{array}{c}1.53 \\
(159) \\
\end{array}$ & .127 \\
\hline $\begin{array}{l}\text { Workplace } \\
\text { Problems }\end{array}$ & $2.84(1.56)$ & $2.44(1.27)$ & $\begin{array}{l}1.79 \\
(151)\end{array}$ & .076 \\
\hline
\end{tabular}


Hypotheses 5 and 6: Sex of peer in relationship. Hypothesis five predicted that female organizational members in workplace relationships would be a) perceived as less credible, more driven by job and ego motives and less by sincere motives, and receiving more unfair advantages; b) trusted less; and c) more likely to be the targets of their coworkers' obstructionism, information manipulation, and aggression than will male organizational members in workplace relationships. Hypothesis six predicted that sexism would interact with organizational member sex to affect a) perceptions of credibility, motives, and unfair advantages; b) trust; and c) obstructionism, information manipulation, and aggression such that the differences in these outcomes between male and female organizational members would be greater for more sexist versus less sexist individuals. To analyze hypotheses five and six a series of multiple linear regressions were conducted. Coworker sex, benevolent sexism, hostile sexism, the interaction term for coworker sex and benevolent sexism, and the interaction term for coworker sex and hostile sexism were entered as predictors. Competence, character, caring, ego motives, job motives, sincere motives, unfair advantages, trust, obstructionism, self-disclosure, deception, the measure of aggression and the single-item employee rating measure were the individual criterion variables in the 13 regression models.

Regarding hypothesis five, results indicate that coworker sex predicted aggression at a statistically significant level, albeit it in the opposite direction of the hypothesis, $\beta=-.16, p=$ $.047, F(5,153)=3.81, R^{2}=.10, p=.009$. That is, results suggest that men received more aggression from coworkers than women received. No other relationships were statistically significant. As such, hypothesis five was not supported.

Regarding hypothesis six, benevolent sexism interacted with coworker sex to predict character, $\beta=-.21, p=.035$, and hostile sexism also interacted with coworker sex to predict 
character, $\beta=.24, p=.016, F(5,150)=2.33, R^{2}=.07, p=.045$. Benevolent sexism interacted with coworker sex to predict caring, $\beta=-.21, p=.028, F(5,152)=3.42, R^{2}=.10, p=.006$. No other statistically significant results were observed. In general, results indicate that although 8 of the 12 multiple regression models were statistically significant, hostile sexism was the primary predictor of the criterion variables. All results for hypotheses five and six can be found in Table 26. 
Table 26

Study 3: Results of Hypotheses 5 and 6

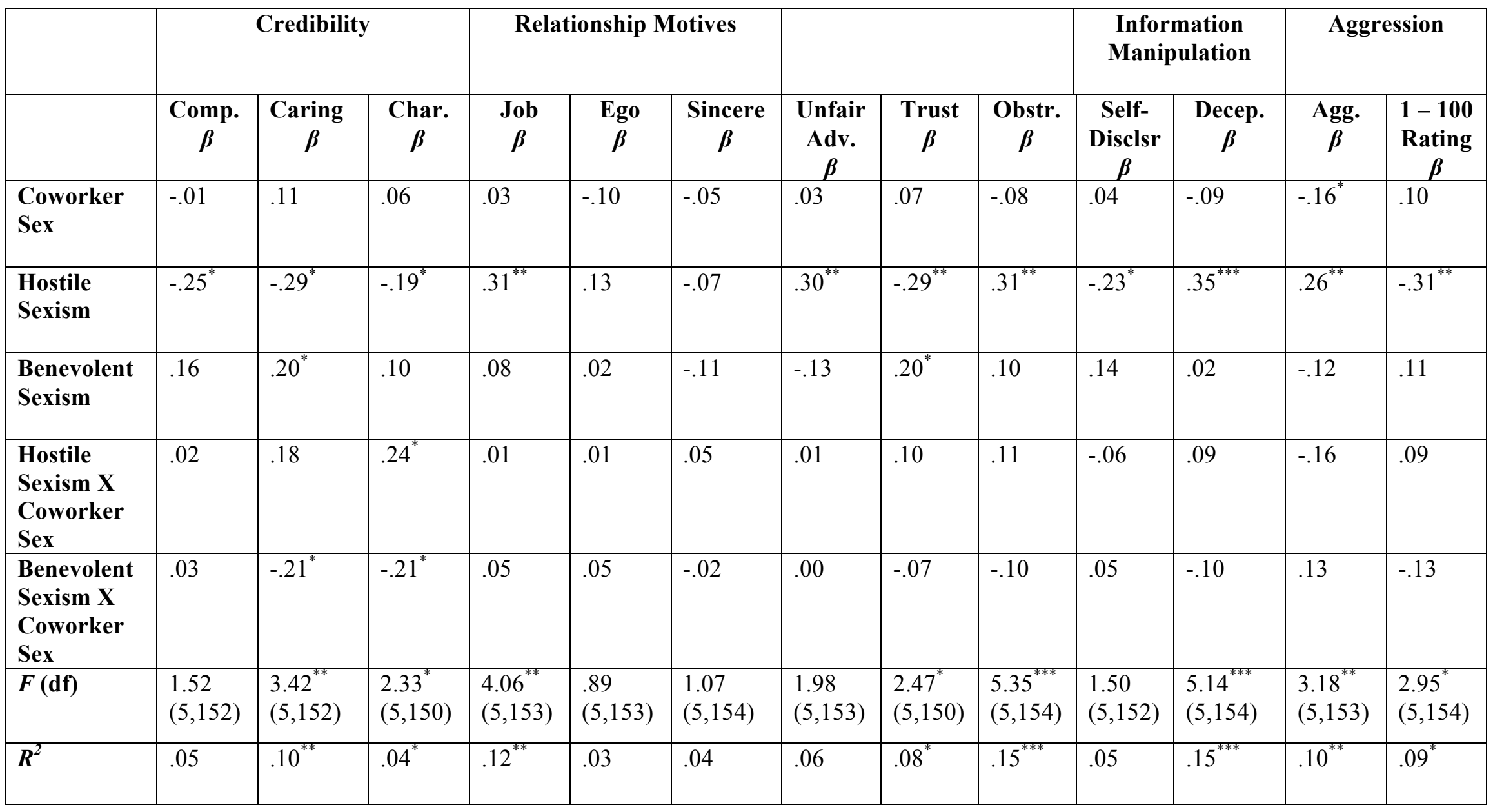

Note. ${ }^{* * *} p<.001 ;{ }^{* *} p<.01 ;{ }^{*} p<.05$; Note: Coworker sex coded $1=$ Male; $2=$ Female 
Hypotheses 7 and 8: Status dynamic of the relationship. Hypothesis seven predicted that organizational members in cross-sex workplace friendships with a superior would be a) perceived as less credible, more driven by job and ego motives and less by sincere motives, and receiving more unfair advantages; b) trusted less; and c) more likely to be the targets of their coworkers' obstructionism, information manipulation, and aggression than would organizational members in cross-sex workplace friendships with a peer or a subordinate. Hypothesis eight predicted that sexism would interact with the status dynamic of cross-sex workplace friendships to affect a) perceptions of credibility, relationship motives, and unfair advantages; b) trust; and c) obstructionism, information manipulation, and aggression such that the differences in these outcomes between cross-sex workplace friendships with superiors versus peers or subordinates would be greater for more sexist versus less sexist individuals. To analyze hypotheses seven and eight a series of multiple linear regression analyses were conducted with status dynamic, benevolent sexism, hostile sexism, the interaction term for status dynamic and benevolent sexism, and the interaction term for status dynamic and hostile sexism were entered as predictors and competence, character, caring, ego motives, job motives, sincere motives, unfair advantages, trust, obstructionism, self-disclosure, deception, aggression, and the single-item employee rating score entered as criterion variables in the regressions.

Regarding hypothesis seven, results indicate that status dynamic predicted the ego motive at a statistically significant level, $\beta=.26, p=.004, F(5,154)=2.57, R^{2}=.08, p=.029$, with individuals in a friendship with a peer or subordinate being more likely to be perceived as having an ego motive for that relationship than those in friendships with a superior, a result opposite in direction of the hypothesis. No other relationships were statistically significant. As such, hypothesis seven was not supported. 
Regarding hypothesis eight, only hostile sexism interacted with status dynamic to predict self-disclosure, $\beta=-.18, p=.043, F(5,153)=2.45, R^{2}=.08, p=.037$. That is, more sexist respondents reported more honest and accurate self-disclosure with individuals who were friends with their superior than those who were friends with subordinates or peers. No other results were statistically significant. As such, hypothesis eight was not supported.

In general, results indicate that although 8 of the 12 multiple regression models were statistically significant, hostile sexism was the primary predictor of the criterion variables. All results for hypotheses seven and eight can be found in Table 27 . 
Table 27

Study 3: Results of Hypotheses 7 and 8

\begin{tabular}{|c|c|c|c|c|c|c|c|c|c|c|c|c|c|}
\hline & \multicolumn{3}{|c|}{ Credibility } & \multicolumn{3}{|c|}{ Relationship Motives } & \multirow[b]{2}{*}{$\begin{array}{c}\text { Unfair } \\
\beta\end{array}$} & \multirow[b]{2}{*}{$\begin{array}{c}\text { Trust } \\
\beta\end{array}$} & \multirow[b]{2}{*}{$\begin{array}{c}\text { Obstr. } \\
\beta\end{array}$} & \multicolumn{2}{|c|}{$\begin{array}{l}\text { Information } \\
\text { Manipulation }\end{array}$} & \multicolumn{2}{|c|}{ Aggression } \\
\hline & $\underset{\beta}{\text { Comp. }}$ & $\begin{array}{c}\text { Caring } \\
\beta\end{array}$ & $\underset{\beta}{\text { Char. }}$ & $\begin{array}{c}\text { Job } \\
\beta\end{array}$ & $\begin{array}{c}\text { Ego } \\
\beta\end{array}$ & $\begin{array}{c}\text { Sincere } \\
\beta\end{array}$ & & & & $\begin{array}{c}\text { Self- } \\
\text { Dis. } \\
\beta\end{array}$ & $\begin{array}{c}\text { Decept. } \\
\beta\end{array}$ & $\underset{\beta}{\text { Agg. }}$ & $\begin{array}{c}1-100 \\
\text { Rating } \\
\beta\end{array}$ \\
\hline $\begin{array}{l}\text { Status } \\
\text { Dynamic }\end{array}$ & .06 & -.04 & .01 & -.10 & $.26^{* *}$ & .17 & -.14 & -.03 & .00 & -.02 & -.02 & .05 & -.10 \\
\hline $\begin{array}{l}\text { Hostile } \\
\text { Sexism }\end{array}$ & $-.25^{*}$ & $-.27^{* *}$ & -.17 & $.29^{* *}$ & .08 & -.09 & $.31^{* *}$ & $-.29^{* *}$ & $.35^{* * *}$ & $.24^{*}$ & $.39^{* * *}$ & $.27^{*}$ & $-.29^{* *}$ \\
\hline $\begin{array}{l}\text { Benevolent } \\
\text { Sexism }\end{array}$ & .17 & .17 & .07 & .09 & -.01 & -.13 & -.14 & $.19^{*}$ & .06 & $.19^{*}$ & -.02 & -.11 & .11 \\
\hline $\begin{array}{l}\text { Hostile } \\
\text { Sexism X } \\
\text { Status } \\
\text { Dynamic }\end{array}$ & -.07 & .0 & -.05 & .03 & .08 & -.04 & .09 & -.03 & -.01 & $-.18^{*}$ & -.01 & .01 & -.05 \\
\hline $\begin{array}{l}\text { Benevolent } \\
\text { Sexism X } \\
\text { Status } \\
\text { Dynamic }\end{array}$ & -.03 & -.05 & -.04 & .01 & .11 & .11 & -.06 & -.03 & -.07 & .07 & -.08 & -.04 & .03 \\
\hline$F(\mathrm{df})$ & $\begin{array}{l}1.90 \\
(5,152)\end{array}$ & $\begin{array}{l}1.90 \\
(5,153)\end{array}$ & $\begin{array}{l}.93 \\
(5,151 \\
) \\
\end{array}$ & $\begin{array}{l}4.45^{* *} \\
(5,154)\end{array}$ & $\begin{array}{l}2.57^{* *} \\
(5,154)\end{array}$ & $\begin{array}{l}2.30^{*} \\
(5,155)\end{array}$ & $\begin{array}{l}3.22^{* *} \\
(5,154)\end{array}$ & $\begin{array}{l}2.12 \\
(5,151)\end{array}$ & $\begin{array}{l}4.94^{* * *} \\
(5,155)\end{array}$ & $\begin{array}{l}2.45^{*} \\
(5,153)\end{array}$ & $\begin{array}{l}4.79^{* * *} \\
(5,155)\end{array}$ & $\begin{array}{l}1.85 \\
(5,154)\end{array}$ & $\begin{array}{l}2.56^{*} \\
(5,155)\end{array}$ \\
\hline$R^{2}$ & .06 & .06 & .03 & $.13^{* *}$ & $.05^{* *}$ & $.07^{*}$ & $.10^{* *}$ & .07 & $.14^{* * *}$ & $.08^{*}$ & $.14^{* * *}$ & .06 & $.08^{*}$ \\
\hline
\end{tabular}

Note. ${ }^{* * *} p<.001 ;{ }^{* *} p<.01 ;{ }^{*} p<.05$; Status Dynamic coded as $1=$ Friends with superior; $2=$ Friends with peer or subordinate 
Research question 6: Interactions. Research question six asked if type of workplace relationship, sex composition of the relationship, sex of the peer being reported on, the status dynamic of the relationship, and sexism would interact to affect perceptions of a) credibility, relationship motives, and unfair advantages; b) trust; and c) obstructionism, information manipulation, and aggression. Because the relationship type and sex composition of the relationship did not vary in Study 3 (all relationships were cross-sex workplace friendships), interactions concerning these variables were not assessed here. To answer research question six, a multiple regression was conducted with a single interaction term (sex of the peer being reported on X status dynamic of the relationship X benevolent sexism X hostile sexism) entered as a predictor, and competence, character, caring, job motives, ego motives, sincere motives, unfair advantages, trust, obstructionism, deception, self-disclosure, the single-item aggression rating and the aggression scale entered as the criterion variables. Results indicate that the interaction between sex composition of the relationship, sex of the peer being reported on, the status dynamic of the relationship, and benevolent and hostile sexism was a statistically significant predictor of the sincere motive, $\beta=.25, p=.002, F(1,154)=10.11, R^{2}=.06, p=$ .002 . Results of the regressions can be found in Table 28 . 
Table 28

Study 3: Results of Research Question 6

\begin{tabular}{|c|c|c|c|c|c|c|c|c|c|c|c|c|c|}
\hline & \multicolumn{3}{|c|}{ Credibility } & \multicolumn{3}{|c|}{ Relationship Motives } & \multirow[b]{2}{*}{$\begin{array}{c}\text { Unfair } \\
\beta\end{array}$} & \multirow[b]{2}{*}{$\underset{\beta}{\text { Trust }}$} & \multirow[b]{2}{*}{$\begin{array}{c}\text { Obstr. } \\
\beta\end{array}$} & \multicolumn{2}{|c|}{$\begin{array}{l}\text { Information } \\
\text { Manipulation }\end{array}$} & \multicolumn{2}{|c|}{ Aggression } \\
\hline & $\underset{\beta}{\text { Comp. }}$ & $\underset{\beta}{\text { Caring }}$ & $\begin{array}{c}\text { Char. } \\
\beta\end{array}$ & $\begin{array}{c}\text { Job } \\
\beta\end{array}$ & $\begin{array}{c}\text { Ego } \\
\beta\end{array}$ & $\begin{array}{c}\text { Sincere } \\
\beta\end{array}$ & & & & $\begin{array}{c}\text { Self- } \\
\text { Dis. } \\
\beta\end{array}$ & $\begin{array}{c}\text { Decept. } \\
\beta\end{array}$ & $\underset{\beta}{\text { Agg. }}$ & $\begin{array}{c}1-100 \\
\text { Rating } \\
\beta\end{array}$ \\
\hline $\begin{array}{l}\text { Peer Sex X } \\
\text { Status } \\
\text { Dynamic X } \\
\text { Benevolent } \\
\text { Sexism X } \\
\text { Hostile } \\
\text { Sexism }\end{array}$ & -.01 & .02 & .06 & .03 & .12 & $.25^{* *}$ & .02 & -.05 & .05 & -.10 & .05 & .03 & -.10 \\
\hline $\begin{array}{l}F \\
(d f)\end{array}$ & $\begin{array}{l}1.41 \\
(1,152)\end{array}$ & $\begin{array}{l}.03 \\
(1,152)\end{array}$ & $\begin{array}{l}.60 \\
(1,150 \\
)\end{array}$ & $\begin{array}{l}.16 \\
(1,15 \\
3) \\
\end{array}$ & $\begin{array}{l}2.16 \\
(1,153)\end{array}$ & $\begin{array}{l}10.11^{* *} \\
(1,154)\end{array}$ & $\begin{array}{l}2.30 \\
(1.153)\end{array}$ & $\begin{array}{l}.30 \\
(1,150)\end{array}$ & $\begin{array}{l}.45 \\
(1,154)\end{array}$ & $\begin{array}{l}1.43 \\
(1,152)\end{array}$ & $\begin{array}{l}.37 \\
(1,154)\end{array}$ & $\begin{array}{l}.12 \\
(1,153)\end{array}$ & $\begin{array}{l}1.59 \\
(5,154)\end{array}$ \\
\hline $\boldsymbol{R}^{2}$ & .01 & .00 & .01 & .01 & .01 & $.06^{* *}$ & $.10^{* *}$ & .02 & .00 & .01 & .00 & .01 & .01 \\
\hline
\end{tabular}

Note. ${ }^{* * *} p<.001 ;{ }^{* *} p<.01 ;{ }^{*} p<.05$ 


\section{Hypotheses 9 and 10: Trust, motives, and unfair advantages correlations. Hypothesis}

nine predicted that trust and perceptions of sincere motives would be negatively related to obstructionism, information manipulation, and aggression. Results of Pearson correlations (see Table 19) indicate no relationship between the sincere motive and obstructionism or information manipulation, though the sincere motive and the aggression measure $(r=-.23, p<.01)$ were correlated at a statistically significant level. Trust in the coworker was related to obstructionism $(r=-.45, p<.01)$, self-disclosure $(r=.48, p<.01)$, deception $(r=-.52, p<.01$, and the aggression measure $(r=-.78, p<.01)$ and rating $(r=.49, p<.01)$. Hypothesis nine was partially supported.

Hypothesis ten predicted that perceptions of unfair advantages and ego and job motives would be positively related to obstructionism, information manipulation, and aggression. Results of Pearson correlations (see Table 19) indicate that although the ego motive and aggression were not related, unfair advantages and job and ego motives were positively correlated with obstructionism, information manipulation, and aggression. Overall, hypothesis ten was supported for 14 of the 15 relationships tested.

Additionally, for hypotheses 9 and 10, a series of multiple linear regressions were conducted in order to understand the role of each motive in predicting obstructionism, information manipulation, and aggression. In these regressions, job motives, ego motives, and sincere motives were entered as predictors and obstructionism, self-disclosure, deception, the measure of aggression, and the single-item rating measure each served as separate criterion variables. Results of these multiple linear regressions can be found in Table 29. 
Table 29

Study 3: Results of Hypotheses 9 and 10

\begin{tabular}{|l|l|l|l|l|l|}
\hline & & \multicolumn{2}{|c|}{$\begin{array}{c}\text { Information } \\
\text { Manipulation }\end{array}$} & \multicolumn{2}{c|}{ Aggression } \\
\hline & $\begin{array}{c}\text { Obstructionism } \\
\boldsymbol{\beta}\end{array}$ & $\begin{array}{c}\text { Self- } \\
\text { Disclosure } \\
\boldsymbol{\beta}\end{array}$ & $\begin{array}{c}\text { Deception } \\
\boldsymbol{\beta}\end{array}$ & $\begin{array}{c}\text { Aggression } \\
\text { Scale } \\
\boldsymbol{\beta}\end{array}$ & $\begin{array}{c}\text { 1 - 100 } \\
\text { Rating } \\
\boldsymbol{\beta}\end{array}$ \\
\hline Job Motive & $.47^{* * *}$ & $-.19^{*}$ & $.48^{* * *}$ & $.33^{* * *}$ & $-.30^{* * *}$ \\
\hline Ego Motive & $.20^{*}$ & $-.31^{* *}$ & $.19^{*}$ & .18 & -.14 \\
\hline Sincere Motive & $-.18^{*}$ & $.33^{* *}$ & $-.23^{* *}$ & $-.34^{* *}$ & .09 \\
\hline (df) & $\begin{array}{l}26.23^{* * *} \\
(3,166)\end{array}$ & $\begin{array}{l}10.49^{* * *} \\
(3,165)\end{array}$ & $\begin{array}{l}27.71^{* * *} \\
(3,167)\end{array}$ & $\begin{array}{l}15.92^{* * *} \\
(3,166)\end{array}$ & $\begin{array}{l}8.54^{* * *} \\
(3,167)\end{array}$ \\
\hline $\boldsymbol{R}^{2}$ & $.33^{* * *}$ & $.16^{* * *}$ & $.32^{* * *}$ & $.23^{* * *}$ & $.14^{* * *}$ \\
\hline & & & & & \\
\hline
\end{tabular}

Note. $\stackrel{* * *}{p}<.001 ; \stackrel{* *}{p}<.01 ;{ }^{*} p<.05$

Further, a series of regressions were conducted with job, ego and sincere motives, trust, and unfair advantages entered as predictors and obstructionism, self-disclosure, deception, the aggression scale, and the single item aggression rating entered as criterion variables. For results of these regressions, see Table 30. Results indicate that obstructionism and deception were predicted primarily by perceptions of unfair advantages, with trust also a statistically significant predictor. Trust was the strongest predictor of self-disclosure, with the ego and sincere motives also statistically significant predictors. Finally, only trust was a statistically significant predictor of both measures of aggression. 
Table 30

Study 3: Results of Hypothesis 9 and 10 Supplementary Regression Analyses

\begin{tabular}{|c|c|c|c|c|c|}
\hline & & \multicolumn{2}{|c|}{$\begin{array}{l}\text { Information } \\
\text { Manipulation }\end{array}$} & \multicolumn{2}{|c|}{ Aggression } \\
\hline & $\underset{\beta}{\text { Obstructionism }}$ & $\begin{array}{c}\text { Self- } \\
\text { Disclosure } \\
\beta\end{array}$ & $\begin{array}{c}\text { Deception } \\
\beta\end{array}$ & $\begin{array}{c}\text { Aggression } \\
\text { Scale } \\
\beta\end{array}$ & $\begin{array}{c}1-100 \\
\text { Rating } \\
\beta\end{array}$ \\
\hline Job Motive & .16 & .05 & .11 & .07 & -.14 \\
\hline Ego Motive & .13 & $-.24^{* * *}$ & .10 & .02 & -.04 \\
\hline Sincere Motive & -.09 & $.23^{* * *}$ & -.12 & -.14 & -.03 \\
\hline Trust & $-.18^{* * *}$ & $.33^{* * *}$ & $-.23^{* * *}$ & $-.74^{* * *}$ & $.45^{* * *}$ \\
\hline $\begin{array}{l}\text { Unfair } \\
\text { Advantages }\end{array}$ & $.36^{* * *}$ & -.16 & $.42^{* * *}$ & -.02 & .02 \\
\hline $\begin{array}{l}F \\
(d f)\end{array}$ & $\begin{array}{l}24.21^{* * *} \\
(5,160)\end{array}$ & $\begin{array}{l}11.97^{* * *} \\
(5,159)\end{array}$ & $\begin{array}{l}30.18^{* * *} \\
(5,161)\end{array}$ & $\begin{array}{l}55.10^{* * *} \\
(5,160)\end{array}$ & $\begin{array}{l}11.67^{* * *} \\
(5,165)\end{array}$ \\
\hline$R^{2}$ & $.44^{* * *}$ & $.28^{* * *}$ & $.49^{* * *}$ & $.64^{* * * *}$ & $.27^{* * *}$ \\
\hline
\end{tabular}

Note. ${ }^{* * *} p<.001 ;{ }^{* *} p<.01 ;{ }^{*} p<.05$

Hypothesis 11: Mediation. Hypothesis 11 predicted that trust, motives, and unfair advantages would mediate the relationships between the independent variables (relationship type, sex composition, sex of peer reported on, status dynamic) and obstructionism, information manipulation, and aggression. Because the relationship type and sex composition of the relationship did not vary in Study 3 (all relationships were cross-sex workplace friendships), only sex of peer reported on and status dynamic were included as independent variables. Regarding sex of the peer, results of hypothesis five indicated that peer sex was not related to trust, unfair advantages, or motives, so mediation was not tested. 
With regard to status dynamic, results of hypothesis seven indicate that status dynamic was only related to the ego motive. As such, the ego motive was the only potential mediator. Results of hypothesis 10 indicate that the ego motive was related to obstructionism, deception, self-disclosure, and the 1-item rating of aggression. Path analyses were conducted using the AMOS software package. Model fit was assessed through the chi-square statistic, as well as the Root Mean Square Error of Approximation (RMSEA), and the Bentler and Bonett normed fit index (NFI), comparative fit index (CFI), and relative fit index (RFI). Models that had nonstatistically significant chi-squares, RMSEAs above .08, and/or NFI, CFI, and/or RFI values in excess of .90 were considered good fits to the data.

Results of these analyses indicated that all models provided very good fits for the data, $\chi^{2}$ $(1)=03, p=.87 ; \mathrm{RMSEA}=00, \mathrm{NFI}=.99, \mathrm{CFI}=1.0, \mathrm{RFI}=.99($ obstructionism $) ; \chi^{2}(1)=03, p=$ $.86 ; \mathrm{RMSEA}=.00, \mathrm{NFI}=.99, \mathrm{CFI}=1.0, \mathrm{RFI}=.98($ deception $) ; \chi^{2}(1)=1.59, p=.21 ; \mathrm{RMSEA}$ $=.06, \mathrm{NFI}=.89, \mathrm{CFI}=.93, \mathrm{RFI}=.32($ self-disclosure $) ;$ and $\chi^{2}(1)=.01, p=.93 ; \mathrm{RMSEA}=.00$, $\mathrm{NFI}=1.0, \mathrm{CFI}=1.0, \mathrm{RFI}=.99$ (aggression rating). Results suggest that organizational members perceive coworkers in friendships with subordinates or peers versus superiors as being driven more by ego motives, which leads them to obstruct the work of these coworkers more, deceive them more, self-disclose less honestly and accurately to them, and rate these coworkers lower.

\section{Research questions 7 and 8: Credibility correlations and mediation. Research} question seven concerned the relationships between credibility and obstructionism, information manipulation, and aggression. Results of Pearson correlations (see Table 19) indicate that all three dimensions of credibility (competence, character and caring) were negatively related to obstructionism, information manipulation, and aggression. 
Additionally, for research question seven, a series of multiple linear regressions were conducted in order to understand the role of each dimension of credibility in predicting obstructionism, information manipulation, and aggression. In these regressions, competence, character, and caring were entered as predictors and obstructionism, self-disclosure, deception, the measure of aggression, and the single-item rating measure were separate criterion variables in each regression. Results of these multiple linear regressions can be found in Table 31.

Table 31

Study 3: Results of Research Question 7

\begin{tabular}{|l|l|l|l|l|l|}
\hline & \multicolumn{4}{|c|}{ Information Manipulation } & \multicolumn{2}{c|}{ Aggression } \\
& $\begin{array}{c}\text { Obstructionism } \\
\boldsymbol{\beta}\end{array}$ & $\begin{array}{c}\text { Self- } \\
\text { Disclosure } \\
\boldsymbol{\beta}\end{array}$ & $\begin{array}{c}\text { Deception } \\
\boldsymbol{\beta}\end{array}$ & $\begin{array}{c}\text { Aggression } \\
\text { Scale } \\
\boldsymbol{\beta}\end{array}$ & $\begin{array}{c}\mathbf{1}-100 \\
\text { Rating } \\
\boldsymbol{\beta}\end{array}$ \\
\hline Competence & $-.35^{* * *}$ & $.28^{* *}$ & $-.42^{* * *}$ & $-.21^{* *}$ & .12 \\
\hline Character & -.27 & -.21 & -.25 & $-.40^{* * *}$ & $.39^{*}$ \\
\hline Caring & .07 & $.54^{* * *}$ & .03 & $-.31^{* * *}$ & .08 \\
\hline $\begin{array}{l}\boldsymbol{F} \\
(\mathbf{d f})\end{array}$ & $20.92^{* * *}$ & $\begin{array}{l}24.88^{* * *} \\
(3,162)\end{array}$ & $\begin{array}{l}30.71^{* * *} \\
(3,164)\end{array}$ & $\begin{array}{l}122.08^{* * *} \\
(3,163)\end{array}$ & $\begin{array}{l}23.04^{* * *} \\
(3,164)\end{array}$ \\
\hline $\boldsymbol{R}^{2}$ & $.28^{* * *}$ & $.31^{* * *}$ & $.36^{* * *}$ & $.70^{* * *}$ & $.30^{* * *}$ \\
\hline
\end{tabular}

Note. $* * * p<.001 ; * * p<.01 ; * p<.05$

Research question eight asked if credibility mediated the relationships between the independent variables (relationship type, sex composition, sex of peer reported on, status dynamic) and obstructionism, information manipulation, and aggression. Because the relationship type and sex composition of the relationship did not vary in Study 3 (all relationships were cross-sex workplace friendships), mediation concerning these variables was 
not assessed here. Results of hypotheses five and seven indicate that the independent variables were not related to credibility, therefore, mediation could not have occurred.

Post-hoc analyses. The results of Study 1 lead to the creation of measures assessing suspected romance and workplace problems. As such, the analyses conducted for the research questions and hypotheses were conducted with suspected romance and workplace problems where relevant.

Results indicate that coworker sex did not predict suspected romance or workplace problems and sexism did not interact with coworker sex to predict suspected romance or workplace problems. Results for these post-hoc analyses can be found in Table 32 .

Table 32

Study 3: Coworker Sex and Sexism as Predictors of Suspected Romance and Workplace Problems

\begin{tabular}{|l|l|l|}
\hline & \multicolumn{1}{|c|}{$\begin{array}{c}\text { Suspected } \\
\text { Romance } \\
\boldsymbol{\beta}\end{array}$} & \multicolumn{1}{|c|}{$\begin{array}{c}\text { Workplace } \\
\text { Problems } \\
\boldsymbol{\beta}\end{array}$} \\
\hline Coworker Sex & -.12 & -.10 \\
\hline Hostile Sexism & $.23^{*}$ & $.48^{*}$ \\
\hline Benevolent Sexism & .11 & -.17 \\
\hline Hostile Sexism X Coworker Sex & .05 & -.08 \\
\hline Benevolent Sexism X Coworker Sex & .02 & .12 \\
\hline $\begin{array}{l}\boldsymbol{F} \\
(\mathbf{d})\end{array}$ & $\begin{array}{l}3.24^{* * *} \\
(5,153)\end{array}$ & $\begin{array}{l}6.88^{* * *} \\
(5,153)\end{array}$ \\
\hline $\boldsymbol{R}^{2}$ & $.01^{* * *}$ & $.12^{* * *}$ \\
\hline
\end{tabular}

Note. $\stackrel{* * *}{p}<.001 ;{ }^{* *} p<.01 ; \stackrel{*}{p}<.05$; Coworker sex coded $1=$ Male; 2 = Female 
Results also indicate that status dynamic of the relationship did not predict suspected romance or workplace problems and sexism did not interact with status dynamic of the relationship to predict suspected romance or workplace problems. Results for these post-hoc analyses can be found in Table 33 .

Table 33

Study 3: Status Dynamic and Sexism as Predictors of Suspected Romance and Workplace Problems

\begin{tabular}{|l|l|l|}
\hline & \multicolumn{1}{|c|}{$\begin{array}{c}\text { Suspected } \\
\text { Romance }\end{array}$} & $\begin{array}{l}\text { Workplace } \\
\text { Problems }\end{array}$ \\
\hline Status Dynamic & .12 & .02 \\
\hline Hostile Sexism & $.23^{*}$ & $.46^{* * *}$ \\
\hline Benevolent Sexism & .08 & $-.17^{*}$ \\
\hline Hostile Sexism X Coworker Sex & -.08 & .03 \\
\hline Benevolent Sexism X Coworker Sex & .06 & .05 \\
\hline $\boldsymbol{F}$ & 3.56 & $6.19^{* *}$ \\
$(\mathbf{d f})$ & $(5,154)$ & $(5,154)$ \\
\hline $\boldsymbol{R}^{2}$ & .07 & $.17^{* *}$ \\
\hline
\end{tabular}

Note. ${ }^{* *} p<.001 ; * * p<.01 ; * p<.05$; Status Dynamic coded as $1=$ Friends with superior; $2=$ Friends with peer or subordinate

Results indicate that the interaction between sex composition of the relationship, sex of the peer being reported on, the status dynamic of the relationship, and benevolent and hostile 
sexism was not a statistically significant predictor of either suspected romance or workplace problems. Results of the regressions can be found in Table 34.

Table 34

Study 3: The Interaction of Coworker Sex, Status Dynamic, and Sexism as a Predictor of Suspected Romance and Workplace Problems

\begin{tabular}{|l|l|l|}
\hline & $\begin{array}{c}\text { Suspected } \\
\text { Romance } \\
\boldsymbol{\beta}\end{array}$ & $\begin{array}{c}\text { Workplace } \\
\text { Problems } \\
\boldsymbol{\beta}\end{array}$ \\
\hline $\begin{array}{l}\text { Peer Sex X Status Dynamic X } \\
\text { Benevolent Sexism X Hostile Sexism }\end{array}$ & .05 & .10 \\
\hline $\boldsymbol{F}$ & .35 & 1.49 \\
$(\mathbf{d f})$ & $(1,153)$ & $(1,153)$ \\
\hline $\boldsymbol{R}^{2}$ & .02 & .01 \\
\hline Note. $^{* * *} p<.001 ;{ }^{* *} p<.01 ;{ }^{*} p<.05$ & & \\
\hline
\end{tabular}

Results of Pearson correlations indicate that suspected romance was related to trust, unfair advantages, and all three workplace friendship motives. Trust, unfair advantages, and the job and ego motives were related to perceptions that the friendship caused workplace problems. Correlations can be found in Table 19. Results of a series of linear regressions indicate that the ego motive was the only statistically significant predictor of suspected romance, and the job motive was the strongest predictor of workplace problems, with ego and sincere motives also statistically significant predictors. Results of these linear regressions can be found in Table 35 . 
Table 35

Study 3: Friendship Motives as Predictors of Suspected Romance and Workplace Problems

\begin{tabular}{|l|l|l|}
\hline & $\begin{array}{c}\text { Suspected } \\
\text { Romance } \\
\boldsymbol{\beta}\end{array}$ & $\begin{array}{c}\text { Workplace } \\
\text { Problems } \\
\boldsymbol{\beta}\end{array}$ \\
\hline Job Motive & .10 & $.45^{* * *}$ \\
\hline Ego Motive & $.60^{* * *}$ & $.40^{* * *}$ \\
\hline Sincere Motive & -.11 & $-.21^{* *}$ \\
\hline $\begin{array}{l}\boldsymbol{F} \\
(\mathbf{d f})\end{array}$ & $27.62^{* * *}$ & $\begin{array}{l}40.18^{* * *} \\
(3,161)\end{array}$ \\
\hline $\boldsymbol{R}^{2}$ & $(3,159)$ & $.43^{* * *}$ \\
\hline & $.35^{* * *}$ & \\
\hline
\end{tabular}

Note. $\stackrel{* * *}{p}<.001 ; \stackrel{* *}{p}<.01 ;{ }^{*} p<.05$

Results of a series of regressions with job, ego, and sincere motives, trust, and unfair advantages entered as predictors indicate that suspected romance was only predicted by the ego motive. Workplace problems were predicted primarily by the ego motive, with trust and the job motive also statistically significant predictors. For results of these regressions, see Table 36. 
Table 36

Study 3: Friendship Motives, Trust, and Unfair Advantages as Predictors of Suspected Romance and Workplace Problems

\begin{tabular}{|l|l|l|}
\hline & $\begin{array}{c}\text { Suspected } \\
\text { Romance } \\
\boldsymbol{\beta}\end{array}$ & $\begin{array}{c}\text { Workplace } \\
\text { Problems } \\
\boldsymbol{\beta}\end{array}$ \\
\hline Job Motive & .09 & $.27^{* * *}$ \\
\hline Ego Motive & $.59^{* * *}$ & $.32^{* * *}$ \\
\hline Sincere Motive & -.09 & -.11 \\
\hline Trust & -.05 & $-.31^{* * *}$ \\
\hline Unfair Advantages & -.01 & .10 \\
\hline $\begin{array}{l}\boldsymbol{F} \\
(\text { df) }\end{array}$ & $15.75^{* * *}$ & $\begin{array}{l}30.70^{* * *} \\
(5,156)\end{array}$ \\
\hline $\boldsymbol{R}^{2}$ & $(5,154)$ & $.50^{* * *}$ \\
\hline
\end{tabular}

Note. $\stackrel{* * *}{p}<.001 ;{ }^{* *} p<.01 ;{ }^{*} p<.05$

Regarding sex of the peer, results of hypothesis five indicated that peer sex was not related to motives, trust, or unfair advantages. Therefore, mediation was not tested. With regard to status dynamic, results of hypothesis seven indicate that status dynamic was related to the ego motive. Post hoc analyses also revealed that the ego motive was related to both suspected romance and workplace problems. Therefore, ego motives as the mediator of the relationship between status dynamic and suspected romance and between status dynamic and workplace problems was tested. 
Results of these analyses indicated that both models provided very good fits for the data, with $\chi^{2}(1)=.02, p=.90 ;$ RMSEA $=.00, \mathrm{NFI}=1.00, \mathrm{CFI}=1.00, \mathrm{RFI}=1.00$; for suspected romance; and $\chi^{2}(1)=.89 p=.35 ; \mathrm{RMSEA}=.00, \mathrm{NFI}=.97, \mathrm{CFI}=1.00, \mathrm{RFI}=.86$; for workplace problems. Results suggest that organizational members perceive coworkers in friendships with subordinates or peers as being more driven by ego motives, which leads organizational members to suspect friendships with subordinates or peers to be romantic to a greater extent and to cause more workplace problems.

Results of Pearson correlations (see Table 19) indicate that all three dimensions of credibility (competence, character and caring) were negatively related to both suspected romance and workplace problems. However, results of a multiple linear regressions indicate that the model for competence, character, and caring did not predict suspected romance. The credibility model did predict workplace problems. Only competence was a statistically significant predictor of workplace problems. Perceptions of coworker competence negatively predicted workplace problems caused by the coworker's friendship. Results of these multiple linear regressions can be found in Table 37. 
Table 37

Study 3: Credibility as a Predictor of Suspected Romance and Workplace Problems

\begin{tabular}{|l|l|l|}
\hline & $\begin{array}{c}\text { Suspected } \\
\text { Romance } \\
\boldsymbol{\beta}\end{array}$ & $\begin{array}{c}\text { Workplace } \\
\text { Problems } \\
\boldsymbol{\beta}\end{array}$ \\
\hline Competence & -.09 & $-.29^{* * *}$ \\
\hline Character & -.01 & -.16 \\
\hline Caring & -.14 & -.17 \\
\hline $\boldsymbol{F}$ & 2.36 & $22.17^{* * *}$ \\
$(\mathbf{d f})$ & $(3,151)$ & $(3,153)$ \\
\hline $\boldsymbol{R}^{2}$ & .05 & $.31^{* * *}$ \\
\hline
\end{tabular}

Note. $* * * p<.001 ; * * p<.01 ; * p<.05$

Regarding sex of the peer, results indicate that peer sex was not related to credibility, therefore, mediation was not tested. With regard to status dynamic, results indicate that status dynamic was not related to credibility, so credibility as a mediator was not tested.

Summary of results. The data in Study 3 were used to examine hypotheses 5, 6 7, 8 9, 10 , and 11 , as well as research questions 6,7 , and 8 . Results indicate respondents reported perceiving that male organizational members receive more aggressive behavior from their workplace relationships than female organizational members do, which is counter to hypothesis five. Regarding hypothesis six, benevolent sexism interacted with coworker sex to predict both character and caring, while hostile sexism also interacted with coworker sex to predict character. Hypothesis seven was not supported, with coworkers in a friendship with a peer or subordinate being perceived as having a stronger ego motive for that relationship than those in friendships 
with a superior, a result in the opposite direction of the hypothesis. Hypothesis eight was not supported, with more sexist respondents reporting more honest and accurate self-disclosure with coworkers who were friends with their superior than with those who were friends with subordinates or peers. Hypothesis nine was partially supported, with 7 of the 10 tested relationships reaching statistical significance and hypothesis 10 was partially supported, with 14 of the 15 tested relationships reaching statistical significance. Relationships that did not achieve statistical significance included the relationships between the sincere motive and obstructionism, the sincere motive and deception, the sincere motive and self-disclosure, and the ego motive and the aggression scale. Hypothesis eleven was supported, with the ego motive mediating the relationships between status dynamic of the relationship and obstructionism, deception, selfdisclosure, and rating. Results of research question six indicate that the interaction between sex composition of the relationship, sex of the peer being reported on, the status dynamic of the relationship, and benevolent and hostile sexism was a statistically significant predictor of the sincere motive. Results of research question seven indicate that all three dimensions of credibility (competence, character and caring) were negatively related to obstructionism, information manipulation, and aggression. For research question eight, because the independent variables were not related to credibility, mediation could not have occurred.

Finally, results of post-hoc analyses suggest that coworker sex did not predict suspected romance or workplace problems and sexism did not interact with coworker sex to predict suspected romance or workplace problems. Further, status dynamic of the relationship did not predict suspected romance or workplace problems and sexism did not interact with status dynamic of the relationship to predict suspected romance or workplace problems. The interaction of sex composition of the relationship, sex of the peer being reported on, the status dynamic of 
the relationship, and benevolent and hostile sexism did not predict either suspected romance or workplace problems. Post-hoc analyses also revealed that suspected romance was related to trust, unfair advantages, and all three workplace friendship motives. Trust, unfair advantages, and the job and ego motives were related to perceptions that the friendship caused workplace problems. The ego motive mediated the relationships between status dynamic of the relationship and both suspected romance and workplace problems. Additionally, all three dimensions of credibility (competence, character and caring) were negatively related to both suspected romance and workplace problems.

\section{Discussion}

Status dynamic of relationship. Regarding the status dynamic of the relationship, results indicated that, overall, organizational members did not perceive or respond to coworkers based on the status dynamic of the relationship being reported on. Only perceptions of the ego motive differed, with individuals in relationships with superiors being perceived as being less driven by ego than those in relationships with peers or subordinates. The ego motive, as developed by Malachowski et el. (2012), based on Quinn (1977), refers to entering into relationships for "excitement, adventure, and sexual experience” (Malachowski et el., 2012, p. 360), though in the current investigation, the item involving sexual experience was omitted as it was deemed irrelevant for workplace friendships. One explanation for this result, which is counter to the hypothesis, is that individuals would be inclined to enter into a relationship with a peer for the excitement of having a friend at work. In short, organizational members do not perceive that their coworkers become friends with opposite-sex superiors for fun, excitement, or adventure. 
Additionally, perceived ego motive was found to mediate the relationships between the status dynamic of the relationship and obstructionism, deception, self-disclosure, and aggression. Individuals in cross-sex friendships with subordinates or peers were seen as being more driven by ego motives, which caused respondents to behave more antisocially towards these individuals. While, as mentioned previously, the relationship between status dynamic and the ego motive was counter to the hypothesis, the result that the ego motive mediated the relationship between the status dynamic of the relationship and antisocial behaviors supports previous workplace romance research that suggests that romances perceived to be motivated by ego or job motives are perceived less positively than are relationships attributed to love (sincere) motives (Dillard \& Broetzmann, 1989). Further, individuals who believe that their coworkers are in a friendship for less than sincere motives might be inclined to believe that those individuals have ulterior motives, perhaps more self-serving, for the friendship.

Sex of the peer reported on. In terms of the sex of the coworker in the cross-sex workplace relationship being reported on by the respondent, results indicated that, in general, perceptions of men and women did not differ. Results did suggest that, counter to the hypothesis, male organizational members in workplace relationships are more likely to be the targets of aggressive behavior from their coworkers than are female organizational members. Past research supporting the hypothesized relationship indicates that women in workplace romances are perceived more negatively than men (Dillard, 1987 in Pierce, Bryne, \& Aquinis, 1996; Gillen \& Chory,2014a Horan \& Chory, 2011, 2013; Jones, 1999; Malachowski et al., 2012; Sias, 2009), that female versus male workplace romance partners are perceived as receiving more unfair advantages (Gillen \& Chory, 2014a), and that coworkers behave in negative or antisocial ways toward women in workplace relationships (Gillen \& Chory, 2014a; Horan \& Chory, 2013; Jones, 
1999). These antisocial reactions may be attempts to restore the inequity caused by unfair advantages. Given the previously mentioned finding of this dissertation that women versus men were perceived as receiving more unfair advantages by virtue of their workplace relationships, it is especially interesting that men were perceived as receiving more aggressive behavior. One possible explanation for this inconsistent finding is the effect of social norms regarding aggressive behavior towards women. As noted in the discussion of the benevolent sexism scale, the stereotype exists that women are more sensitive than men, and as such, should be protected. It is possible that organizational members choose different, perhaps more subtle, behaviors when attempting to restore equity after perceiving that women receive unfair advantages. They may do this in order to avoid any negative backlash from violating this social norm. An additional explanation for this finding may lie in the perceptions individuals hold regarding who might be a threat in the organization. As organizational members could perceive women as being unable to move upward easily in the organization, they could perceive female coworkers as less threatening, and therefore, it being less necessary to behave aggressively towards them in the workplace.

Sexism. Results indicate that, regarding the status dynamic of the relationship, more hostile sexist organizational members reported more honest and accurate self-disclosure with coworkers who were friends with their superior than with those who were friends with subordinates or peers. This result is counter to the hypothesized notion that individuals would be more honest and accurate in their self-disclosures with coworkers in cross-sex friendships with peers because individuals may be inclined to believe that coworkers in cross-sex friendships with superiors are more likely to receive unfair advantages by virtue of that friendship. It is possible that sexist individuals are more inclined to be honest and accurate in their self-disclosures with 
coworkers in cross-sex workplace friendship with superiors because they understand that, as noted in Study 1, that cross-sex friends share information. Therefore, they may be inclined to self-disclose in the hopes that it would get back to the superior, which may make them look more open and honest.

Additionally, regarding the sex of the benevolent sexist organizational members perceive female, but not male, coworkers in workplace relationships as lower in caring and character. This may be related to perceptions that women are in workplace relationships as a means of upward movement in the organization because, due to the glass ceiling, they have difficulty doing so on their own (Davies-Netzley, 1998; Ignatius, 2013; Sias, 2008). It could be, then, that organizational members believe that female coworkers are in their workplace friendships for less than sincere or genuine reasons, leading them to perceive these coworkers as having lower character and being less caring. Additionally, results indicate that hostile sexist organizational members perceive men, but not women, in workplace relationships as lower in character. This could be because sexist individuals subscribe to traditional, stereotypical gender roles that often put men on a higher level of worth than women (Glick \& Fiske, 1996). As such, sexist individuals may believe that men that are in workplace relationships are somehow "weak" or lacking character if they need to be connected to others in the organization, especially female coworkers. 


\section{CHAPTER V: DISCUSSION}

The results of the three studies presented in this dissertation provide insight into the perceptions individuals hold of their coworkers in various types of workplace relationships (strictly professional relationships, workplace friendships, and workplace romances), with a focus on the perceptions of coworkers in cross-sex workplace friendships. By employing three unique research methodologies, the studies, when taken together, provide a view of these relationships that have been previously understudied in the Communication Studies discipline.

Research suggests that cross-sex friendships are often perceived as romantic (Afifi \& Burgoon, 1998; Dainton et al., 2003; Elesser \& Peplau, 2006; Guerrero \& Chavez, 2005; Marks, 1994; Messman et al., 2000) and that organizational members in workplace romances tend to be perceived and responded to negatively by coworkers (Cowan \& Horan, 2014, in press; Gillen \& Chory, 2014a; Horan \& Chory, 2009, 2011, 2013; Malachowski, et al., 2012). What has not been studied is the perceptions of the possibility of romance in cross-sex workplace friendships, as well as the general perceptions of and behaviors towards individuals in cross-sex workplace friendships. This dissertation aimed to fill that void in research by examining how cross-sex workplace friendships are perceived by coworkers, and subsequently, how coworkers behave toward individuals in these relationships. The studies were framed using equity theory (Adams, 1965), aiming to understand if specific factors (relationship type, sex composition, sex and status of the peer being reported on) influence perceptions of equity, which in turn influence the specific antisocial behaviors coworkers enact.

\section{Theoretical Implications}

The studies here hypothesized that workplace relationship type, sex composition of the relationship, sex of the peer being reported on, and the organizational status of the peer in the 
friendship relative to his/her friend would be related to coworkers' perceptions of [in] equity, which would be associated with coworkers' non-behavioral and behavioral responses. Nonbehavioral responses related to equity included perceptions of unfair advantages, credibility, relationship motives, and trust, and behavioral equity-restoration responses included obstructionism, information manipulation, and aggression.

In terms of the non-behavioral responses, the results of these studies provided interesting details concerning how individuals perceive their co-workers in relationships. In regards to relationship type, organizational members in professional relationships were perceived as being more motivated by the job and less motivated by ego than were coworkers in friendships or romantic relationships and perceptions of sincere motives were lower for more intimate relationships. Concerning sex of the peer, respondents in Study 2 reported perceiving that women in workplace relationships receive more unfair advantages by virtue of those relationships, consistent with previous research on women in the workplace (e.g., Gillen \& Chory, 2014a; Horan \& Chory, 2011, 2013; Malachowski et al., 2012). In regards to sex composition of the relationship, individuals in same sex relationships were perceived as receiving more unfair advantages than those in cross-sex relationships. This result, which is counter to the hypothesis, may be due to individuals' perceived desire to be supportive of their own sex, with men being perceived as more likely to help other men, and women more likely to help other women. Concerning the status dynamic between the individuals involved in the friendship, individuals in cross-sex workplace friendships with a peer or subordinate were perceived as having higher ego motives for the relationship than were individuals in cross-sex workplace friendships with a superior. This result, which again, is counter to the hypothesized 
relationship, may be due to individuals not perceiving others to be in cross-sex relationships with superiors for excitement or adventure, but instead for alternative motives.

Regarding the behavioral responses to the independent variables, the studies presented here also provided interesting results. Relationship type, sex composition of the relationship, and status of the relationship did not directly predict any of the behavioral responses. It seems then, that when considering the direct relationships, individuals tend not to behave in antisocial ways toward their coworkers in relationships based purely on the type of the relationship, whether it is same or cross sex, or based on the status of the individuals involved (relative to one another). Concerning the sex of the peer, respondents in Study 3 reported that they behaved more aggressively toward their male coworkers in cross-sex workplace friendships. This direct relationship may be due to individuals believing that men are more likely to move ahead at work (and therefore be a direct threat), so they must behave aggressively toward them in order to assert their position at work.

In addition to the relationships between the independent variables and responses to inequity (both behavioral and non-behavioral), results of a series of path analyses provide encouraging support for equity theory. First, results suggest that perceptions of unfair advantages due to the workplace relationship mediated the relationships between both sex of the organizational peer reported on and sex composition of the workplace relationship and coworkers' obstructionism, information manipulation, and aggression concerning the peer. These results may be explained in terms of equity theory. Organizational members perceived female versus male peers in workplace relationships and peers in same-sex versus cross-sex workplace relationships as receiving more unfair advantages, which may be representative of perceptions of inequity. That is, organizational members may believe that a coworker's 
advantages lead to a more favorable cost-reward ratio for that coworker. Consistent with prior work on equity theory, organizational justice, and antisocial organizational behavior and communication (e.g., Carrell \& Dittrich, 1976, 1978; Chory \& Hubbell, 2008; Greenberg, 2011) these unfairness-related perceptions predicted organizational members engaging in obstructionism, information manipulation, and aggression, perhaps as means to restore equity. In addition, organizational members in cross-sex workplace friendships with peers and subordinates versus superiors were perceived as being motivated to engage in these relationships for excitement, adventure, and ego-related reasons to a greater extent, which lead to increased antisocial behaviors directed toward these organizational members. It is possible that individuals, when perceiving that others are in a relationship for fun and excitement, believe that they receive some kind of advantage or benefit (perhaps the reason why the relationship is existing) or an adventure. This could by why respondents then report behaving in more antisocial ways. It is suggested that these antisocial responses towards these individuals may be a means of restoring equity. This notion is consistent with previous research suggesting that perceptions of injustice lead to antisocial responses by others in the organization (e.g., Carrell \& Dittrich, 1976, 1978; Chory \& Hubbell, 2008; Greenberg, 2011). These results provide encouraging support for equity theory in this context and indicate the importance of continued study of the theory as it pertains to third party coworkers' perceptions of and responses to workplace relationships.

In addition to equity theory, a second theoretical perspective that could be used to help understand the results of this study is that of attribution theory (Heider, 1944; Malle, 2011). This theory helps explain how and why individuals make sense of their own and (relevant to the current discussion) others' behaviors. Specifically, the results of the studies concerning the perceived motives of individuals involved in workplace relationships can be viewed through the 
perspective of attribution theory. It is possible that respondents are attributing their coworkers' involvement in specific types of relationship (and relationships with specific others) to the motives they feel they have for that relationship. For example, individuals may attribute their coworkers' involvement in romances and friendships to their perceptions that they want to be in relationships for excitement and adventure, as opposed to attributing others' involvement in professional relationships to their perceptions that they have job motives for choosing their connections at work.

\section{Major Findings}

In addition to the theoretical implications of the results, the three studies in this dissertation, when taken together, provide four key findings. These results demonstrate the unique contribution of the series of studies presented in this dissertation and provide encouraging areas for continued research on the topic of workplace relationships more generally, and crosssex relationships specifically.

First, it seems that overall, coworkers' perceptions of their peers in cross-sex workplace friendships are not overwhelmingly negative. Results of Study 1 indicate that individuals tend to recognize these relationships as being generally positive and providing benefits for those involved, the organization, and others in the organization. This notion is further supported as many of the negative perceptions and behaviors hypothesized to exist in relation to cross-sex workplace friendships in Studies 2 and 3 were not observed in the results. Therefore, it appears as if perceptions of cross-sex workplace friendships are not necessarily viewed negatively. This is a key finding, as the limited previous research on cross-sex friendship has focused on the negative aspects, and nearly all existing Communication Studies research on workplace romances indicates that these relationships are perceived overwhelmingly negative. Future 
research should examine the positive benefits, as well as identify factors that lead to negative perceptions (such as the suspicion that the friendship is romantic).

A second major result of the studies concerns coworkers' perceptions that cross-sex workplace friends are (or may become) involved in a romantic relationship. In Study 1, nearly one fourth of respondents noted some romantic aspect of the cross-sex friendship they observed. For some, this was a confirmed romance that either developed while working together or later blossomed from the friendship that was formed at work. For other respondents, it was simply a suspicion of romance. This result is worth noting, as suspected, but not confirmed, romances may be subject to even harsher scrutiny than those that are open and visible. Cowan and Horan (2014) found that individuals perceived workplace romances more negatively when they were discovered via impersonal revelations (such as overt and covert nonverbal behaviors, gossip, and "getting caught in the act") supporting the notion that it is possible that relationships that are perceived as romantic, but presented as friendships, are considered responsible for causing more problems in the workplace.

The finding that cross-sex workplace friendships are often perceived as romantic is especially important as results of Studies 2 and 3 showed that suspicion of romance in the relationship was positively correlated at a relatively high level with perceptions of the relationship causing problems in the workplace $(r=.52$ and $r=.54)$. In addition to supporting the notion that "hidden" but suspected romances are perceived more negatively, this result is consistent with existing research that indicates that romances at work are perceived negatively and produce potentially problematic effects in the organization (Cowan \& Horan, 2014, in press; Gillen \& Chory, 2014a; Horan \& Chory, 2009, 2011, 2013; Malachowski, et al., 2012). 
Third, the results of Study 2 demonstrated that female organizational members, regardless of the type of workplace relationship they are involved in, are perceived as receiving more unfair advantages by virtue of that relationship than male organizational members were perceived to receive as a result of their workplace relationships. This result is consistent with previous research suggesting that women in workplace romances are generally perceived more negatively than men in workplace romances (Dillard, 1987 in Pierce, Bryne, \& Aquinis, 1996; Gillen \& Chory, 2014a; Horan \& Chory, 2011, 2013; Jones, 1999; Malachowski et al., 2012; Sias, 2009). What this study further contributes is the finding that women are perceived more negatively simply by being in a relationship, being associated with, or being connected to another individual at work, regardless of the type of relationship. This finding may be due to coworkers believing that women need these relationships to move upward, and therefore, must be benefitting in some way by being in said relationships.

Finally, the results of Study 2 showed that all three workplace relationship types (professional, friendship, and romance) differed from one another in terms of the problems they were perceived as causing in the workplace. Romantic relationships were perceived as causing the most workplace problems (significantly more than workplace friendships or professional relationships), a result that is consistent with previous research suggesting that these relationships are perceived as problematic in that they tend to negatively impact the work environment, interfere with others' work, and/or do not have an overall positive effect on the workplace. Interestingly, workplace friendships were also perceived as causing more problems than professional workplace relationships were. This finding is especially significant and provides a unique perspective to a common understanding of workplace friendships as overall positive. The results here suggest that these relationships are not simply closer or enhanced 
versions of professional relationships, but that they have unique problems that may affect others and the workplace as a whole. This result should be a starting point for future research on the negative implications of workplace friendships.

\section{Practical Implications}

The research presented here is a preliminary investigation of coworkers' perceptions of cross-sex friendships in the workplace, a previously understudied topic. One primary set of implications of this research concerns the application and relevance for organizations, managers, and employees. First, organizations and managers should recognize the importance and role of relationships in the workplace-- they have implications and these implications differ based on a number of factors, including the sex-composition of the relationship, the sex and status of those involved, as well as the type of relationship. Additionally, results suggest that managers should encourage the formation of cross-sex workplace friendships, as many positive effects of these relationships were identified. However, they should also be aware of the problems that may arise from these friendships, such as the negative perceptions others may hold. Further, individuals involved should be cognizant of how others perceive their friendships in order to clarify or make known the platonic nature of the relationship.

They should also be aware of how others may behave toward them due to their relationships. For example, results suggest that individuals in same-sex workplace relationships, as well as female organizational members in workplace relationships, are perceived as receiving unfair advantages, which may lead to antisocial behaviors from coworkers. While the results presented here do not necessarily point to the need to discourage workplace relationships, they do suggest that organizational members do, in fact, behave differently towards their coworkers in relationships. 


\section{Limitations}

A potential methodological limitation for this dissertation was the use of relatively new and/or modified measures. Two scales (workplace romance suspicions and workplace problems) were created for use in Studies 2 and 3 based on responses garnered in Study 1, and the ego and love workplace romance motive measures (Quinn, 1977) were adapted to assess motives for engaging in professional relationships and workplace friendships. Although all measures obtained acceptable to very high internal reliabilities, their validity has not yet been established. Future research should seek to further develop these measures.

On a related note, the results for the motives scale were, in many cases, counter to the hypothesized relationships. One reason for this may be the revision of the scales noted above. For example, results indicated that professional relationships were found to have the highest perceived job motives, but this may have been influenced by the limited description respondents were given for the professional relationship. Respondents may have considered it purely motivated by job reasons because it was described as "generally communicating about workrelated tasks." Further, reporting on the ego motive for friendships and professional relationships may have seemed awkward or confusing to respondents, given that people likely do not think of these relationships as being driven by ego, excitement, or adventure.

A second set of limitations concerns those limitations inherent to the types of methodologies employed. Each method has its own set of restrictions and concerns, including the generalizability of qualitative data (due to smaller sample sizes), the ecological validity of studies employing scenarios, and concerns regarding unmeasured variables influencing examinations based on personal experience. While these limitations are no doubt important, it is key to note that the three studies here were intended to complement each other and to work 
together to test the hypotheses. This strategy was designed to allow a more holistic understanding of the variables and relationships being studied, accounting for and compensating for the weaknesses of each individual methodology employed.

\section{Future Research Directions}

As the investigation of cross-sex workplace friendships is relatively new, there are a number of topics that future research should examine. One possible area for future research is examining the personal responses of individuals in cross-sex workplace friendships. The studies presented here focused on the perceptions of organizational members (third parties) who observed cross-sex workplace friendships. Therefore, future research could examine how these perceptions compare to the actual experiences of employees in cross-sex workplace friendships. Examining how these individuals may choose to navigate these relationships, factors that influence the formation of the relationships, and the ways in which those involved understand how others perceive these relationships could provide a broader understanding of the impact these friendships have for those involved, coworkers, and the organization as a whole. Examining these topics would as also increase knowledge that could inform how organizational leaders should discuss or approach these friendships with their employees.

A second area for future research is the use of dyadic data. Research examining the perspectives of both the man and woman in a workplace friendship would allow for richer understanding of the differences between the way men and women experience work and specifically how they experience and approach a relationship in which others may perceive them differently.

Third, future research should examine the impact of sexual orientation on these relationships and the perceptions of them held by coworkers. As results demonstrated the role of 
suspected romance in coworkers' perceptions, researchers should examine how cross-sex friendships between homosexual and heterosexual individuals may differ from those between a heterosexual man and a heterosexual woman.

Finally, researchers should examine how perceptions of cross-sex workplace friendships differ based on organization or industry type. For example, it is possible that these relationships function and are perceived differently in blue-collar versus white-collar working environments. It would be especially informative to examine cross-sex workplace friendships in organizations or fields where women (or men) are the minority, such as manual labor or nursing.

\section{Conclusion}

Taken together, the results of the three studies presented in this dissertation indicate that although third-party organizational members' perceptions of cross-sex workplace friendships are not overwhelmingly negative, they do recognize that these relationships provide benefits for those in the friendship and may cause problems for others in the workplace. Additionally, the current studied applied equity theory (Adams, 1965) to a previously unexamined context. Results indicated that coworkers in same-sex relationships and female organizational members were perceived as receiving more unfair advantages, while coworkers in relationships with peers and subordinates were perceived as being motivated by ego, which lead to increased antisocial behaviors. These antisocial responses may be means of restoring equity.

Finally, results suggest, consistent with previous research on cross-sex friendships in general (Afifi \& Burgoon, 1998; Dainton et al., 2003; Elesser \& Peplau, 2006; Guerrero \& Chavez, 2005; Marks, 1994; Messman et al., 2000), that individuals in cross-sex workplace friendships often face suspicion that the relationship is more than platonic. The results of this dissertation showed that such suspicions are associated with negative perceptions and even 
antisocial behaviors in the workplace. Future research should more closely examine these suspicions, their outcomes, and the implications for the individuals involved, their coworkers, and the organization. 


\section{References}

Acker, J. (1990). Hierarchies, jobs, bodies: A theory of gendered organizations. Gender and Society, 4, 139-158. doi:10.1177=089124390004002002

Adams, J. S. (1965). Inequity in social exchange. In L. Berkowitz (Ed.), Advances in experimental social psychology (pp. 267-299). New York, NY: Academic Press.

Allport, G. W. (1954). The nature of prejudice. Reading, MA: Addison-Wesley.

Ashcraft, K. L. (2005). Feminist organizational communication studies. In S. May \& D. K. Mumby (Eds.), Engaging organizational communication theory and research: Multiple perspectives (pp. 141-168). London, England: Sage.

Afifi, W. A., \& Burgoon, J. K. (1998). "We never talk about that”: A comparison of cross-sex friendships and dating relationships on uncertainty and topic avoidance. Personal Relationships, 5, 255-272. doi:10.1111/j.1475-6811.1998.tb00171.x

Anderson, C. A., \& Bushman, B. J. (2002). Human aggression. Annual Review of Psychology, 53, 27-51. doi:10.1146/annurev.psych.53.100901.135231

Ballou, J. (2008). Open-ended question. In P. Lavrakas (Ed.), Encyclopedia of survey research methods. (pp. 548-550). Thousand Oaks, CA: SAGE doi:http://dx.doi.org/10.4135/9781412963947.n350

Baumgarte, R., \& Nelson, D. (2009). Preference for same- versus cross-sex friendships. Journal of Applied Social Psychology, 39, 901-917. doi:10.1111/j.1559-1816.2009.00465.x

Bolino, M. C., \& Turnley, W. H. (2008). Old faces, new places: Equity Theory in cross-cultural contexts. Journal of Organizational Behavior, 29, 29-50. doi:10.1002/job.452

Bose, C. E., \& Rossi, P. H. (1983). Gender and jobs: Prestige standings of occupations as affected by gender. American Sociological Review, 48, 316-330. 
Boyd, C. (2010). The debate over the prohibition of romance in the workplace. Journal of Business Ethics, 97, 325-338. doi:10.1007/s10551-010-0512-3

Brewer, J., \& Hunter, A. (2006). Foundations of multimethod research: Synthesizing styles. Thousand Oaks: SAGE

Bridge, K., \& Baxter, L. A. (1992). Blended relationships: Friends as work associates. Western Journal of Communication, 56, 200-225. doi:10.1080/10570319209374414

Buller, D. B., \& Burgoon, J. K. (1996). Interpersonal deception theory. Communication Theory, 6, 203-242. doi: 10.1111=j.1468-2885.1996.tb00129.x

Burrell, G. \& Hearn, J. (1989). The sexuality of organization. In J. Hearn, D. Sheppard, P. Tancred-Sheriff, and G. Burrell (Eds.), The sexuality of organization. London, UK: Sage

Buzzanell, P. (1994). Gaining a voice: Feminist organizational communication theorizing. Management Communication Quarterly, 7, 339 -383. doi: $10.1177 / 0893318994007004001$

Canary, D. J., \& Stafford, L. (1992). Relational maintenance strategies and equity in marriage. Communication Monographs, 59, 243-267.

Carrell, M. R., \& Dittrich, J. E. (1976). Employee perceptions of fair treatment. Personnel Journal, 55, 523-524.

Carrell, M. R., \& Dittrich, J. E. (1978). Equity Theory: The recent literature, methodological considerations, and new directions. The Academy of Management Review, 3, 202-210.

Cicchirillo, V., \& Chory-Assad, R. M. (2005). Effects of affective orientation and video game play on aggressive thoughts and behaviors. Journal of Broadcasting \& Electronic Media, 49, 435-449. doi:10.1207/s15506878jobem4904_5 
Chory-Assad, R. M., Goodboy, A., Hixson, N., \& Baker, S. (2006). Exploring involvement in the violent video game content: Effects of player identification, interest, and presence on aggressive outcomes. Paper presented at the National Communication Association Conference, San Antonio, TX.

Chory-Assad, R. M., Goodboy, A., Hixson, N., \& Baker, S. (2007). Does personality moderate the effects of violent video game play on aggression? An exploratory investigation. Paper presented at the International Communication Association Conference, San Francisco, CA.

Chory-Assad, R. M., \& Paulsel, M. L. (2004). Antisocial classroom communication: Instructor influence and interactional justice as predictors of student aggression. Communication Quarterly, 52, 98-114. doi: 10.1080/01463370409370184

Chory, R. M., \& Hubbell, A. P. (2008). Organizational justice and managerial trust as predictors of antisocial employee responses. Communication Quarterly, 56, 357-375. doi: $10.1080=01463370802448121$

Cohen, J. (1988). Statistical power analysis for the behavioral sciences. New Jersey: Lawrence Erlbaum.

Cole, N. (2009). Workplace romance: A justice analysis. Journal of Business Psychology, 24, 363-372. doi:10.007/s10869-009-9117-1

Cowan, R. L., \& Horan, S. M. (2014). Love at the office: Understanding workplace romance disclosure and reactions from the coworker perspective. Western Journal of Communication, 78, p.238-253. doi:10.1080/10570314.2013.866688

Cowan, R. L., \& Horan, S. M. (in press). Why are you dating him? Contemporary motives for workplace romance. Qualitative Research Reports in Communication. 
Cropanzano, R., \& Greenberg, J. (1997). Progress in organizational justice: Tunneling through the maze. International Review of Industrial and Organizational Psychology, 12, 317372. doi: $10.1245=0043226700598701$

Dainton, M. D., Zelley, E. D., \& Langan, E. (2003). Maintaining friendships throughout the lifespan. In D. J. Canary \& M. D. Dainton (Eds.), Maintaining relationships through communication: Relational, contextual, and cultural variations (pp. 79-102). Mahwah, NJ: Lawrence Erlbaum.

Davies-Netzley, S. A. (1998). Women above the glass ceiling: Perceptions on corporate mobility and strategies for success. Gender and Society, 12, 339-355.

doi:10.1177/0891243298012003006

Deutsch, M. (1985). Distributive justice, a social psychological perspective. New Haven: Yale University Press.

Dillard, J. P. (1987). Close relationships at work: Perceptions of the motives and performance of relational participants. Journal of Social and Personal Relationships, 4, 179-193. doi: $10.1177 / 0265407587042005$

Dillard, J. P., \& Broetzmann, S. M. (1989). Romantic relationships at work: Perceived changes in job-related behaviors as a function of participant's motive, partner's motive, and gender. Journal of Applied Social Psychology, 19, 93-110.

Doll, J. (2011). Situational and individual moderators of the decision to engage in a workplace romance. (Unpublished doctoral dissertation). Clemson University, Clemson, SC.

Eisenberg, E. M., Goodall, H. L. Jr. \& Trethewey, A. (2007). Organizational communication: Balancing creativity and constraint. Boston, MA: Bedford/St. Martin's. 
Elesser, K., \& Peplau, L. A. (2006). The glass partition: Obstacles to cross-sex friendships at work. Human Relations, 69, 1077-1100. doi:10.1177/0018726706068783

Fehr, B. (1996). Friendship processes. Thousand Oaks, CA: Sage.

Gerstner, C.R., \& Day, D.V. (1997) Meta-analytic review of leader-member exchange theory: Correlates and construct issues. Journal of Applied Psychology, 82, 827-844. doi:10.1037/0021-9010.82.6.827

Gillen, H. G., \& Chory, R. M. (2014a). Perspectives on workplace romance: A comparison of workplace romance participants and organizational observers. Paper presented at the annual meeting of the International Communication Association, Seattle, WA.

Gillen, H. G. \& Chory, R. M. (2014b). Positive and negative effects of workplace romance: A comparison of participants' and observers' perceptions. Paper presented at the annual meeting of the Eastern Communication Association, Providence, RI.

Glaser, B. G. \& Strauss, A. L. (1967). The Discovery of Grounded Theory: Strategies for Qualitative Research. Chicago, IL: Aldine Publishing Company

Glick, P., \& Fiske, S. T. (1996). The Ambivalent Sexism Inventory: Differentiating hostile and benevolent sexism. Journal of Personality and Social Psychology, 70, 491-512. doi:10.1111/j.1471-6402.1997.tb00104.x

Goodboy, A. K., Chory, R. M., \& Dunleavy, K. N. (2008). Organizational dissent as a function of organizational justice. Communication Research Reports, 25, 255-265. doi: $10.1080 / 08824090802440113$

Gordon, J., \& Hartman, R. L. (2009). Exploration of affinity-seeking strategies and open communication in peer workplace relationships. Atlantic Journal of Communication, 17,111-125. doi:10.1080/15456870902873184 
Graen, G. B., \& Uhl-Bien, M. (1995). Relationship-based approach to leadership: Development of leader-member exchange (LMX) theory of leadership over 25 years: Applying a multilevel domain perspective. Leadership Quarterly, 6, 219-247. doi:10.1016/10489843(95)90036-5

Greenberg, J. (2011). Organizational justice: Yesterday, today, and tomorrow. Journal of Management, 16, 399-432

Guerrero, L. K., \& Chavez, A. M. (2005). Relational maintenance in cross-sex friendships characterized by different types of romantic intent: An exploratory study. Western Journal of Communication, 69, 339-358. doi:10.1080/10570310500305471

Haavio-Mannila, E., Kauppinen-Toropainen, K., \& Kandolin, I. (1988). The effect of sex composition of the workplace on friendship, romance, and sex at work. In B. A. Gutek, A. H. Stromberg, \& L. Larwood (Eds.), Women and work (pp. 123-137). Beverly Hills, CA: Sage.

Heider, F. (1944). Social perception and phenomenal causality. Psychological Review, 51, 358374.

Hennessy, D. A. (2003). From driver stress to workplace aggression. Paper presented at the annual meeting of the American Psychological Association, Toronto, Ontario.

Homans, G. (1961). Social behavior. New York: Harcourt, Brace \& World.

Horan, S. M., \& Chory, R. M. (2009). When work and love mix: Perceptions of peers in workplace romances. Western Journal of Communication, 73, 349-369. doi:10.1080/10570310903279042. 
Horan, S. M., \& Chory, R. M. (2011) Understanding work/life blending: Credibility implications for those who date at work. Communication Studies, 62, 563-580. doi: 10.1080/105109 74.2011.582663.

Horan, S. M., \& Chory, R. M. (2013) Relational implications of gay and lesbian workplace romances: Understanding trust, deception, and credibility. Journal of Business Communication, 50, 170-189. doi:10.1177/0021943612474993

Hsieh, H. F. \& Shannon, S. E. (2005). Three approaches to qualitative content analysis. Qualitative Health Research, 15, 1277-1288. doi:10.1177/1049732305276687

Hubbell, A. P., Chory-Assad, R. M., \& Medved, C. E. (2005). A new approach to the study of deception in organizations. North American Journal of Psychology, 7, 171-180. doi: $10.1266=45877209871$

Hurley, A.E. (1996). Challenges in cross-gender mentoring relationship: Psychological, intimacy, myths, rumors, innuendoes and sexual harassment. Leadership and Organization, 17, 42-50. doi:10.1108/01437739610116993

Ignatius, A. (2013, April 1). “Now is our time.” Harvard Business Review. pp. 84-88.

Jones, G. E. (1999). Hierarchical workplace romance: An experimental examination of team member perceptions. Journal of Organizational Behavior, 20, 1057-1072. doi:10.1002/(SICI)1099-1379(199912)20:7<1057::AID-JOB956>3.0.CO;2.0

Jones, K., Stewart, K., King, E. Morgan, W. B., Gilrane, V., \& Hylton, K., (2014) "Negative consequence of benevolent sexism on efficacy and performance", Gender in Management: An International Journal, 29, 171 - 189 
Karl, K. A., \& Sutton, C. L. (2000). An examination of the perceived fairness of workplace romance policies. Journal of Business and Psychology, 14, 429-442. doi:10.1023/A:1022928216431

Khalifa, M. H. E. (2011). Perceptions of equity and job satisfaction: A study of university employees in Egypt. International Journal of Management, 28, 130-143.

Kram, K. E., \& Isabella, L. A. (1985). Mentoring alternatives: The role of peer relationships in career development. Academy of Management Journal, 28, 110-132. doi:10.2307/256064

Kiser, S. B., Coley, T., Ford, M. \& Moore, M. (2006). Coffee, tea, or me? Romance and sexual harassment in the workplace. Southern Business Review, 31, 35- 49.

Lancaster, A., \& Chory, R. M. (2013). Friends with [workplace] benefits: Peer coworkers' perceptions of supervisor-subordinate friendships. Paper presented at the annual meeting of the National Communication Association, Washington, DC.

Lenton, A. P., \& Webber, L. (2006). Cross-sex friendships: Who has more? Sex Roles, 54, 809820. doi:10.1007/s11199-006-9048-5

Lutgen-Sandvik, P. (2007). “...But words will never hurt me,” abuse and bullying at work: A comparison between two worker samples. Ohio Communication Journal, 45, 81-105.

Lutgen-Sandvik, P., \& Hood, J. (2009). Positive organizational communication and workplace bullying: The risk of building one and avoiding the other. Paper presented at the meeting of the National Communication Association, Chicago, IL.

Malachowski, C. C., Chory, R. M., \& Claus, C. J. (2012). Mixing pleasure with work: Employee perceptions of and responses to workplace romance. Western Journal of Communication, 76, 358-379. doi:10.1080/ 10570314.2012656215 
Mainiero, L. (1989). Office romance: Love, power, and sex in the workplace. New York, NY: Rawson Associates.

Mainiero, L., \& Jones, K. (2013). Sexual harassment versus workplace romance: Social media spillover and textual harassment in the workplace. Academy of Management Perspectives, 27, 187-203. doi:10.5465/amp.2012.0031

Malle, B. F. (2011). Attribution theories: How people make sense of behavior. In Chadee, D. (Ed.), Theories in social psychology (pp. 72-95).

Mano, R., \& Gabriel, Y. (2006). Workplace romances in cold and hot organizational climates: The experience of Israel and Taiwan. Human Relations, 59, 7- 35. doi:10.1177/0018726706062739

Marks, S. R. (1994). Intimacy in the public realm: The case of co-workers. Social Forces, 72 , 843-858. doi:10.1093/sf/72.3.843

McCornack, S. A., Levine, T. A., Solowczuk, K. A., Torres, H. I., \& Campbell, D. M. (1992). When the alteration of information is viewed as deception: An empirical test of information manipulation theory. Communication Monographs, 59, 17-29. doi:10.1080/ 03637759209376246

McCroskey, J. C. (2006). Reliability and validity of the generalized attitude measure and generalized belief measure. Communication Quarterly, 54, 265-274. doi:10.1080/01463370600877893

McCroskey, J. C., \& Richmond, V. P. (1996). Fundamentals of human communication: An interpersonal perspective. Prospect Heights, IL: Waveland Press. 
McCroskey, J. C., \& Teven, J. J. (1999). Goodwill: A reexamination of the construct and its measurement. Communication Monographs, 66, 90-103. doi:10.1080/03637759909376464

Messman, S. J., Canary, D. J., \& Hause, K. S. (2000). Motives to remain platonic, equity, and the use of maintenance strategies in opposite-sex friendships. Journal of Social and Personal Relationships, 17, 67-94. doi:10.1177/0265407500171004

Miller, V. D., \& Jablin, F. M. (1991). Information seeking during organizational entry: Influences, tactics, and a model of the process. Academy of Management Review, 16, 92120. doi:10.5465/AMR.1991.4278997

Monsour, M. (2002). Women and men as friends: Relationships across the life span in the 21st century. Mahwah, NJ: Erlbaum.

Mumby, D. K., \& Putnam, L. L. (1992). The politics of emotion: A feminist reading of bounded rationality. The Academy of Management Review, 17, 465-486.

Myers, S. A. (1998). Sibling communication satisfaction as a function of interpersonal solidarity, individualized trust, and self-disclosure. Communication Research Reports, 15, 309-317. doi:10.1080/08824099809362127

Myers, S. A., Goodboy, A. K., \& Members of COMM 201 (2013). Using equity theory to explore adult siblings' use of relational maintenance behaviors and relational characteristics. Communication Research Reports, 30, 275-281. doi: $10.1080 / 08824096.2013 .836627$

Myers, S. A., \& Johnson, A. D. (2004). Perceived solidarity, self-disclosure, and trust in organizational peer relationships. Communication Research Reports, 21, 75-83. doi:10.1080/08824090409359969 
Myers, S. A., Knox, R. L., Pawlowski, D. R., \& Ropog, B. L. (1999). Perceived communication openness and functional communication skills among organizational peers. Communication Reports, 12, 71-83. doi:10.1080/08934219909367712

Neuman, J. H., \& Baron, R. A. (1998). Workplace violence and workplace aggression: Evidence concerning specific forms, potential causes, and preferred targets. Journal of Management, 24, 391-419. doi:10.1177/014920639802400305

Parks, M. (2006). 2006 Workplace romance: Poll findings. SHRM Research. Retrieved from http://www.lrgllc.com/rpubs/7.pdf

Pearce, J.A. (2010), "What execs don't get about office romance." Sloan Management Review, $51,37-44$

Pierce, C. A. (1998). Factors associated with participating in a romantic relationship in a work environment. Journal of Applied Social Psychology, 28, 1712-1730. doi:10.1111/j.15591816.1998.tb01342.x

Pierce, C. A., \& Aguinis, H. (1997). Bridging the gap between romantic relationships and sexual harassment in organizations. Journal of Organizational Behavior, 18, 197-200. doi:10.1002/(SICI)1099-1379(199705)18:3<197::AID-JOB812>3.0.CO;2-O

Pierce, C. A., \& Aguinis, H. (2001). A framework for investigating the link between workplace romance and sexual harassment. Group \& Organization Management, 26, 206-229. doi:10.1177/ 1059601101262005

Pierce, C. A., Byrne, D., \& Aguinis, H. (1996). Attraction in organizations: A model of workplace romance. Journal of Organizational Behavior, 17, 5-32. doi:10.1002/(SICI)1099-1379(199601)17:1<5::AID-JOB734>3.0.CO;2-E 
Pierce, C. A., Aquinis, H., \& Adams, S. K. R. (2000). Effects of a dissolved workplace romance and rater characteristics on responses to a sexual harassment accusation. Academy of Management Journal, 43, 869-880.

Pierce, C. A., Broberg, B. J., McClure, J. R., \& Aguinis, H. (2004). Responding to sexual harassment complaints: Effects of a dissolved romance on decision-making standards. Organizational Behavior and Human Decision Process, 95, 66-82. doi:10.1016/j.obhdp.2003.06.001

Pierce, C. A., Muslin, I. S., Dudley, C. M., \& Aguinis, C. (2007). From charm to harm: A content-analytic review of sexual harassment court cases involving workplace romance. Management Research, 6, 27-45. doi:10.2753/ JMR1536-5433060102

Potter, W. J., \& Levine-Donnerstein, D. (1999). Rethinking validity and reliability in content analysis. Journal of Applied Communication Research, 27, 258.

Porter, L. W., \& Roberts, K. H. (1973). Communication in organizations. In M. D. Dunnette (Ed.), Handbook of industrial and organizational psychology. Chicago: Rand McNally College Publishing Company.

Quinn, R. E. (1977). Coping with cupid: The formation, impact, and management of romantic relationships in organizations. Administrative Science Quarterly, 22, 30-45. doi: $10.2307=2391744$

Reeder, H. M. (2003). The effect of gender role orientation on same- and cross-sex friendship formation. Sex Roles, 49, 143 - 152. doi: 0360-0025/03/0800-0143/0

Reskin, B. F., \& Hartmann, H. (1986). Women's work, men's work. Washington, DC: National Academy Press. 
Rook, K. S . (1987). Social support versus companionship: Effects on life stress, loneliness, and evaluations by others. Journal of Personality and Social Psychology 52, 1132-1147. doi: $10.1037 / 0022-3514.52 .6 .1132$

Rose, S. M. (1985). Same- and cross-sex friendships and the psychology of homosociality. Sex Roles, 12 , 63-74.

Scandura, T. A., Graen, G. B., \& Novak, M. A. (1986). When managers decide not to decide autocratically: Leader-member exchange and decision influence. Journal of Applied Psychology, 71, 250-256. doi: 10.1037/0021-9010.71.4.579

Shellenbarger, S. (2010, Feb 10). For office romance, the secret's out. The Wall Street Journal, p. D1

Sias, P. M. (2005). Workplace relationship quality and employee information experiences. Communication Studies, 56, 375-396. doi:10.1080/10510970500319450

Sias, P. M. (2006). Workplace friendship deterioration. In J. M. H. Fritz \& B. L. Omdahl (Eds.), Problematic relationships in the workplace (pp. 69-87). New York, NY: Peter Lang.

Sias, P.M. (2008). Supervisor-subordinate relationships. In W. Donsbach (Ed.), The International Encyclopedia of Communication (pp. 4896-4900). Malden, MA: Blackwell Publishing.

Sias, P. M. (2009). Organizing relationships: Traditional and emerging perspectives on workplace relationships. Los Angeles: Sage.

Sias, P. M., \& Cahill, D. J. (1998). From coworkers to friends: The development of peer friendships in the workplace. Western Journal of Communication, 62, 273-299. doi:10.1080/10570319809374611 
Sias, P. M., \& Jablin, F. M. (1995). Differential superior-subordinate relations, perceptions of fairness, and coworker communication. Human Communication Research, 22, 5-38. doi:10.1111/j.1468-2958.1995.tb00360.x

Sias, P. M., \& Perry, T. (2004). Disengaging from workplace relationships. Human Communication Research, 30, 589-602. doi:10.1111/j.1468-2958.2004.tb00746.x

Sias, P. M., Smith, G., \& Avdeyeva, T. (2003). Sex and sex-composition differences and similarities in peer workplace friendship development. Communication Studies, 54, 322340. doi: $10.1080 / 10510970309363289$

Sias, P. M., Heath, R. G., Perry, T., Silva, D., \& Fix, B. (2004). Narratives of workplace friendship deterioration. Journal of Social and Personal Relationships, 21, 321-340. doi:10.1177/0265407504042835

Sias, P. M., Gallagher, E. B., Kopaneva, I., \& Pedersen, H. (2012). Maintaining workplace friendships: Perceived politeness and predictors of maintenance tactic choice. Communication Research, 39, 239-268. doi:10.1177/0093650210396869

Skalski, P., Tamborini, R., Westerman, D., \& Smith, S. (2003). TV violence and aggression: Do hostile thoughts mediate the relationship between viewing violent content and antisocial behavior? Paper presented at the annual meeting of the National Communication Association, New Orleans, LA.

Stafford, L., \& Canary, D. J., (2006). Equity and interdependence as predictors of relational maintenance behaviors. The Journal of Family Communication, 6, 227-254. doi: $10.1207 / \mathrm{s} 15327698 j \mathrm{jfc} 0604 \_1$

Strauss, A., \& Corbin, J. (1998). Basics of qualitative research: Techniques and procedures for developing grounded theory. Thousand Oaks, CA: Sage. 
Tamborini, R., Eastin, M. S., Skalski P., Lachlan, K., Fediuk, T. A., \& Brady, R. (2004). Violent virtual video games and hostile thoughts. Journal of Broadcasting \& Electronic Media, 48, 335-357. doi:10.1207/s15506878jobem4803_1

Teboul, J. C. B., \& Cole, T. (2005) Relationship development and workplace integration: An evolutionary perspective. Communication Theory, 15, 389-413. doi:10.1111/j.14682885.2005.tb00341.x

Tracy, S. J., \& Scott, C. (2006). Sexuality, masculinity, and taint management among firefighters and correctional officers. Management Communication Quarterly, 20, 6-38. doi: $10.1177 / 0893318906287898$

Trethewey, A. (1999). Disciplined bodies: Women's embodied identities at work. Organizational Studies, 20, 423-450. doi:10.1177/0170840699203003

Walster, E., Walster, G. W., \& Berscheid, E. (1978). Equity: Theory and research. Boston, MA: Allyn \& Bacon.

Watkins, M., Smith, L., \& Aquino, K. (2013). The use and consequences of employee sexual performances. Academy of Management Perspectives, 27, 173-186. doi: 10.5465/amp.2010.0109

Werking, K. (1997). We're just good friends: Women and men in nonromantic friendships. New York: Guilford.

Wheeless, L. R. (1978). A follow-up study of the relationships among trust, disclosure, and interpersonal solidarity. Human Communication Research, 4, 143-157. doi: 10.1111/j.1468-2958.1978.tb00604.x 
Wheeless, L. R., \& Grotz, J. (1976). Conceptualization and measurement of reported selfdisclosure. Human Communication Research, 2, 338-346. doi:10.1111/j.14682958.1976.tb00494.x

Wheeless, L. R., \& Grotz, J. (1977). The measurement of trust and its relationship to selfdisclosure. Human Communication Research, 3, 250-257. doi:10.1111/j.14682958.1977.tb00523.x

Williams, C. L., Giuffre, P. A., \& Dellinger, K. (1999). Sexuality in the workplace: Organizational control, sexual harassment, and the pursuit of pleasure. Annual Review of Sociology, 25, 73-93. doi:10.1111/j.1744-6570.2007.00067.x

Women and the workplace: The glass ceiling: Hearing before the Subcommittee on Employment and Productivity of the Committee on Labor and Human Resources, 101st Cong., Sess. 1 (1991).

Wrigley, B. J. (2002). Glass ceiling? What glass ceiling? A qualitative study of how women view the glass ceiling in public relations and communications management. Journal of Public Relations Research, 14, 27-55.

Yager, J. (1997). Friendships: The power of friendship and how it shapes our lives. Stamford, CT: Hannacroix Creek Books.

Yum, Y., \& Canary, D. J. (2009). Cultural differences in equity theory predictions of relational maintenance strategies. Human Communication Research, 35, 384-406. doi: 10.1111/j.1468-2958.2009.01356.x 


\title{
Appendix A
}

Study 1 Questionnaire

\begin{abstract}
A workplace friendship is a relationship between two people who work for the same organization. Although we don't always get to choose the people we work with, we do choose the people at work that we become friends with. Workplace friendships are voluntary relationships, they are not imposed - people choose employees they become friends with. Workplace friendships are more personal than other workplace relationships-workplace friends understand and communicate with each other as whole persons, not simply as work role occupants. Workplace friends choose to spend time together at work and away from the workplace.

A cross-sex workplace friendship refers to a workplace friendship between individuals of the opposite sex (between a man and a woman).

We are interested in studying what people think about cross-sex friendships in their organization. We are asking you to report on a cross-sex friendship you observed in your current or former workplace that left an impression on you. We would appreciate any information you can offer that you think is relevant to our research.“
\end{abstract}

1. Please describe the cross-sex workplace friendship you observed. Tell me a story about the friendship.

2. What do/did you think about the cross-sex workplace friendship and the man and woman involved?

3. Why did/do you feel this way?

4. How did/do you behave around the man and woman in the cross-sex workplace friendship?

5. Have you changed your behavior toward either the man or the woman due to your knowledge of their cross-sex workplace friendship? Explain.

6. Do you have any other thoughts about the cross-sex workplace friendship you reported on that you would like to share with us? 
1. The MAN in the cross-sex workplace friendship you reported on is/was your:

Superior

Same level in the Organization

Subordinate

2. The WOMAN in the cross-sex workplace friendship you reported on is/was your:

Superior

Same level in the Organization

Subordinate

3. The MAN in the cross-sex workplace friendship you reported on is/was the

of the WOMAN in the workplace friendship.

Superior

Same level in the Organization

Subordinate

Please answer the following questions about yourself.

1. Your Sex: Male Female

2. Your Age:

3. Your Ethnic Background: Hispanic/Latino Other:
Caucasian/White

Native American
African American/Black Asian American/Asian

4. Do you still work at the organization where you observed the cross-sex workplace friendship?

Yes No

5. Your occupation during the time you observed the cross-sex workplace friendship:

6. Your job title during the time you observed the cross-sex workplace friendship: 
7. Your job field during the time you observed the cross-sex workplace friendship (Chose ONE): $\overline{\text { scientists, etc.) }}$

Managerial \& Professional (e.g., doctors, lawyers, educators, business executives,

Technical, Sales, \& Administrative Support (e.g., health technicians, salespeople, secretaries, etc.)

hairdressers, etc.)

Service Occupations (e.g., child care, police, food service, cleaning, building,

Precision Production, Craft, \& Repair (e.g., mechanics, construction, etc.)

Operators, Fabricators, \& Laborers (e.g., machine operators, truck drivers, farming, assemblers, etc.)

8. On average, how many hours per week do/did you work at the organization in which you observed the cross-sex workplace friendship?

9. How long have you worked/did you work at the organization where you observed the cross-sex workplace friendship? months

10. Approximately how much do you earn per year at this job? (Circle one)

Under $\$ 20,000$

$\$ 40,001-50,000$

$\$ 70,001-80,000$

Over $\$ 100,000$
$\$ 20,000-30,000$

$\$ 50,001-60,000$

$\$ 80,001-90,000$
$\$ 30,001-40,000$

$\$ 60,001-70,000$

$\$ 90,001-100,000$

11. Please write the first names of the individuals you have been reporting on: 


\section{Appendix B}

\section{Study 1 Code Categories and Definitions}

\section{Benefits/ Positive}

Responses that discuss the personal or work benefits associated with the relationship, the way in which the relationship was positive/"good," or helped the organization.

- Helped Personally/Supportive

- Helped with Work/Work benefits

- Doesn't impact other relationships

- Close/Very close

- Good

- Normal/Healthy/ Not wrong

- Includes others/fun/good people/friendly

- Helps organization/work

- Support/Emotional support

- Encouraged

- Values

- Is a learning experience/can be learned from

\section{Detriments/Negative}

Responses that indicate the friendship was negative for others, negative for those involved, did not specify who the relationship negatively affected or responses that were generally negative.

- Generally negative (or not clear, but obviously negative)

- Excludes others

- Woman benefits

- Too close

- Unfair

- Negative Gossip/Center of attention

- Others complained

- Affects work/others/impacts other relationships

- Unnecessary

- Causes problems

- Awkward

- Should be avoided

- Has risks

- Causes problems

- Needs limits 


\section{Romantic Nature}

Responses regarding the possibility of concern of romance, suspicion of a romance and those that indicated the friendship was, in fact, romantic or developed into a non-platonic relationship.

- Romance suspicion

- Verified romance/turned to romance

- Both or one married

- Gossip about the (possible) romantic nature of the relationship

\section{Non-Issue/Normal/Behaved Normally}

Responses that indicate that the relationships were a "non-issue", did not cause any issues (for the individuals involved, co-workers, or the organization itself) or were the same as same sex. **This also includes responses from participants who noted that they behaved normally around the individuals involved.

- Okay/Fine/Nothing wrong

- Doesn't affect work/ Doesn't affect others

- Natural/healthy

- No different than same sex

- Respondent behaved normally/like myself/genuinely

- Behaved the same as around others

- Respondent did not pry/involve him/herself

- No need to change

- Not their business

\section{Respondent Behaved Mindfully/Aware}

Responses describing behaving more mindfully, including not wanting to be involved, not being negative about the relationship or behavior based on an awareness that the friends would probably share information with one another.

- Careful not to be negative

- Aware that they would talk to each other

- Aware of crossing boundaries

- Has to control emotions

- Aware of own emotions

- Aware of target's behavior

- Some change/trying to change 


\section{Respondent Behaved Positively}

Responses that note the respondent was friendly, open or intentionally positive in his/her interactions with those in the friendship or indicated that $\mathrm{s} /$ he changed his/her behavior in a positive manner.

- Friendly

- Proud/Impressed

- Spend time with both people

- Everyone is friends/friends with targets

- Respected them

\section{Respondent Behaved Negatively}

Responses that included descriptions of the respondent trying to avoid or leave the situation as well as generally negative behaviors or changes in behaviors (by the respondent). Also includes behaviors based on a lack of trust.

- Avoid/leave

- Didn't trust 


\section{Appendix C}

\section{Study 1 Categories and Examples}

\section{Responses to "Please describe the cross-sex workplace friendship you observed. Tell me a story about the friendship."}

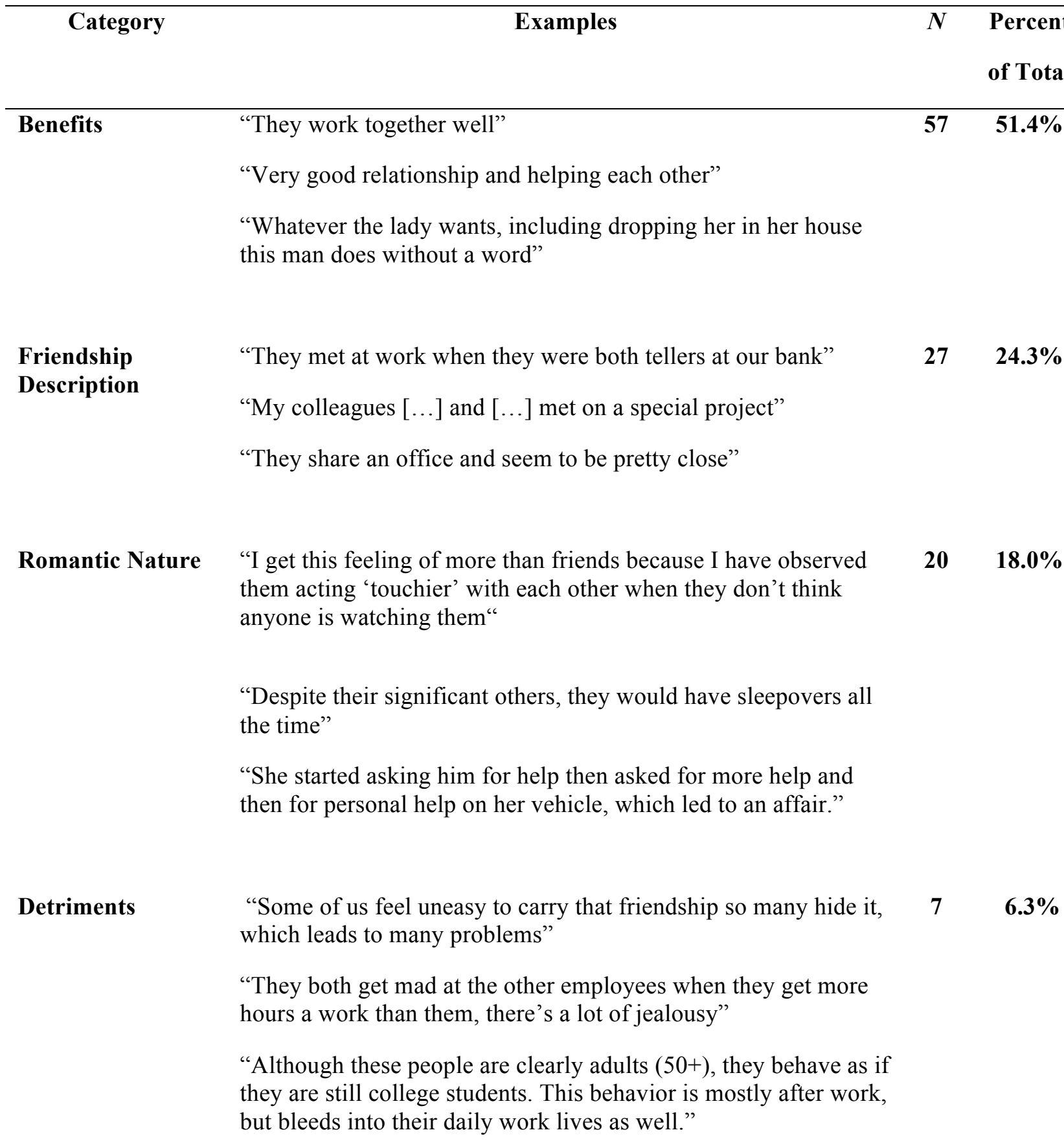


Responses to "What do/did you think about the cross-sex workplace friendship and the man and woman involved?"

\begin{tabular}{|c|c|c|c|}
\hline Category & Examples & $N$ & $\begin{array}{l}\text { Percent } \\
\text { of Total }\end{array}$ \\
\hline Non-Issue & $\begin{array}{l}\text { "It is perfectly fine" } \\
\text { "I don't think anything about it" } \\
\text { "A normal relationship" }\end{array}$ & 38 & $38.8 \%$ \\
\hline Benefits & $\begin{array}{l}\text { "I thought it was marvelous that two bright, hard-working, } \\
\text { talented people found each other" } \\
\text { "Men and women working as a team is very good for the } \\
\text { company" } \\
\text { "I think it is good for man and woman to be involved in the } \\
\text { workplace" }\end{array}$ & 33 & $33.7 \%$ \\
\hline Romantic Nature & $\begin{array}{l}\text { "There are two types of cross-sex relationships. First is those } \\
\text { who have had sex, and the second is those who haven't had } \\
\text { sex YET" } \\
\text { "Their friendship had crossed the line and became romantic" } \\
\text { "I thought they were doing something other than just being } \\
\text { friends." }\end{array}$ & 18 & $18.4 \%$ \\
\hline Detriments & $\begin{array}{l}\text { "I thought the relationship was ok but it made it difficult for } \\
\text { several of the subordinates" } \\
\text { "They think they have to team up against the other } \\
\text { employees to get more work hours" } \\
\text { "Sometimes this relationship creates a misunderstanding } \\
\text { with other colleagues. They feel jealous and try to create a } \\
\text { different atmosphere in the office." }\end{array}$ & 9 & $9.1 \%$ \\
\hline
\end{tabular}




\section{Responses to "Why did/do you feel this way?"}

\begin{tabular}{cc}
\hline Category & \multicolumn{1}{c}{ Examples } \\
\hline Non-Issue & "They were enjoyable to be around" \\
& "They are both nice people and it doesn't interfere with any work" \\
& "A great, multi-year friendship has continued from that workplace \\
& friendship!"
\end{tabular}

Past "I felt this way from my own experience"

"The way they moved with each other both inside as well as outside the office brought this impression in my mind"

Benefits "Both were helpful and made doing business easier"

"They might help each other out more than they do others, but nothing big"

"Since they talk so much, they tell each other about stuff that is happening, which I don't think other people get to know about. I guess that's true with anyone at work that are close"

Romantic "Flirt with your co worker at lunch on your own time" which were sometimes double the allocated time"

"I felt this way because I know those who fall in love, do face problem in focusing on key matters especially the ones at the office. So I did not want his attention to be diverted from the office works because of his close relationship with that girl"

Detriments "I believe it is a bad choice to have an inappropriate relationship with a coworker due to the fact that if something goes wrong it usually effects productivity and creates a bad work environment"

"Their friendship slowly invaded they way she treated other people on staff that her new friend didn't like. Her decisions are obviously colored by his views even when he has no expertise in the area that is being affected." 


\section{Responses to "How did/do you behave around the man and woman in the cross-sex workplace friendship?"}

\begin{tabular}{|c|c|c|c|}
\hline Category & Examples & $N$ & $\begin{array}{l}\text { Percent } \\
\text { of Total }\end{array}$ \\
\hline Normally & $\begin{array}{l}\text { "I behave how I normally would" } \\
\text { "Indifferently" } \\
\text { "The same as I do everyone else. I'm nice to them, but not } \\
\text { in their office, so I'm never really involved in their } \\
\text { conversations" }\end{array}$ & 43 & $43.0 \%$ \\
\hline Positively & $\begin{array}{l}\text { "We were always professional and got all of the work } \\
\text { done" } \\
\text { "Friendly, open and respectful" } \\
\text { "I was very much impressed" }\end{array}$ & 28 & $28.0 \%$ \\
\hline
\end{tabular}

Mindfully

"I was just careful not to say anything against one or the

$15 \quad \mathbf{1 5 . 0 \%}$ other but I do that with all work relationships anyway as you never know who may be friends."

"I was friends with them as well both in and out of work, but I did not participate in some activities where I thought it may cross professional boundaries"

"I am careful to not say anything negative about either of them in front of the other one." finally had a talk to my boss. Now the "couple" don't talk to me much but hey they are doing work!!"

"I was quiet around them but complained all the time to my spouse about it."

"I was angry at first and even moved away didn't want to see them" 


\section{Responses to "Have you changed your behavior toward either the man or the woman due} to your knowledge of their cross-sex workplace friendship? Explain."

\begin{tabular}{|c|c|c|c|}
\hline Category & Examples & $N$ & $\begin{array}{l}\text { Percent } \\
\text { of Total }\end{array}$ \\
\hline No & $\begin{array}{l}\text { "No" } \\
\text { "Not at all" }\end{array}$ & 70 & $64.8 \%$ \\
\hline Mindfully & $\begin{array}{l}\text { "I may be more cautious of what I would say to either } \\
\text { knowing they are friends" } \\
\text { "For a while, I was diverting my attention away from that } \\
\text { man because I thought that I might be disturbing his bond } \\
\text { with that girl. But then I thought that my friendship with } \\
\text { him should not be bothered by any external factors and } \\
\text { hence I chose to be normal with him as I was before." }\end{array}$ & 17 & $15.7 \%$ \\
\hline Negatively & $\begin{array}{l}\text { "Yes. I trust both of them less than I did previously, but I } \\
\text { mistrust him much more than her. I still feel like I can tell } \\
\text { her what I am thinking, but I also know that she will not } \\
\text { listen to anything negative about him" } \\
\text { "Yes, I lost all respect for them. Before the "friendship" } \\
\text { they did more work. Now they flirt and get minimal work } \\
\text { done" } \\
\text { "I didn't trust either of them that much, seemed like they } \\
\text { were always thinking some plot" }\end{array}$ & 13 & $12.1 \%$ \\
\hline Positively & $\begin{array}{l}\text { "Yes, she is no longer employed at work but we still } \\
\text { remain friends outside of work" } \\
\text { "Definitely. I have a huge respect to them" } \\
\text { "I was very friendly to them" }\end{array}$ & 8 & $7.4 \%$ \\
\hline
\end{tabular}




\section{Responses to "Do you have any other thoughts about the cross-sex workplace friendship you reported on that you would like to share with us?"}

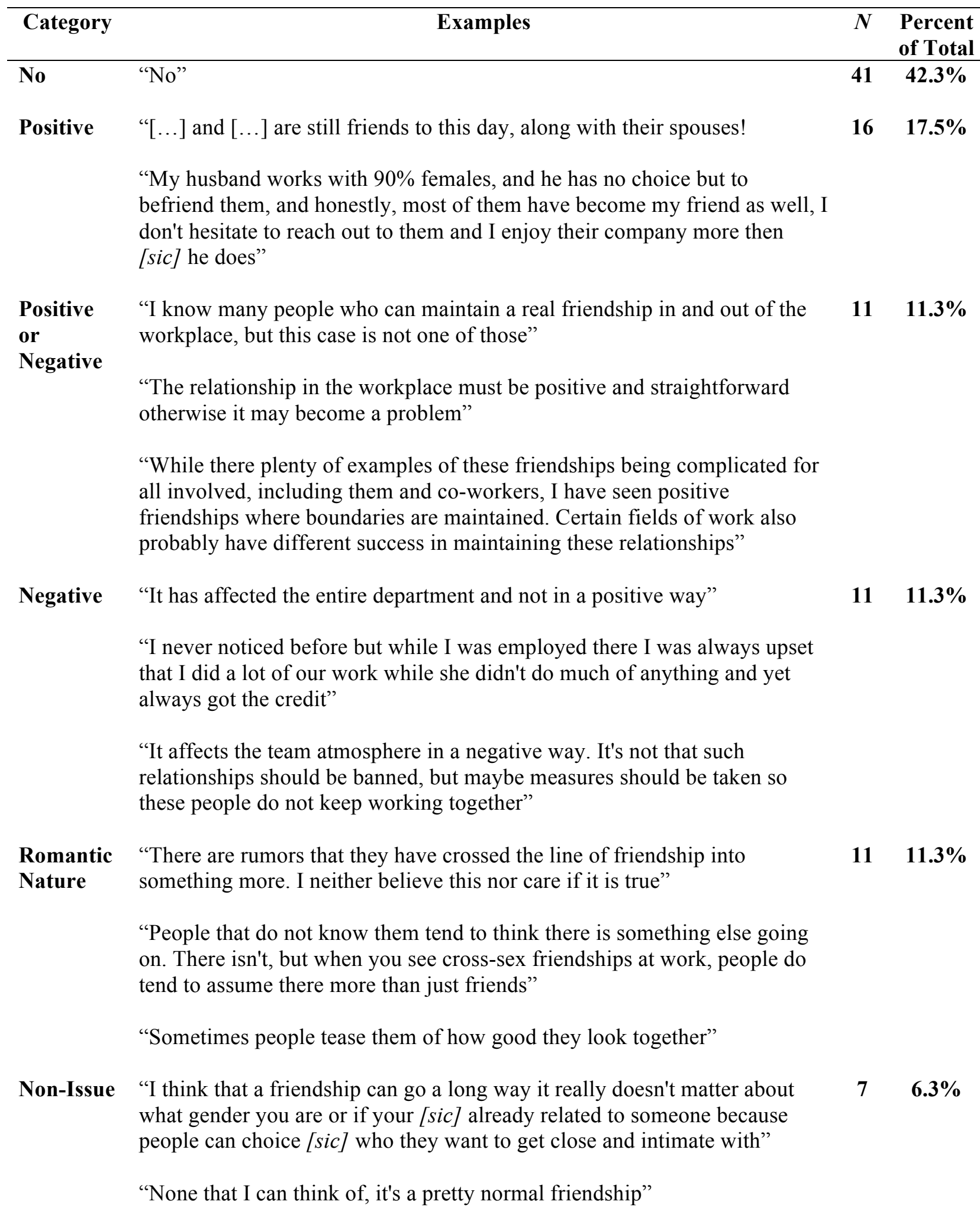




\section{Appendix D}

Study 2 Scenarios

\section{Cross-sex Friendship: Female}

"Think of the organization you currently work in. Lisa and John are your coworkers at this organization. Both Lisa and John are the same job level you are - they are neither your superiors nor your subordinates.

Imagine that Lisa and John are very good friends. As friends, their relationship is more personal than other workplace relationships. They understand and communicate with each other as whole persons, not simply as work role occupants. Lisa and John choose to spend time together at and away from the workplace. Please respond to the following items based on your feelings about Lisa."

\section{Cross-sex Friendship: Male}

"Think of the organization you currently work in. Lisa and John are your coworkers at this organization. Both Lisa and John are the same job level you are - they are neither your superiors nor your subordinates.

Imagine that Lisa and John are very good friends. As friends, their relationship is more personal than other workplace relationships. They understand and communicate with each other as whole persons, not simply as work role occupants. Lisa and John choose to spend time together at and away from the workplace. Please respond to the following items based on your feelings about John."

\section{Same Sex Friendship: Female}

"Think of the organization you currently work in. Lisa and Claire are your coworkers at this organization. Both Lisa and Claire are the same job level you are - they are neither your superiors nor your subordinates.

Imagine that Lisa and Claire are very good friends. As friends, their relationship is more personal than other workplace relationships. They understand and communicate with each other as whole persons, not simply as work role occupants. Lisa and Claire choose to spend time together at and away from the workplace. Please respond to the following items based on your feelings about Lisa."

\section{Same Sex Friendship: Male}

"Think of the organization you currently work in. John and Chad are your coworkers at this organization. Both John and Chad are the same job level you are - they are neither your superiors nor your subordinates. 
Imagine that John and Chad are very good friends. As friends, their relationship is more personal than other workplace relationships. They understand and communicate with each other as whole persons, not simply as work role occupants. John and Chad choose to spend time together at and away from the workplace. Please respond to the following items based on your feelings about John.”

\section{Cross-sex Romance: Female}

"Think of the organization you currently work in. John and Claire are your coworkers at this organization. Both John and Claire are the same job level you are - they are neither your superiors nor your subordinates.

Imagine that John and Claire are romantically involved with each other. Their relationship involves sexual attraction and affection and is recognized by both of them to be something more than just professional and platonic. Please respond to the following items based on your feelings about Claire."

\section{Cross-sex Romance: Male}

"Think of the organization you currently work in. John and Claire are your coworkers at this organization. Both John and Claire are the same job level you are - they are neither your superiors nor your subordinates.

Imagine that John and Claire are romantically involved with each other. Their relationship involves sexual attraction and affection and is recognized by both of them to be something more than just professional and platonic. Please respond to the following items based on your feelings about John."

\section{Same-sex Romance: Female}

"Think of the organization you currently work in. Lisa and Claire are your coworkers at this organization. Both Lisa and Claire are the same job level you are - they are neither your superiors nor your subordinates.

Imagine that Lisa and Claire are romantically involved with each other. Their relationship involves sexual attraction and affection and is recognized by both of them to be something more than just professional and platonic. Please respond to the following items based on your feelings about Lisa."

\section{Same-sex Romance: Male}

"Think of the organization you currently work in. John and Chad are your coworkers at this organization. Both John and Chad are the same job level you are- they are neither your superiors nor your subordinates. 
Imagine that John and Chad are romantically involved with each other. Their relationship involves sexual attraction and affection and is recognized by both of them to be something more than just professional and platonic. Please respond to the following items based on your feelings about John.”

\section{Cross-sex Professional Relationship: Female}

"Think of the organization you currently work in. Lisa and Claire are your coworkers at this organization. Both Lisa and Claire are the same job level you are - they are neither your superiors nor your subordinates.

Imagine that Lisa and Claire are working together on a project. Please respond to the following items based on your feelings about Claire."

\section{Cross-sex Professional Relationship: Male}

"Think of the organization you currently work in. John and Claire are your coworkers at this organization. Both John and Claire are the same job level you are - they are neither your superiors nor your subordinates.

Imagine that John and Claire are working together on a project. Please respond to the following items based on your feelings about John."

\section{Same-sex Professional Relationship: Female}

"Think of the organization you currently work in. Lisa and Claire are your coworkers at this organization. Both Lisa and Claire are the same job level you are - they are neither your superiors nor your subordinates.

Imagine that Lisa and Claire are working together on a project. Please respond to the following items based on your feelings about Claire."

\section{Same-sex Professional Relationship: Male}

"Think of the organization you currently work in. John and Chad are your coworkers at this organization. Both John and Chad are the same job level you are- they are neither your superiors nor your subordinates.

Imagine that John and Chad are working together on a project. Please respond to the following items based on your feelings about John." 


\section{Appendix E}

Credibility Measure Items

\section{Competence}

$\begin{array}{lllllllll}\text { *Intelligent } & 1 & 2 & 3 & 4 & 5 & 6 & 7 & \text { Unintelligent } \\ \text { Untrained } & 1 & 2 & 3 & 4 & 5 & 6 & 7 & \text { Trained } \\ \text { Inexpert } & 1 & 2 & 3 & 4 & 5 & 6 & 7 & \text { Expert } \\ \text { *Informed } & 1 & 2 & 3 & 4 & 5 & 6 & 7 & \text { Uninformed } \\ \text { Incompetent } & 1 & 2 & 3 & 4 & 5 & 6 & 7 & \text { Competent } \\ \text { *Bright } & 1 & 2 & 3 & 4 & 5 & 6 & 7 & \text { Stupid }\end{array}$

Caring

\begin{tabular}{|c|c|c|c|c|c|c|c|c|}
\hline *Cares about me & 1 & 2 & 3 & 4 & 5 & 6 & 7 & Doesn't care about me \\
\hline $\begin{array}{l}\text { *Has my interests } \\
\text { at heart }\end{array}$ & 1 & 2 & 3 & 4 & 5 & 6 & 7 & $\begin{array}{l}\text { Doesn't have my } \\
\text { interests at heart }\end{array}$ \\
\hline Self-centered & 1 & 2 & 3 & 4 & 5 & 6 & 7 & Not self-centered \\
\hline *Concerned with me & 1 & 2 & 3 & 4 & 5 & 6 & I & Unconcerned with me \\
\hline Insensitive & 1 & 2 & 3 & 4 & 5 & 6 & 7 & Sensitive \\
\hline Not understanding & 1 & & 3 & 4 & 5 & 6 & 7 & Understanding \\
\hline
\end{tabular}

Character

$\begin{array}{lllllllll}\text { *Honest } & 1 & 2 & 3 & 4 & 5 & 6 & 7 & \text { Dishonest } \\ \text { Untrustworthy } & 1 & 2 & 3 & 4 & 5 & 6 & 7 & \text { Trustworthy } \\ \text { *Honorable } & 1 & 2 & 3 & 4 & 5 & 6 & 7 & \text { Dishonorable } \\ \text { *Moral } & 1 & 2 & 3 & 4 & 5 & 6 & 7 & \text { Immoral } \\ \text { Unethical } & 1 & 2 & 3 & 4 & 5 & 6 & 7 & \text { Ethical } \\ \text { Phony } & 1 & 2 & 3 & 4 & 5 & 6 & 7 & \text { Genuine }\end{array}$

*Indicates items that are reverse-scored. 


\title{
Appendix F
}

Relationship Motives Measure Items

\author{
I feel [Target Name 1] is in the workplace friendship/ workplace romance/work \\ relationship... \\ $\underline{\text { Job }}$ \\ ...for job advancement. \\ ...to increase his/her power in the organization. \\ ...to make his/her work easier. \\ ...for job security. \\ ...to increase his/her job efficiency. \\ ...for financial rewards.
}

Ego

...to boost his/her own ego.

...for excitement.

...for adventure.

...for sexual experience (Workplace Romance)/fun (Friendship and Professional).

\section{Sincerity}

...for sincere love (Workplace Romance)/friendship (Friendship).

...to find a spouse (Workplace Romance)/“hang out” with someone (Friendship).

...for companionship (Workplace Romance and Friendship).

NOTE: The "Professional Relationship" scenarios did not receive the Sincerity motives. 


\section{Appendix G}

Unfair Advantages Measure Items

\section{Due to his/her friendship/romance/work relationship, I think [Target Name 1] ...}

1. receives/received special treatment at work.

2. receives/received work-related information that other organizational members do/did not.

3. has/had an advantage over other organizational members.

4. is being/was promoted over other organizational members.

5. is/was favored at work.

6. receives/received benefits that other organizational members do/did not.

7. is/was more powerful in the organization. 


\section{Appendix H}

Generalized Belief Measure Items

"I trust [Target Name 1] as a colleague."

$\begin{array}{lllllllll}\text { 1. Agree } & 1 & 2 & 3 & 4 & 5 & 6 & 7 & \text { Disagree* } \\ \text { 2. False } & 1 & 2 & 3 & 4 & 5 & 6 & 7 & \text { True } \\ \text { 3. Incorrect } & 1 & 2 & 3 & 4 & 5 & 6 & 7 & \text { Correct } \\ \text { 4. Wrong } & 1 & 2 & 3 & 4 & 5 & 6 & 7 & \text { Right } \\ \text { 5. Yes } & 1 & 2 & 3 & 4 & 5 & 6 & 7 & \text { No }^{*}\end{array}$

*Indicates items that are reverse-scored. 


\section{Appendix I}

Obstructionism Measure Items

\section{"If I had the opportunity I would ... "}

1. directly refuse to provide with needed resources or equipment.

2. fail to return phone calls or respond to memos sent by

3. cause others to delay action on matters that were important to

4. fail to warn of impending danger.

5. needlessly consume resources needed by

6. fail to defend 's plans to others.

7. intentionally cause work performed for to slow down.

8. interfere with or block 's work.

9. show up late for meetings run by 


\section{Appendix J}

Deception Measure Items

\section{'If I had the opportunity I would ... ."}

1. be ambiguous in communicating information that needs.

2. keep information from

3. tell "white lies."

4. provide inaccurate information to

5. distort information about an important situation even though the information would allow to avoid trouble.

6. avoid talking to

7. talk to about anything except important information.

8 . be vague when asks me for information that $\mathrm{s} / \mathrm{he}$ needs. 


\section{Appendix K}

Revised Self-Disclosure Measure Items

"If I had the opportunity I would ... ,"

1. always feel/felt completely sincere when revealing my own feelings and experiences to ${ }^{*} \cdot$

2. reveal self-disclosures to that would be completely accurate reflections of who I am/was.*

3. not always be honest in my self-disclosures to

4. always be honest in my self-disclosures to .$^{*}$

5. always feel completely sincere when revealing my own feelings, emotions, behaviors, or experiences to

*Indicates items that are reverse-scored. 


\section{Appendix L}

\section{Aggression Measure Items}

1. How courteous is this person?

$\begin{array}{lllllllll}\text { Not at all Courteous } & 1 & 2 & 3 & 4 & 5 & 6 & 7 & \text { Extremely Courteous }\end{array}$

2. How competent is this person?

$\begin{array}{lllllllll}\text { Not at all Competent } & 1 & 2 & 3 & 4 & 5 & 6 & 7 & \text { Extremely Competent }\end{array}$

3. Based on your experience with this person, how would you feel about him/her being awarded a promotion at work? Is/he deserving of a promotion?

$\begin{array}{lllllllll}\text { Not at all Deserving } & 1 & 2 & 3 & 4 & 5 & 6 & 7 & \text { Extremely Deserving }\end{array}$

4. On a scale from 0 to 100 , how would you rate this person as an employee? 


\section{Appendix M}

Ambivalent Sexism Measure Items

\section{$\underline{\text { Hostile Sexism }}$}

1. Many women are actually seeking special favors, such as hiring policies that favor them over men, under the guise of asking for "equality."

2. Most women interpret innocent remarks or acts as being sexist.

3. Women are too easily offended.

4. Feminists are not seeking for women to have more power than men.*

5. Most women fail to appreciate fully all that men do for them.

6. Women seek to gain power by getting control over men.

7. Women exaggerate problems they have at work.

8. Once a woman gets a man to commit to her, she usually tries to put him on a tight leash.

9. When women lose to men in a fair competition, they typically complain about being discriminated against.

10. There are actually very few women who get a kick out of teasing men by seeming sexually available and then refusing male advances.*

11. Feminists are making entirely reasonable demands of men.*

\section{Benevolent Sexism}

1. No matter how accomplished he is, a man is not truly complete as a person unless he has the love of a woman.

2. In a disaster, women ought not necessarily be rescued before men.* 
3. People are often truly happy in life without being romantically involved with a member of the other sex.*

4. Many women have a quality of purity that few men possess.

5. Women should be cherished and protected by men.

6. Every man ought to have a woman whom he adores.

7. Men are complete without women.*

8. A good woman should be set on a pedestal by her man.

9. Women, compared to men, tend to have a superior moral sensibility.

10. Men should be willing to sacrifice their own well-being in order to provide financially for the women in their lives.

11. Women, as compared to men, tend to have a more refined sense of culture and good taste.

*Indicates items that are reverse-scored. 


\section{Appendix N}

Suspected Romance Measure Items

1. I consider the relationship between [Target Name 1] and [Target Name 2] to be completely platonic.*

2. I believe the relationship between [Target Name 1] and [Target Name 2] is actually romantic.

3. I am suspicious that [Target Name 1] and [Target Name 2] may secretly be romantically involved.

4. I do not believe that [Target Name 1] and [Target Name 2] are dating.*

5. [Target Name 1] and [Target Name 2] behave in ways that suggest a romance.

*Indicates items that are reverse-scored. 


\section{Appendix O}

Workplace Problems Measure Items

1. The relationship between [Target Name 1] and [Target Name 2] causes problems for other workers.

2. [Target Name 1] and [Target Name 2]'s relationship negatively impacts the work environment.

3. [Target Name 1] and [Target Name 2]'s relationship interferes with others' work.

4. The relationship between [Target Name 1] and [Target Name 2] has a positive effect on the overall workplace.*

*Indicates items that are reverse-scored. 


\title{
Appendix P
}

Study 2 Questionnaire

\begin{abstract}
"Think of the organization you currently work in. [Male or female target name] and [male or female target name] are your coworkers at this organization. Both [male or female target name] and [male or female target name] are at the same job level you are-they are neither your superiors nor your subordinates. Imagine that [male or female target name] and [male or female target name] are in a professional relationship/are friends/are romantically involved with each other."
\end{abstract}

The following additional information for the professional relationship scenarios will appear:

"As coworkers in a professional relationship, [Target Name 1] and [Target Name 2] understand and communicate with each other LESS as whole persons and MORE as work role occupants. They choose not to spend time together outside of the workplace and generally communicate about work-related tasks, but not personal topics. Their relationship is recognized by both of them to be nothing more than professional and platonic. Please respond to the following items based on your feelings about [male or female target name]."

\section{The following additional information for the workplace friendship scenarios will appear:}

"As coworkers in a friendship, [Target Name 1] and [Target Name 2] understand and communicate with each other MORE as whole persons and LESS as work role occupants. They choose to spend time together outside of the workplace and generally communicate about workrelated tasks, as well as personal topics. Their relationship is recognized by both of them to be nothing more than professional and platonic. Please respond to the following items based on your feelings about [male or female target name]."

\section{The following additional information for the workplace romance scenarios will appear:}

"As coworkers in a romantic relationship, [Target Name 1] and [Target Name 2] understand and communicate with each other MORE as whole persons and LESS as work role occupants. They choose to spend time together outside of the workplace and generally communicate about workrelated tasks, as well as personal topics. Their relationship is recognized by both of them to be something more than professional and platonic. Please respond to the following items based on your feelings about [male or female target name]." 
Using the scale below, please indicate how you would communicate with [Target Name 1] if s/he was your coworker. Record the number of your response in the space provided.

\begin{tabular}{ccccccc}
1 & 2 & 3 & 4 & 5 & 6 & 7 \\
\hline $\begin{array}{l}\text { Strongly } \\
\text { Disagree }\end{array}$ & Disagree & $\begin{array}{c}\text { Moderately } \\
\text { Disagree }\end{array}$ & Undecided & $\begin{array}{c}\text { Moderately } \\
\text { Agree }\end{array}$ & Agree & Strongly \\
& & & & Agree
\end{tabular}

"If I had the opportunity I would ....",

1. directly refuse to provide [Target Name 1] with needed resources or equipment.

2. fail to return phone calls or respond to memos sent by [Target Name 1].

3. cause others to delay action on matters that were important to [Target Name 1].

4. fail to warn [Target Name 1] of impending danger.

5. needlessly consume resources needed by [Target Name 1] .

6. fail to defend [Target Name 1]'s plans to others.

7. intentionally cause work performed for [Target Name 1] to slow down.

8. interfere with or block [Target Name 1]'s work.

9. show up late for meetings run by [Target Name 1].

10. be ambiguous in communicating information that [Target Name 1] needs.

11. keep information from [Target Name 1].

12. tell [Target Name 1] "white lies."

13. provide inaccurate information to [Target Name 1].

14. distort information about an important situation even though the information would allow [Target Name 1] to avoid trouble.

15. avoid talking to [Target Name 1].

16. talk to [Target Name 1] about anything except important information.

17. be vague when [Target Name 1] asks me for information that $\mathrm{s} /$ he needs.

18. always feel completely sincere when revealing my own feelings and experiences to [Target Name 1]. 
19. reveal self-disclosures to [Target Name 1] that are completely accurate reflections of who I am.

20. not always be honest in my self-disclosures to [Target Name 1].

21. always feel completely sincere when revealing my own feelings, emotions, behaviors, or experiences to [Target Name 1].

22. always be honest in my self-disclosures to [Target Name 1].

Please answer the following questions as if you were evaluating Participant [Target Participant ID Letter] for a promotion at work. Please rate the person on the following dimensions.

1. How courteous is [Target Name 1]?

$\begin{array}{lllllllll}\text { Not at all Courteous } & 1 & 2 & 3 & 4 & 5 & 6 & 7 & \text { Extremely Courteous }\end{array}$

2. How competent is [Target Name 1]?

$\begin{array}{llllllllll}\text { Not at all Competent } & 1 & 2 & 3 & 4 & 5 & 6 & 7 & \text { Extremely Competent }\end{array}$

3. Based on your experience with [Target Name 1], how would you feel about him/her being awarded a promotion at work? Is [Target Name 1] deserving of a promotion?

$\begin{array}{lllllllll}\text { Not at all Deserving } & 1 & 2 & 3 & 4 & 5 & 6 & 7 & \text { Extremely Deserving }\end{array}$

5. On a scale from 0 to 100 , how would you rate [Target Name 1] as an employee? 
Imagine that [Target Name 1] is your coworker. Please indicate how much you would agree with the following statement: "I trust [Target Name 1] as a colleague." Please respond to this statement based on the pairings of adjectives below. The closer the number is to an adjective, the more certain you are of your evaluation.

"I trust [Target Name 1] as a colleague."

$\begin{array}{lllllllll}\text { 1. Agree } & 1 & 2 & 3 & 4 & 5 & 6 & 7 & \text { Disagree } \\ \text { 2. False } & 1 & 2 & 3 & 4 & 5 & 6 & 7 & \text { True } \\ \text { 3. Incorrect } & 1 & 2 & 3 & 4 & 5 & 6 & 7 & \text { Correct } \\ \text { 4. Wrong } & 1 & 2 & 3 & 4 & 5 & 6 & 7 & \text { Right } \\ \text { 5. Yes } & 1 & 2 & 3 & 4 & 5 & 6 & 7 & \text { No }\end{array}$

Please respond to each item below to indicate how you would feel about [Target Name 1] if s/he was your coworker. Please respond based on the pairings of adjectives below. The closer the number is to an adjective, the more certain you are of your evaluation.

$\begin{array}{lllllllll}\text { Cares about me } & 1 & 2 & 3 & 4 & 5 & 6 & 7 & \text { Doesn't care abo } \\ \text { Self-centered } & 1 & 2 & 3 & 4 & 5 & 6 & 7 & \text { Not self-centered } \\ \text { Concerned with me } & 1 & 2 & 3 & 4 & 5 & 6 & 7 & \text { Unconcerned } \\ \text { Insensitive } & 1 & 2 & 3 & 4 & 5 & 6 & 7 & \text { Sensitive } \\ \text { Not understanding } & 1 & 2 & 3 & 4 & 5 & 6 & 7 & \text { Understanding } \\ \text { Has my interests } & 1 & 2 & 3 & 4 & 5 & 6 & 7 & \text { Doesn't have my } \\ \text { heart } & & & & & & & & \text { interests at heart } \\ & & & & & & & & \\ \text { Intelligent } & 1 & 2 & 3 & 4 & 5 & 6 & 7 & \text { Unintelligent } \\ \text { Untrained } & 1 & 2 & 3 & 4 & 5 & 6 & 7 & \text { Trained } \\ \text { Inexpert } & 1 & 2 & 3 & 4 & 5 & 6 & 7 & \text { Expert } \\ \text { Informed } & 1 & 2 & 3 & 4 & 5 & 6 & 7 & \text { Uninformed } \\ \text { Incompetent } & 1 & 2 & 3 & 4 & 5 & 6 & 7 & \text { Competent } \\ \text { Bright } & 1 & 2 & 3 & 4 & 5 & 6 & 7 & \text { Stupid } \\ & & & & & & & & \\ \text { Honest } & 1 & 2 & 3 & 4 & 5 & 6 & 7 & \text { Dishonest } \\ \text { Untrustworthy } & 1 & 2 & 3 & 4 & 5 & 6 & 7 & \text { Trustworthy } \\ \text { Honorable } & 1 & 2 & 3 & 4 & 5 & 6 & 7 & \text { Dishonorable } \\ \text { Moral } & 1 & 2 & 3 & 4 & 5 & 6 & 7 & \text { Immoral } \\ \text { Unethical } & 1 & 2 & 3 & 4 & 5 & 6 & 7 & \text { Ethical } \\ \text { Phony } & 1 & 2 & 3 & 4 & 5 & 6 & 7 & \text { Genuine } \\ & & & & & & & & \end{array}$


Again, imagine [Target Name 1] is your coworker. Please respond to each item below to indicate what you feel about [Target Name 1]'s motives for being involved in his/her friendship/romance/professional relationship at work. Please mark how much you agree with each statement using the scale below. Record the number of your response in the space provided beside each statement.

\begin{tabular}{ccccccc}
1 & 2 & 3 & 4 & 5 & 6 & 7 \\
\hline $\begin{array}{l}\text { Strongly } \\
\text { Disagree }\end{array}$ & Disagree & $\begin{array}{c}\text { Moderately } \\
\text { Disagree }\end{array}$ & Undecided & Moderately & Agree & Strongly \\
& & & Agree & & Agree
\end{tabular}

I feel [Target Name 1] is in the workplace friendship/workplace romance/work relationship...

1. for job advancement.

2. to increase his/her power in the organization.

3. for companionship (Workplace Romance and Friendship)

4. sincere love (Workplace Romance)/friendship (Friendship).

5. for excitement.

6. to increase his/her job efficiency.

7. for adventure.

8. for job security.

9. for sexual experience (Workplace Romance)/fun (Friendship and Professional).

10. for financial rewards.

11. to find a spouse (Workplace Romance)/“hang out" with someone (Friendship).

12. to make his/her work easier.

13. to boost his/her own ego. 
Again, imagine [Target Name 1] is your coworker. Please respond to each item below to indicate what you would think about [Target Name 1]'s friendship/romance/professional relationship at work. Please mark how much you agree with each statement using the scale below. Record the number of your response in the space provided beside each statement.

\begin{tabular}{ccccccc}
1 & 2 & 3 & 4 & 5 & 6 & 7 \\
\hline $\begin{array}{l}\text { Strongly } \\
\text { Disagree }\end{array}$ & Disagree & $\begin{array}{c}\text { Moderately } \\
\text { Disagree }\end{array}$ & Undecided & Moderately & Agree & Strongly \\
& & & Agree & & Agree
\end{tabular}

Due to his/her workplace friendship/workplace romance/work relationship, I think [Target Name 1] ...

1. receives special treatment at work.

2. receives work-related information that other organizational members do not.

3. has an advantage over other organizational members.

4. is being promoted over other organizational members.

5. is favored at work.

6. receives benefits that other organizational members do not.

7. is more powerful in the organization.

\section{Using the scale below, please indicate your agreement with each of the following} statements. Record the number of your response in the space provided.

\begin{tabular}{ccccccc}
1 & 2 & 3 & 4 & 5 & 6 & 7 \\
\hline $\begin{array}{l}\text { Strongly } \\
\text { Disagree }\end{array}$ & Disagree & $\begin{array}{c}\text { Moderately } \\
\text { Disagree }\end{array}$ & Undecided & $\begin{array}{c}\text { Moderately } \\
\text { Agree }\end{array}$ & Agree & Strongly \\
Agree
\end{tabular}

1. Many women are actually seeking special favors, such as hiring policies that favor them over men, under the guise of asking for "equality."

2. No matter how accomplished he is, a man is not truly complete as a person unless he has the love of a woman.

3. Most women interpret innocent remarks or acts as being sexist.

4. In a disaster, women ought not necessarily be rescued before men. 
5. Women are too easily offended.

6. People are often truly happy in life without being romantically involved with a member of the other sex.

7. Feminists are not seeking for women to have more power than men.

8. Many women have a quality of purity that few men possess.

9. Most women fail to appreciate fully all that men do for them.

10. Women should be cherished and protected by men.

11. Every man ought to have a woman whom he adores.

12. Women seek to gain power by getting control over men.

13. Men are complete without women.

14. Women exaggerate problems they have at work.

15. A good woman should be set on a pedestal by her man.

16. Women, compared to men, tend to have a superior moral sensibility.

17. Once a woman gets a man to commit to her, she usually tries to put him on a tight leash.

18. When women lose to men in a fair competition, they typically complain about being discriminated against.

19. There are actually very few women who get a kick out of teasing men by seeming sexually available and then refusing male advances.

20. Men should be willing to sacrifice their own well-being in order to provide financially for the women in their lives.

21. Feminists are making entirely reasonable demands of men.

22. Women, as compared to men, tend to have a more refined sense of culture and good taste. 
Using the scale below, please indicate your agreement with each of the following statements. Record the number of your response in the space provided.

\begin{tabular}{ccccccc}
1 & 2 & 3 & 4 & 5 & 6 & 7 \\
\hline $\begin{array}{ccc}\text { Strongly } \\
\text { Disagree }\end{array}$ & Disagree & $\begin{array}{c}\text { Moderately } \\
\text { Disagree }\end{array}$ & Undecided & $\begin{array}{c}\text { Moderately } \\
\text { Agree }\end{array}$ & Agree & Strongly \\
Agree
\end{tabular}

1. I consider the relationship between [Target Name 1] and [Target Name 2] to be completely platonic. romantic.

2. I believe the relationship between [Target Name 1] and [Target Name 2] is actually

3. I am suspicious that [Target Name 1] and [Target Name 2] may secretly be romantically involved.

4. I do not believe that [Target Name 1] and [Target Name 2] are dating.

5. [Target Name 1] and [Target Name 2] behave in ways that suggest a romance. other workers.

6. The relationship between [Target Name 1] and [Target Name 2] causes problems for

7. [Target Name 1] and [Target Name 2]'s relationship negatively impacts the work environment.

8. [Target Name 1] and [Target Name 2]'s relationship interferes with others' work.

9. The relationship between [Target Name 1] and [Target Name 2] has a positive effect on the overall workplace.

Please answer the following questions about yourself.

1. Your Sex: Male Female

2. Your Age:

3. Your Ethnic Background: Hispanic/Latino Other:
Caucasian/White Native American
African American/Black Asian American/Asian 


\section{Your current occupation:}

5. Your job title:

\section{Your job field: (Check ONE)}

Managerial \& Professional (e.g., doctors, lawyers, educators, business executives, scientists, etc.)

Technical, Sales, \& Administrative Support (e.g., health technicians, salespeople, secretaries, etc.)

Service Occupations (e.g., child care, police, food service, cleaning, building, hairdressers, etc.)

Precision Production, Craft, \& Repair (e.g., mechanics, construction, etc.) Operators, Fabricators, \& Laborers (e.g., machine operators, truck drivers, farming, assemblers, etc.)

7. On average, how many hours per week do you work at your current organization?

8. How long have you worked at this organization?

9. At what type of organization do you work (e.g. hospital, school, etc.)?

10. Approximately how much do you earn per year at this job? (Circle one)

Under $\$ 20,000$

$\$ 40,001-50,000$

$\$ 70,001-80,000$

$\$ 20,000-30,000$
$\$ 50,001-60,000$
$\$ \$ 80,001-90,000$

Over $\$ 100,000$
$\$ 30,001-40,000$

$\$ 60,001-70,000$

$\$ 90,001-100,000$ 


\section{Appendix Q}

Study 3 Questionnaire

A workplace friendship is a relationship between two people who work for the same organization. Although we don't always get to choose the people we work with, we do choose the people at work that we become friends with. Workplace friendships are voluntary relationships, they are not imposed - people choose employees they become friends with. Workplace friendships are more personal than other workplace relationships - workplace friends understand and communicate with each other as whole persons, not simply as work role occupants. Workplace friends choose to spend time together at work and away from the workplace.

A cross-sex workplace friendship refers to a workplace friendship between individuals of the opposite sex (between a man and a woman).

Please respond to the following questions based on a workplace friendship between a man and woman you have personally observed in the workplace. Think of the coworker in the workplace friendship with whom you have had the most work-related contact (e.g., the person you work with the most). Please respond to the following items based on your feelings about that coworker.

1. In the space below, please enter the first name of the individual in the male-female workplace friendship with whom you have had the most work-related contact (e.g., the person you work with the most).

2. [Name of individual listed in Question \#1] is my (please choose the most appropriate option): Superior Same level in the Organization Subordinate

3. [Name of individual listed in Question \#1] is: Male Female 
4. [Name of individual listed in Question \#1] is the of his/her workplace friend: Superior Same level in the Organization Subordinate

5. In the space below, please enter the first name of the friend of [Name of individual listed in Question \#1]

6. [Name of individual listed in Question \#5] is my (please choose the most appropriate option): Superior Same level in the Organization Subordinate

7. [Name of individual listed in Question \#5] is: Male Female

\section{Think of [Name of individual listed in Question \#1]. Please respond to each item below to indicate how you might behave toward [Name of individual listed in Question \#1]if you had the opportunity.}

\begin{tabular}{ccccccc}
1 & 2 & 3 & 4 & 5 & 6 & 7 \\
\hline Strongly & Disagree & Moderately & Undecided & Moderately & Agree & Strongly \\
Disagree & & Disagree & & Agree & & Agree
\end{tabular}

\section{' If I had the opportunity I would ... ,"}

1. directly refuse to provide [Name of individual listed in Question \#1] with needed resources or equipment.

2. fail to return phone calls or respond to memos sent by [Name of individual listed in Question \#1].

3. cause others to delay action on matters that were important to [Name of individual listed in Question \#1]

4. fail to warn [Name of individual listed in Question \#1] of impending danger. 
5. needlessly consume resources needed by [Name of individual listed in Question \#1]

6. fail to defend [Name of individual listed in Question \#1]'s plans to others.

7. intentionally cause work performed for [Name of individual listed in Question \#1] to slow down.

8. Interfere with or block [Name of individual listed in Question \#1]'s work.

9. show up late for meetings run by [Name of individual listed in Question $\# 1]$.

10. be ambiguous in communicating information that [Name of individual listed in Question \#1] needs.

11. keep information from [Name of individual listed in Question \#1].

12. tell [Name of individual listed in Question \#1] "white lies."

13. provide inaccurate information to [Name of individual listed in Question $\# 1]$.

14. distort information about an important situation even though the information would allow [Name of individual listed in Question \#1] to avoid trouble.

15. avoid talking to [Name of individual listed in Question \#1].

16. talk to [Name of individual listed in Question \#1] about anything except important information.

17. be vague when [Name of individual listed in Question \#1] asks me for information that $\mathrm{s} /$ he needs.

18. always feel completely sincere when revealing my own feelings and experiences to [Target Name 1].

19. reveal self-disclosures to [Target Name 1] that are completely accurate reflections of who I am.

20. not always be honest in my self-disclosures to [Target Name 1].

21. always feel completely sincere when revealing my own feelings, emotions, behaviors, or experiences to [Target Name 1].

22. always be honest in my self-disclosures to [Target Name 1]. 
Please answer the following questions as if you were evaluating [Name of individual listed in Question \#1] for a promotion at work. Please rate the person on the following dimensions.

1. How courteous is this person?

$\begin{array}{lllllllll}\text { Not at all Courteous } & 1 & 2 & 3 & 4 & 5 & 6 & 7 & \text { Extremely Courteous }\end{array}$

2. How competent is this person?

$\begin{array}{lllllllll}\text { Not at all Competent } & 1 & 2 & 3 & 4 & 5 & 6 & 7 & \text { Extremely }\end{array}$ Competent

3. Based on your experience with this person, how would you feel about him/her being awarded a promotion at work? Is/he deserving of a promotion?

$\begin{array}{lllllllll}\text { Not at all Deserving } & 1 & 2 & 3 & 4 & 5 & 6 & 7 & \text { Extremely Deserving }\end{array}$

4. On a scale from 0 to 100 , how would you rate this person as an employee?

Again, think of [Name of individual listed in Question \#1]. Please indicate how much you agree with the following statement: "I trust [Name of individual listed in Question \#1] as a colleague." Please respond to this statement based on the pairings of adjectives below. The closer the number is to an adjective, the more certain you are of your evaluation.

"I trust [Name of individual listed in Question \#1] as a colleague."

$\begin{array}{lllllllll}\text { 1. Agree } & 1 & 2 & 3 & 4 & 5 & 6 & 7 & \text { Disagree } \\ \text { 2. False } & 1 & 2 & 3 & 4 & 5 & 6 & 7 & \text { True } \\ \text { 3. Incorrect } & 1 & 2 & 3 & 4 & 5 & 6 & 7 & \text { Correct } \\ \text { 4. Wrong } & 1 & 2 & 3 & 4 & 5 & 6 & 7 & \text { Right } \\ \text { 5. Yes } & 1 & 2 & 3 & 4 & 5 & 6 & 7 & \text { No }\end{array}$


Think of [Name of individual listed in Question \#1]. Please respond to each item below to indicate how you feel about [Name of individual listed in Question \#1]. Please respond to this statement based on the pairings of adjectives below. The closer the number is to an adjective, the more certain you are of your evaluation.

$\begin{array}{lllllllll}\text { Cares about me } & 1 & 2 & 3 & 4 & 5 & 6 & 7 & \text { Doesn't care about } \\ \text { Self-centered } & 1 & 2 & 3 & 4 & 5 & 6 & 7 & \text { Not self-centered } \\ \text { Concerned with me } & 1 & 2 & 3 & 4 & 5 & 6 & 7 & \text { Unconcerned w } \\ \text { Insensitive } & 1 & 2 & 3 & 4 & 5 & 6 & 7 & \text { Sensitive } \\ \text { Not understanding } & 1 & 2 & 3 & 4 & 5 & 6 & 7 & \text { Understanding } \\ \text { Has my interests } & 1 & 2 & 3 & 4 & 5 & 6 & 7 & \text { Doesn't have my } \\ \text { at heart } & & & & & & & & \text { interests at heart } \\ & & & & & & & & \\ \text { Intelligent } & 1 & 2 & 3 & 4 & 5 & 6 & 7 & \text { Unintelligent } \\ \text { Untrained } & 1 & 2 & 3 & 4 & 5 & 6 & 7 & \text { Trained } \\ \text { Inexpert } & 1 & 2 & 3 & 4 & 5 & 6 & 7 & \text { Expert } \\ \text { Informed } & 1 & 2 & 3 & 4 & 5 & 6 & 7 & \text { Uninformed } \\ \text { Incompetent } & 1 & 2 & 3 & 4 & 5 & 6 & 7 & \text { Competent } \\ \text { Bright } & 1 & 2 & 3 & 4 & 5 & 6 & 7 & \text { Stupid } \\ & & & & & & & & \\ \text { Honest } & 1 & 2 & 3 & 4 & 5 & 6 & 7 & \text { Dishonest } \\ \text { Untrustworthy } & 1 & 2 & 3 & 4 & 5 & 6 & 7 & \text { Trustworthy } \\ \text { Honorable } & 1 & 2 & 3 & 4 & 5 & 6 & 7 & \text { Dishonorable } \\ \text { Moral } & 1 & 2 & 3 & 4 & 5 & 6 & 7 & \text { Immoral } \\ \text { Unethical } & 1 & 2 & 3 & 4 & 5 & 6 & 7 & \text { Ethical } \\ \text { Phony } & 1 & 2 & 3 & 4 & 5 & 6 & 7 & \text { Genuine } \\ & & & & & & & & \end{array}$

Think of [Name of individual listed in Question \#1]. Please respond to each item below to indicate what you feel about [Name of individual listed in Question \#1]'s motives for being involved in the friendship. Please mark how much you agree with each statement using the scale below.

\begin{tabular}{ccccccc}
1 & 2 & 3 & 4 & 5 & 6 & 7 \\
\hline Strongly & Disagree & Moderately & Undecided & Moderately & Agree & Strongly \\
Disagree & & Disagree & & Agree & & Agree
\end{tabular}


I feel [Name of individual listed in Question \#1] is friends with [Name of individual listed in Question \#5]...

1. for job advancement.

2. to increase his/her power in the organization.

3. for companionship

4. for sincere love

5. for friendship

6. for excitement.

7. to increase his/her job efficiency.

8. for adventure.

9. for job security.

10. for sexual experience

11. for fun.

12. for financial rewards.

13. to find a spouse.

14. to "hang out" with someone

15. to make his/her work easier.

16. to boost his/her own ego.

Think of [Name of individual listed in Question \#1]. Please respond to each item below to indicate what you think/thought about [Name of individual listed in Question \#1]'s friendship with [Name of individual listed in Question \#5]. Please mark how much you agree with each statement using the scale below. Record the number of your response in the space provided beside each statement.

\begin{tabular}{ccccccc}
1 & 2 & 3 & 4 & 5 & 6 & 7 \\
\hline $\begin{array}{l}\text { Strongly } \\
\text { Disagree }\end{array}$ & Disagree & $\begin{array}{c}\text { Moderately } \\
\text { Disagree }\end{array}$ & Undecided & Moderately & Agree & Strongly \\
& & & Agree & & Agree
\end{tabular}

Due to his/her friendship with [Name of individual listed in Question \#5], I think [Name of individual listed in Question \#1]...

1. receives special treatment at work.

2. receives work-related information that other organizational members do not.

3. has an advantage over other organizational members. 
4. will be promoted over other organizational members.

5. is favored at work.

6. receives benefits that other organizational members do not.

7. is more powerful in the organization.

Using the scale below, please indicate your agreement with each of the statements. Record the number of your response in the space provided.

\begin{tabular}{ccccccc}
1 & 2 & 3 & 4 & 5 & 6 & 7 \\
\hline Strongly & Disagree & Moderately & Undecided & Moderately & Agree & Strongly \\
Disagree & & Disagree & & Agree & & Agree
\end{tabular}

1. Many women are actually seeking special favors, such as hiring policies that favor them over men, under the guise of asking for "equality."

2. No matter how accomplished he is, a man is not truly complete as a person unless he has the love of a woman.

3. Most women interpret innocent remarks or acts as being sexist.

4. In a disaster, women ought not necessarily be rescued before men.

5. Women are too easily offended.

6. People are often truly happy in life without being romantically involved with a member of the other sex.

7. Feminists are not seeking for women to have more power than men.

8. Many women have a quality of purity that few men possess.

9. Most women fail to appreciate fully all that men do for them.

10. Women should be cherished and protected by men.

11. Every man ought to have a woman whom he adores.

12. Women seek to gain power by getting control over men.

13. Men are complete without women.

14. Women exaggerate problems they have at work.

15. A good woman should be set on a pedestal by her man.

16. Women, compared to men, tend to have a superior moral sensibility.

17. Once a woman gets a man to commit to her, she usually tries to put him on a tight leash.

18. When women lose to men in a fair competition, they typically complain about being discriminated against.

19. There are actually very few women who get a kick out of teasing men by seeming sexually available and then refusing male advances. 
20. Men should be willing to sacrifice their own well-being in order to provide financially for the women in their lives.

21. Feminists are making entirely reasonable demands of men.

22. Women, as compared to men, tend to have a more refined sense of culture and good taste.

Using the scale below, please indicate your agreement with each of the following statements. Record the number of your response in the space provided.

\begin{tabular}{ccccccc}
1 & 2 & 3 & 4 & 5 & 6 & 7 \\
\hline $\begin{array}{ccc}\text { Strongly } \\
\text { Disagree }\end{array}$ & Disagree & $\begin{array}{c}\text { Moderately } \\
\text { Disagree }\end{array}$ & Undecided & $\begin{array}{c}\text { Moderately } \\
\text { Agree }\end{array}$ & Agree & $\begin{array}{c}\text { Strongly } \\
\text { Agree }\end{array}$
\end{tabular}

1. I consider the relationship between [Target Name 1] and [Target Name 2] to be completely platonic. romantic.

2. I believe the relationship between [Target Name 1] and [Target Name 2] is actually

3. I am suspicious that [Target Name 1] and [Target Name 2] may secretly be romantically involved.

4. I do not believe that [Target Name 1] and [Target Name 2] are dating.

5. [Target Name 1] and [Target Name 2] behave in ways that suggest a romance. other workers.

6. The relationship between [Target Name 1] and [Target Name 2] causes problems for

7. [Target Name 1] and [Target Name 2]'s relationship negatively impacts the work environment.

8. [Target Name 1] and [Target Name 2]'s relationship interferes with others' work.

9. The relationship between [Target Name 1] and [Target Name 2] has a positive effect on the overall workplace.

Please answer the following questions about yourself.

1. Your Sex: Male Female

2. Your Age: 
3. Your Ethnic Background: Hispanic/Latino Other:
Caucasian/White Native American
African American/Black Asian American/Asian

4. Do you still work at the organization where you observed the male-female friendship? Yes No

5. Your occupation during the time you observed the male-female friendship:

6. Your job title during the time you observed the male-female friendship:

7. Your job field during the time you observed the male-female friendship: (Check ONE) Managerial \& Professional (e.g., doctors, lawyers, educators, business executives, scientists, etc.)

Technical, Sales, \& Administrative Support (e.g., health technicians, salespeople, secretaries, etc.)

Service Occupations (e.g., child care, police, food service, cleaning, building, hairdressers, etc.)

Precision Production, Craft, \& Repair (e.g., mechanics, construction, etc.)

Operators, Fabricators, \& Laborers (e.g., machine operators, truck drivers, farming, assemblers, etc.)

8. On average, how many hours per week do/did you work at the organization where you observed the male-female friendship?

9. How long have you worked/ did you work at this organization?

10. At what type of organization do/did you work (e.g. hospital, school, etc.)?

11. Approximately how much do/did you earn per year at this job? (Circle one)

Under $\$ 20,000$

$\$ 40,001-50,000$

$\$ 70,001-80,000$

$\$ 20,000-30,000$
$\$ 50,001-60,000$
$\$ \$ 80,001-90,000$

Over $\$ 100,000$
$\$ 30,001-40,000$

$\$ 60,001-70,000$

$\$ 90,001-100,000$ 